\title{
TOWARDS A “MALL-LESS” SUBURB
}

By

\author{
Stephen Wong
}

B.Arch.Sc., Ryerson University, Toronto, 2008

\author{
A thesis \\ presented to Ryerson University \\ in partial fulfillment of the \\ requirements for the degree of \\ Master of Architecture \\ in the program of \\ Architecture \\ Toronto, Ontario, Canada, 2019 \\ (c) Stephen Wong 2019
}





\section{AUTHOR'S DECLARATION}

I hereby declare that I am the sole author of this thesis. This is a true copy of the thesis, including any required final revisions, as accepted by my examiners.

I authorize Ryerson University to lend this thesis to other institutions orindividuals for the purpose of scholarly research. I further authorize Ryerson University to reproduce this thesis by photocopying or by other means, in total or in part, at the request of other institutions or individuals for the purpose of scholarly research.

I understand that my thesis may be made electronically available to the public.

Stephen Wong 



\title{
TOWARDS A “MALL-LESS” SUBURB
}

\author{
Stephen Wong
}

Master of Architecture 2019

Architecture Program, Ryerson University

\section{ABSTRACT}

The creation of suburbs has led to segregated functional spaces that once helped nourish their growth, including the shopping mall. However, as the shopping phenomenon evolves, it is crucial to reexamine this building type to accommodate changing needs and their effect on the surrounding area. Shopping malls have been important contributors to social life and through transformation, street and square life can be recreated for suburban communities. This thesis explores the formation of a square within a mixeduse neighbourhood that intertwines public and private spaces to create opportunities for social connectivity. This enhances the existing community and strengthens the relational benefits between public and private realms, and strives to establish a balanced growth. Architecture mediates public and private spaces, and redefines boundaries so that underutilized private space can be optimized and reintegrated into the suburban environment, reestablishing the social life in the suburbs. 



\section{ACKNOWLEDGEMENT}

I would like to thank my thesis advisor, Kendra Schank Smith, for her vaulable time, patience, and guidance for the past year. I really appreciate and treasure all the discussions we had, and her words of encouragement on my educational and personal goals.

I would also like to recognize Yew-Thong Leong, my second reader, and Marco Polo, my program representative, for their insight and perspectives. Their critiques helped refine this thesis and I appreciate every comment on how we can improve our built world.

Lastly, I would like to thank my parents for their support all these years. 

To my baba, mami and friends. 


\section{TABLE OF CONTENTS}

Author's Declaration iii

Abstract $\quad v$

Acknowledgements $\quad$ vii

Table of Contents $\quad x$

List of Figures $\quad x i$

List of Appendices $\quad$ xix

$\begin{array}{ll}\text { Introduction } & 1\end{array}$

1 Shopping Malls and Their Current Conditions 3

2 City Structure and Space 5

2.1 Image of The City

2.2 Territory

2.3 Space

2.4 Public Space

2.5 Semi-Public Space

2.6 Semi-Private Space

2.7 Private Space

2.8 Appropriation of Space

2.9 Objectives of Public Space

2.10 What is lost space and placelessness?

3 Suburban Development and Planning

3.1 Urban Planning of Suburbs

3.2 Shopping Mall as Node

3.3 Economic Model of Shopping Mall

3.4 Visions for the Malls and Current Proposals

4 Nodes and Strategies

4.1 Urban Planning Strategy

4.2 Purpose of Squares

4.3 Appropriate Size of Squares

4.4 Boundary

4.5 Soft Edges and Edge Effect

4.6 Types of Outdoor Activities

4.7 The Human Dimension

4.8 Case Studies

5 Design Project

5.1 Site - Centerpoint Mall

5.2 Zoning

5.3 Site Analysis

5.4 Master Plan

5.5 The Mixed-Use Hub

5.6 Programs

5.7 Design

6 Speculation 


\section{LIST OF FIGURES}

Figure $1.1 \quad$ First Mall by Gruen, Southdale Mall

Source: https://amp.businessinsider.com/images/59809d06b50ab1011c8b5dbd-750-503.jpg. Accessed September 2018.

Figure 1.2 Store Closing at Fairview Mall

Source: Stephen Wong

Figure 1.3 Vision of Herizon Mall

Source: http://www.calgaryherald.com/cms/binary/9038878.jpg. Accessed October 2018.

Figure 1.4 Realized Version of Herizon Mall

Source: https://i.cbc.ca/1.4938070.1544237707!/filelmage/httplmage/image.jpeg_gen/derivatives/original_780/newhorizon-mall.jpeg. Accessed December 2018.

Figure 2.1 Domestic Workers' Sunday Gathering at HSBC, Hong Kong

Source: https://cdn1.i-scmp.com/sites/default/files/styles/1200x800/public/images/methode/2017/11/11/2a0e3d76c605-11e7-9f00-d8b0ccf89a9f_1280x720_234743.JPG?itok=I-gsJvfN. Accessed December 2018.

Figure 2.2 Mel Lastman Square, Toronto

Source: Stephen Wong

Figure 2.3 Semi-Public Space at Citigroup Center, New York

Source: http://2.bp.blogspot.com/-01xSLrw1t70/UtiYnoSCWUI/AAAAAAAACrE/XorJVJTkbUk/s1600/citi7.jpg.

Accessed December 2018.

Figure 2.4 Semi-Private Space

Source: www.contemporist.com/wp-content/uploads/2015/05/contemporary-architecture_080515_10.jpg. Accessed December 2018.

Figure $2.5 \quad$ Private Space

Source: www.contemporist.com/a-semi-private-courtyard-extends-the-living-space-of-this-home/contemporaryarchitecture_080515_22/. Accessed December 2018.

Figure 2.6 People Sitting on Ledges

Source: Stephen Wong

Figure 2.7 People Sitting on Ledges

Source: Stephen Wong

Figure 2.8 Chess Playing at Foodcourt, Markham

Source: Stephen Wong

Figure 2.9 Unused Plaza, Arrecife

Source: www.architectsjournal.co.uk/pictures/2000x1333/3/7/1/3098371_10.jpg. Accessed September 2018.

Figure 2.10 Empty Building

Source: https://betterdwelling.com/wp-content/uploads/2017/02/Toronto\%E2\%80\%99s-Trendy-Queen-Street-West-ls-

Filling-With-Empty-Storefronts.jpg. Accessed September 2018. 
Figure 3.1 Shops at Don Mills, 1983

Source: http://reurbanist.com/wp-content/uploads/2012/08/1992-Don-Mills-564x553.jpg. Accessed April 2019.

Figure 3.2 Shops at Don Mills, 2007

Source: http://reurbanist.com/wp-content/uploads/2012/08/2007-Don-Mills-564×553.jpg. Accessed April 2019.

Figure 3.3 Shops at Don Mills, 2009

Source: http://reurbanist.com/wp-content/uploads/2012/08/2009-Don-Mills-564×553.jpg. Accessed April 2019.

Figure 3.4 Mall Distribution in GTA

Source: Stephen Wong

Figure $3.5 \quad 1 \mathrm{~km}$ Radius Around Centerpoint Mall

Source: Stephen Wong

Figure 3.6 Pacific Mall, Markham

Source: http://flocons.blogspot.com/2010/08/how-to-park-at-pacific-mall-or-any.html. Accessed April 2019.

Figure 3.7 Chinese New Year Celebration at Pacific Mall

Source: https://dynamicmedia.zuza.com/zz/m/original_/5/0/50428b60-e297-4f66-a30d-b0be442d7d0d/

M_1ChineseNewYear1A_SS_020417__Super_Portrait.jpg. Accessed April 2019.

Figure 3.8 Chinese New Year Celebration at Pacific Mall

Source: https://dynamicmedia.zuza.com/zz/m/original_/0/f/0f14f496-9b35-49f7-a09a-b1e6ce87f9dd/

M_1ChineseNewYear3_SS_020417__Super_Portrait.jpg. Accessed April 2019.

Figure 3.9 Yorkdale Shopping Centre Aerial View

Source: Google Maps. Accessed August 2019.

Figure 3.10 New Expansion Proposal at Yorkdale Shopping Centre

Source: https://media.blogto.com/uploads/2019/03/15/1552684975-20190315-yorkdaleoption1.jpg?w=1400\&cmd=re size\&height=2500\&quality=70. Accessed March 2019.

Figure 3.11 New Proposal for Galleria Mall Master Plan

Source: https://cdn.skyrisecities.com/sites/default/files/images/articles/2016/10/23034/23034-80077.jpg. Accessed March 2019.

Figure 3.12 New Proposal for Galleria Mall

Source: https://i1.wp.com/reimaginegalleria.com/wp-content/uploads/2018/02/new-masthead.jpg. Accessed March 2019.

Figure 4.1 Cornell Neighbourhood, Markham

Source: https://www.torontorentals.com/blog/wp-content/uploads/markham.jpg. Accessed September 2019.

Figure 4.2 Jacobs' The Need of Small Block Sketch

Source: The Death and Life of Great American Cities, p.179 and 181

Figure 4.3 Night It Up, Markham

Source: https://markhamreview.com/wp-content/uploads/2017/05/June-2017-Night-It-Up-Overview-Pic.jpg. Accessed August 2019. 
Figure 4.4 NBA Viewing Party at Markham Downtown

Source: https://www.remingtongroupinc.com/wp-content/uploads/2019/06/0611raptorsviewing.jpg. Accessed August 2019.

Figure 4.5 NBA Viewing Party at Markham Downtown

Source: https://downtownmarkham.ca/wp-content/uploads/2019/06/0611 raptors2-800x428.jpg. Accessed August 2019.

Figure 4.6 Gehl's City Planning Principles Diagram

Source: Cities for People, p.233

Figure 4.7 Soft Edges Sketch

Source: Stephen Wong

Figure 4.8 Edge Effect at Shops at Don Mills

Source: Stephen Wong

Figure 4.9 Edge Effect at Shops at Nathan Phillips Square

Source: Stephen Wong

Figure 4.10 Activity Relationship Diagram

Source: Stephen Wong

Figure 4.11 Gehl's Threshold Diagram

Source: Cities for People, p.40

Figure 4.12 View of Nathan Phillips Square from Stage

Source: Stephen Wong

Figure 4.13 Ramp as Threshold

Source: Stephen Wong

Figure 4.14 Elevated Walkway as Boundary

Source: Stephen Wong

Figure 4.15 Nathan Phillips Square on a Normal Saturday Afternoon

Source: Stephen Wong

Figure 4.16 Shops at Don Mills Square in Summer

Source: Stephen Wong

Figure 4.17 Families at Shops at Don Mills Square

Source: Stephen Wong

Figure 4.18 People Gathering at Shops at Don Mills Square

Source: Stephen Wong

Figure 4.19 Shops at Don Mills Square in Winter

Source: Stephen Wong 
$\begin{array}{ll}\text { Figure } 4.20 & \text { Distillery District Streetlife } \\ & \text { Source: Stephen Wong }\end{array}$

Figure 4.21 Square at Distillery District

Source: Stephen Wong

Figure 4.22 Distillery District Performance Stage

Source: Stephen Wong

Figure 4.23 Nathan Phillips Square Figure Ground

Source: Stephen Wong

Figure 4.24 Distillery District Figure Ground

Source: Stephen Wong

Figure 4.25 Shops at Don Mills Figure Ground

Source: Stephen Wong

Figure 4.26 Nathan Phillips Square Section at Square

Source: Stephen Wong

Figure 4.27 Distillery District Section at Square

Source: Stephen Wong

Figure 4.28 Shops at Don Mills Section at Square

Source: Stephen Wong

Figure 4.29 Shops at Don Mills Square Superimposed on Centerpoint Mall

Source: Stephen Wong

Figure 5.1 Conversion from Introvert to Extrovert Approach

Source: Stephen Wong

Figure 5.2 Hub Program Category

Source: Stephen Wong

Figure 5.3 Context Map

Source: Stephen Wong

Figure 5.4 Northeast Corner, Centerpoint Mall

Source: Stephen Wong

Figure 5.5 Northeast Entrance, Centerpoint Mall

Source: Stephen Wong

Figure 5.6 People Sitting inside Centerpoint Mall

Source: Stephen Wong

Figure 5.7 People Sitting inside Centerpoint Mall

Source: Stephen Wong 
$\begin{array}{ll}\text { Figure } 5.8 & \text { People Sitting inside Centerpoint Mall } \\ & \text { Source: Stephen Wong }\end{array}$

Figure 5.9 Store Closed at Centerpoint Mall

Source: Stephen Wong

Figure 5.10 Centerpoint Mall Food Court

Source: Stephen Wong

Figure 5.11 Store Closed at Centerpoint Mall

Source: Stephen Wong

Figure 5.12 Neighbourhood Demographic

Source: www.toronto.ca/ext/sdfa/Neighbourhood\%20Profiles/pdf/2016/pdf1/cpa50.pdf. Accessed March 2019.

www.toronto.ca/ext/sdfa/Neighbourhood\%20Profiles/pdf/2016/pdf1/cpa36.pdf. Accessed March 2019.

Figure 5.13 Context Map

Source: Google Map

Figure 5.14 Site Analysis

Source: Stephen Wong

Figure 5.15 Rental Apartment Nearby

Source: Stephen Wong

Figure 5.16 New Development Notice North of Steeles

Source: Stephen Wong

Figure 5.17 Pedestrian Unfriendly on Yonge Street

Source: Stephen Wong

Figure 5.18 View Facing South on Yonge Street

Source: Stephen Wong

Figure 5.19 View Facing North at Major Intersection

Source: Stephen Wong

Figure 5.20 Site Analysis

Source: Stephen Wong

Figure 5.21 Master Plan Diagram

Source: Stephen Wong

Figure 5.22 Master Plan Massing

Source: Stephen Wong

Figure 5.23 Master Plan

Source: Stephen Wong 
Figure 5.24 Statistics Comparison of Existing and Proposed Conditions

Source: Stephen Wong

Figure 5.25 Sketch Diagram

Source: Stephen Wong

Figure 5.26 Program Diagram

Source: Stephen Wong

Figure 5.27 Program Diagram

Source: Stephen Wong

Figure 5.28 Program Diagram

Source: Stephen Wong

Figure 5.29 Program Diagram

Source: Stephen Wong

Figure 5.30 WeWork, Toronto

Source: https://cdn.wework.com/locations/image/62b0fa3a-0b90-11e8-a34d-1202be33576a/20180201_Richmind_ Street_West-1.jpg?auto=compress\&fit=crop\&h=800\&w=1400\&dpr=. Accessed July 2019.

Figure 5.31 Program Diagram

Source: Stephen Wong

Figure 5.32 Distribution of Toronto Public Library

Source: Stephen Wong

Figure 5.33 Level 1 Plan

Source: Stephen Wong

Figure 5.34 Level 2 Plan

Source: Stephen Wong

Figure 5.35 East-West Section

Source: Stephen Wong

Figure 5.36 North-South Section

Source: Stephen Wong

Figure 5.37 Connecting Streets and Square on Ground Floor Through Openings

Source: Stephen Wong

Figure 5.38 Massing Concept Diagram

Source: Stephen Wong

Figure 5.39 Concept Diagram

Source: Stephen Wong 
Figure 5.40 Northeast Perspective
Source: Stephen Wong

Figure $5.41 \quad$ North Entry

Source: Stephen Wong

Figure 5.42 Outdoor Square

Source: Stephen Wong

Figure 5.43 Outdoor Performance Stage

Source: Stephen Wong

Figure 5.44 East Elevation

Source: Stephen Wong

Figure 5.45 Main Lobby with Sunken Seating Area

Source: Stephen Wong

Figure 5.46 Cafe View Looking Towards Outdoor Square

Source: Stephen Wong

Figure 5.47 Access from New Internal Street from the South Source: Stephen Wong

Figure 5.48 Amphitheatre

Source: Stephen Wong

Figure 5.49 Southwest Perspective

Source: Stephen Wong

Figure 5.50 Square Entry from the South

Source: Stephen Wong

Figure 5.51 Library

Source: Stephen Wong

Figure 5.52 Library Seating Area

Source: Stephen Wong

Figure 5.53 Market

Source: Stephen Wong

Figure 5.54 Coworking Space

Source: Stephen Wong

Figure 5.55 Event Hall and Rooftop Terrace

Source: Stephen Wong

Figure 5.56 Night Gathering at Outdoor Stage

Source: Stephen Wong 
Figure 5.57 Christmas Market at Outdoor Square
Source: Stephen Wong

Figure 5.58 Winter Activity at Outdoor Square

Source: Stephen Wong

Figure 5.59 North Elevation

Source: Stephen Wong

Figure 5.60 Partial West Elevation

Source: Stephen Wong

Figure 5.61 Partial South Elevation

Source: Stephen Wong

Figure 5.62 Aerial View

Source: Stephen Wong

Figure 5.63 Sectional Perspective

Source: Stephen Wong

Figure 5.64 Northeast Perspective

Source: Stephen Wong 


\section{LIST OF APPENDICES}

Figure 7.1 Sun Study - Summer Solstice 2019

Source: Stephen Wong

Figure 7.2 Sun Study - Fall Equinox 2019

Source: Stephen Wong

Figure 7.3 Sun Study - Winter Solstice 2019

Source: Stephen Wong

Figure 7.4 1:200 Model - South Perspective Source: Stephen Wong

Figure 7.5 1:200 Model - North Perspective Source: Stephen Wong

Figure 7.6 1:200 Model - Interior

Source: Stephen Wong

Figure 7.7 North Elevation

Source: Stephen Wong

Figure 7.8 South Elevation

Source: Stephen Wong

Figure 7.9 East Elevation

Source: Stephen Wong

Figure 7.10 West Elevation

Source: Stephen Wong 



\section{INTRODUCTION}

As the daily routines of life change with technology, some spaces dedicated to those routines become ripe for re-examination to accommodate new needs. Shopping malls have served their neighbourhoods for decades, but as the nature of shopping evolves, the purpose of shopping malls has changed. This model requires a revisit in order to serve new societal needs. Although shopping malls are privately owned and seem to focus mainly on consumerism, they also provide the 'public' aspect of social life that people need, such as a meeting place and a place to socialize. If shopping malls are in decline, this will also deteriorate the social aspect of the neighbourhood and the surrounding physical environment.

In a growing built environment, competition for space has been an ongoing issue. In a world driven by economy, the private sector dominates the development of land while public space sometimes becomes a secondary focus of city planning. With a sharp delineation between public and private spaces, there is always a demarcation of who owns and can use which space. As the city continues to grow, the demand for densification increases and in turn the demand for new public space increases. A recent staff report from the City of Toronto's city planning division indicated this need for public space for retreat, relaxation and recreation for its residents, as a means to contribute to their health and well-being (City of Toronto, Protecting). The city also acknowledged that as land values increase, it is not always feasible to buy properties to create new public space. Given this evidence of the current situation, it is crucial to understand how shopping malls can be reimagined to cater to both economic incentive and demand for public space, in search of a balanced situation. In order to sustain the city's growth in a balanced manner between public and private realms, a new paradigm is needed to accommodate the vital need for public space in an economy-driven world.

A well-designed public space invites people to stay as they can find comfortable space at their personal level and feel a sense of belonging. Often, public and private spaces are created by different organizations and thus there is a lack of unity in the overall planning, which makes these public spaces even more fragmented. In the suburbs, functions are usually segregated and far apart and thus there is a lack of centrality. This thesis attempts to explore a public space acting as a meeting point for the suburban community to come together, located at the sites of shopping malls. The objective of this thesis begins with the idea of how private space can be generously given back to the public and provide a balanced 
and healthier environment for the neighbourhood. It attempts to explore how underutilized private space can be remodelled with a future vision that serves more purposes than a single-use approach and benefits a larger group of users. Some of the questions addressed in this thesis include:

What is the vision for the public spaces of the near future? What is the future use for lost space? How can public and private spaces benefit each other, in serving the community of the future? What is the role of architecture in forming these spaces, and its association with social connectivity, that can encourage people to come together?

This thesis aims to explore the role of architecture in shaping and connecting the relationships between public and private spaces for the future. It attempts to strengthen the concept of peopleoriented vision in any decision making as they are the ultimate users experiencing the space. Architecture ultimately is a space creating tool that contributes to how people engage socially and with their environment, so that a healthier community can be established. It defines the spatial volume which sets up the stage for everyday activities to occur. 


\section{SHOPPING MALLS AND THEIR CURRENT CONDITIONS}

According to David Smiley, the rise of a new form of retailing organization, known as the shopping centre, was developed to serve the suburbanites who had left the city after World War II (13). Also, the rise of automobile dependency inspired the establishment of the shopping centre (Scharoun 7). It was meant to provide "easy access to downtown department stores, specialty stores, and local services" (Smiley 13). The shopping centres "provided important centrality and focus for dispersed suburban settlements" (Crawford 24). They were planned as nodes for the suburbs, where people could shop for everything under one roof for convenience. Also, the early days of shopping plazas exhibited three design principles, which were entirely commercial, low density and catered to shoppers with cars (Sewell 113). Scharoun mentioned that teens and the elderly are the most evident user groups in the mall because it provides them with a sense of community (69). She also explained that the mall provides seniors with a sense of security, similar to the parents of teens who feel safe leaving their kids there (81). Other than consumption and security, the mall holds a strong social relationship for people to come together.

Recently, one of the renowned department stores,
Sears, declared bankruptcy and has closed its stores. Before Sears had its first store, it began selling its products through its catalogs. When Walmart came into the market in the 1990s with low prices, other retailers began to look for innovation in their products and services, but not Sears (Delventhal). Sears began to lose money when it merged with Kmart due to economic restructuring, while Amazon began to thrive online (Delventhal). Sears got outplayed by other competitors. It is difficult to determine whether e-commerce was a major factor in Sears' decline, but the rise of online shopping nevertheless had an impact on brick-and-mortar stores. When department stores anchored to the shopping malls are gone, downward spiral in mall performance would occur that eventually leads to decreased income, since they take up large retail spaces, and foot traffic (Peterson). As a result, anchor stores greatly influence the economic structure of the malls.

An example of a 'dead mall' is Calgary's New Horizon Mall, which opened in May 2018 with only 9 of 517 potential retail spaces having been leased, as reported by Global News (Healing). These stores were sold like condo units, and about $70 \%$ of the units were sold to individual investors who could either lease the space out or operate on their own (Healing). Healing also reported that the developer has been waiting for 
large anchor tenants. In the absence of tenants, the mall becomes 'dead' as there is not enough foot traffic. The lack of high profile anchor tenants has a ripple effect on the other smaller businesses, contributing to the death of the mall.

In America, there are suburban malls that are at risk of shutting down as big anchor stores such as Macy's and JCPenney close hundreds of stores due to falling sales (Peterson). When big anchor stores leave, their relative large retail space becomes a big gap to be filled. If the malls are at risk, they will slowly disengage from the existing neighbourhood. What is the future of these mall sites?
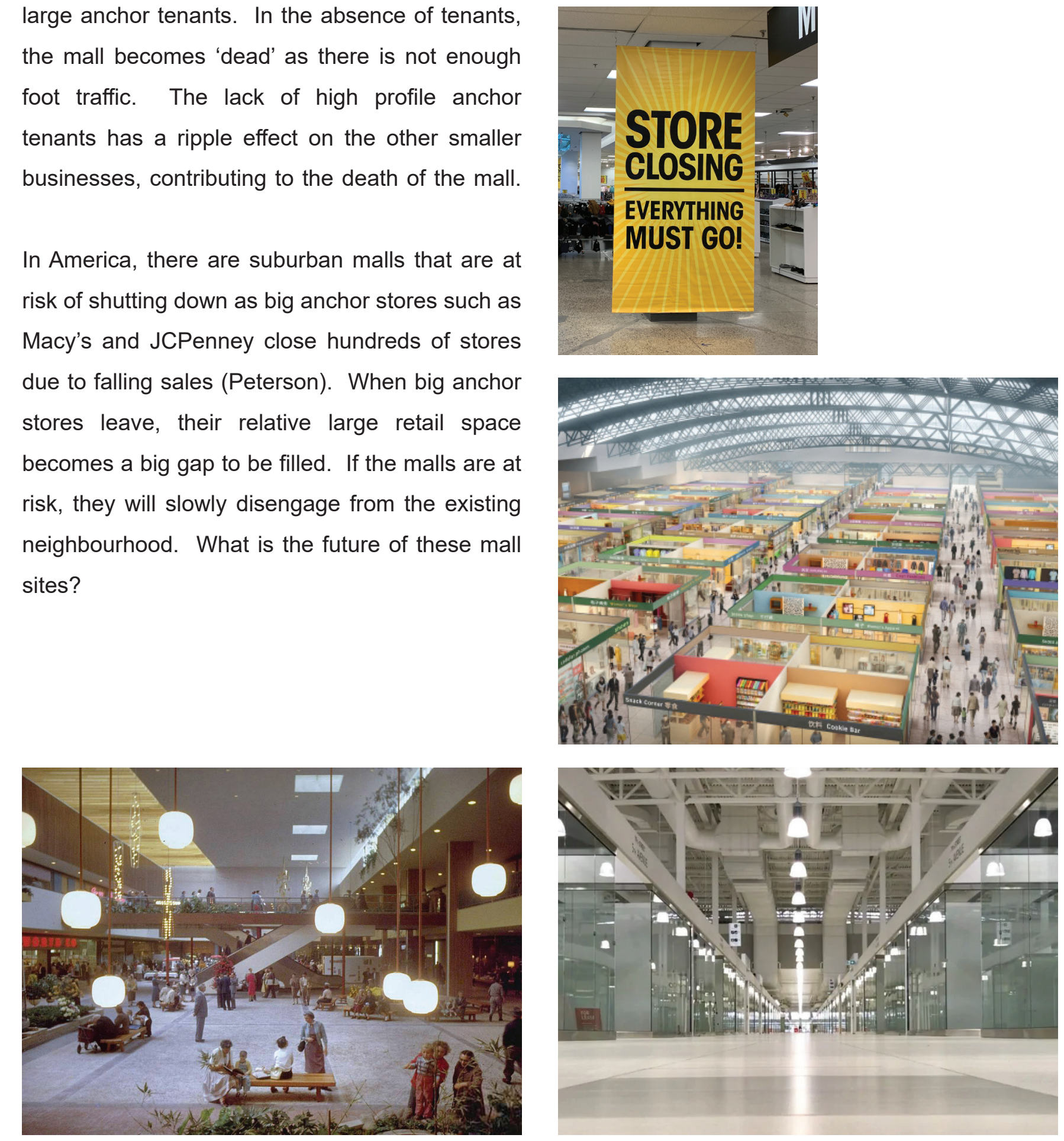

Fig. 1.2 Store Closing at Fairview Mall

Fig. 1.3 Vision of Herizon Mall

Fig.1.1 First Mall by Gruen, Southdale Mall 


\section{CITY STRUCTURE AND SPACE}

\subsection{IMAGE OF THE CITY}

Kevin Lynch categorized the image of the city into three components, including identity, structure and meaning (8). He first pointed out identity as a recognizable and distinct character, which makes it separable from others and provides meaning to individuality (8). Without identity, the object becomes homogenous with other objects; a good example would be the effect of mass production. Structure refers to "the spatial and pattern relation of the object to the observer and to other objects" (Lynch 8). Objects must have meaning for the observer, which can be practical or emotional. All these components are in relation to the observer's experience of the environment, and so the image is created as a perception of the observer. The human perception of the city allows them to determine if the space is significant for their needs. There should be a recognizable image to every part of the city, but not every part is clear or distinct. When the image of a place seems uninviting, people will avoid it unless there are no other options. Thus the image of the city has an impact on the observers' daily experiences of their environment. In the case of decaying malls where foot traffic is declining, they do not provide an image of liveliness and thus lose their attractiveness. As a result, people will not go there unless they have to and eventually an image of dead space will be perceived by the public. 


\subsection{TERRITORY}

Ali Madanipour pointed out that territoriality, defined by environmental psychologists, is "a set of behaviours and cognitions a person or group exhibits, based on perceived ownership of physical space" (43). This sense of ownership by individuals leads to the control of space, and usually there can be many layers of control. There can be a hierarchy of power, but each level can feel a sense of territoriality with different degrees of ownership over the physical space (Madanipour 44). Territory can be seen as an organizer of activities with various types of people and behaviours anticipated at different locations (Madanipour 44). Thus, space and activity are closely tied together when defining territory, where one asserts control over the space through activity either temporarily or permanently. Often, the physical environment plays a role in shaping these spaces for such

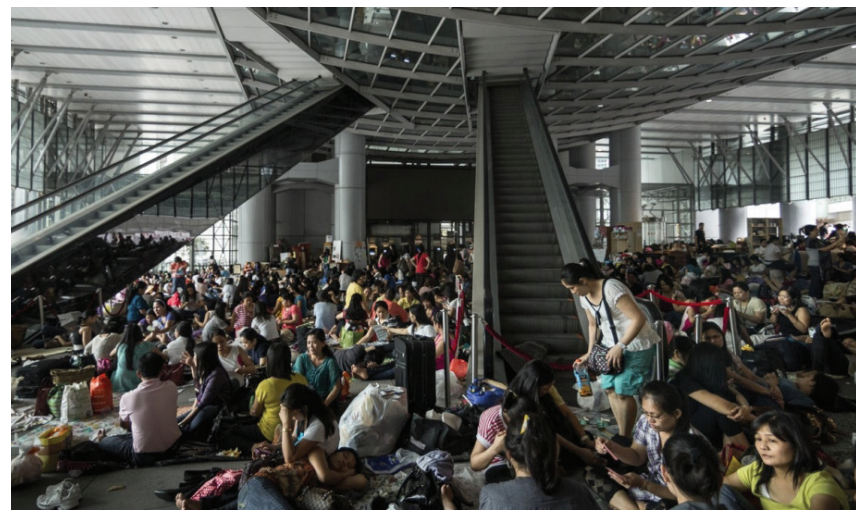
activities to occur. People establish their own territories by their behaviour and the authorities establish a territory with control which influences the users' behaviour. Sometimes when people establish their territories on private properties, it may foster local businesses to thrive. Thus, from an economic perspective, such establishment of territory by people can benefit property owners.

Fig.2.1 Domestic Workers' Sunday Gathering at HSBC, Hong Kong 


\subsection{SPACE}

Space is an intangible entity that may not be quantified, but it is closely linked to people's experience through their senses. According to Relph, perceptual space is the most immediate form of awareness of space that is self-centered and is perceived to have content and meaning to the individual (10). It is this self-consciousness that allows people to recognize their immediate surroundings as they experience the space. There are usually "emotional encounters... with the built or created spaces" (Relph 10). In a broader scope, existential space is the lived-space of a culture which can be experienced by individual (Relph 12). Relph continued that "existential space is not merely a passive space waiting to be experienced, but is constantly being created and remade by human activities (12). In this sense, space can be described as opportunities for human activities that provide meaning to it. It is this experience which enables people to feel a sense of being a part of creating space. People become a unit in shaping space. For example, a classroom with many students can make the space feel very crowded as compared to the same classroom with just one student. As Yi-Fu Tuan explained, experience is "acting on the given and creating out of the given" (9). There is a constant dialogue between space and action, as space allows people to act on it and people make use of the given space for their desired purposes. Space can be defined as a relative location of objects within which the individual is situated (Tuan 12). In other words, it is the individual's perspective of these objects, such as boundaries, that define the network of objects encompassing the 'form' of space. Relative to these objects, space can be viewed as a void that accommodates people and their movement and actions. Wherever a void is defined or limited, an enclosed space is created, whether it is in the streets or squares, and the void space can be experienced (Zevi 29). In this sense, enclosed space does not necessarily require all six planes to encapsulate; for example, a public square can still be considered a space. More importantly, the space is usually associated with activities, which give character to the space. For example, a street with many cafe patios creates an atmosphere that will invite people to stay on the street.

Space also ties into the ownership of space, which ultimately defines the types of activities in a space. There is a spectrum of ownership conditions of spaces including public, semi-public, semi-private and private spaces. It may be difficult to draw a clear line between these four categories since there are many definitions from different perspectives. The following is an attempt to explain the differences 


\subsection{PUBLIC SPACE}

According to Zachary Neal, public space includes "all areas that are open and accessible to all members of the public in a society, in principle though not necessarily in practice" (1). Neal states that, 'all areas' can be viewed as either outdoor areas, such as parks, streets, sidewalks, and public buildings that include schools and libraries (1). He summarizes public space as "any physical... area where individuals and groups can interact with one another" (2). Based on this, the word 'interact' becomes a critical keyword in defining public space. Furthermore, all members of the public can be interpreted as all human beings, regardless of age, gender, ethnicity, social status etc., and everyone is treated equally in this space. Public property, as officially defined by the
City of Toronto, refers to "any government owned sidewalk, lane, street, boulevard, road or street allowance, right-of-way or parks" (City of Toronto, Public). This clearly defines that only government owned spaces are public. Also, in this definition, it satisfies what Neal has mentioned earlier as these listed areas are open and are accessible to all members of the public. However, it should be noted that in a democratic city, as long as the municipal laws are not violated, anyone shall be able to enjoy the space as part of the right of the citizen.

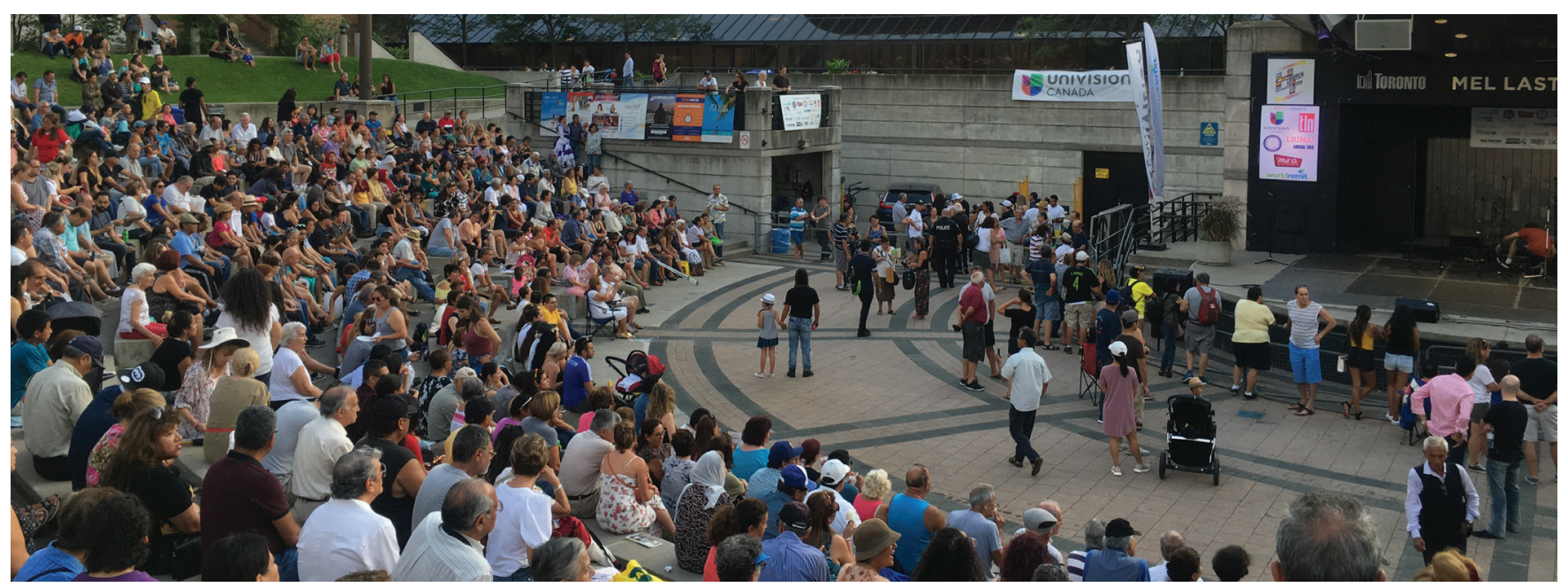

Fig.2.2 Mel Lastman Square, Toronto 


\subsection{SEMI-PUBLIC SPACE}

Semi-public space is the space connected to public space, but with a higher degree of control over the space by authority, either public or private entities, depending on the ownership of the property. Semi-public space is usually outdoors where the public has easy access, which is similar to public space. Often this space is perceived to be owned by the public and thus the activities associated are similar to those found in public space. However, with a higher degree of control, these activities might be restricted depending on the owners' generosity. An example of semipublic space would be the privately-owned public space (POPS). POPS is often open to the public as a courtesy of the owner wanting to give back to the city, but often involves a deal with the government in exchange for such act of courtesy.

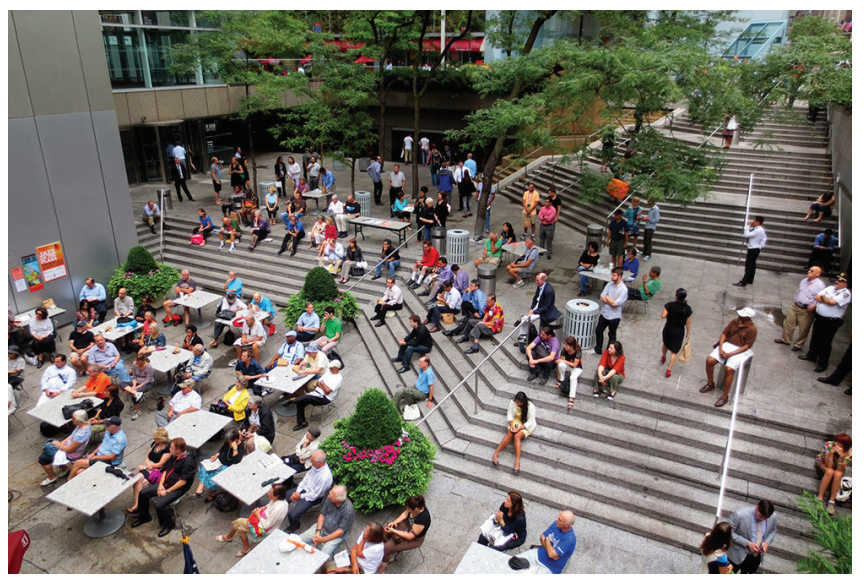

Fig.2.3 Semi-Public Space at Citigroup Center, New York 


\subsection{SEMI-PRIVATE SPACE}

If private space is exclusive to the individual's use and control, then semi-private space is the shared common space for those who have access to the private space. The space would still be controlled by the owner of the private space with certain guidelines. Semi-private spaces can include the corridor, lobby, or amenity spaces serving the private space, such as those found in residential or commercial buildings. This space is often separated by a physical boundary from the outdoors, restricted to those authorized to use it. Inside a shopping mall, the semi-private space can be the corridor that connects all the different retail stores where the public can walk.

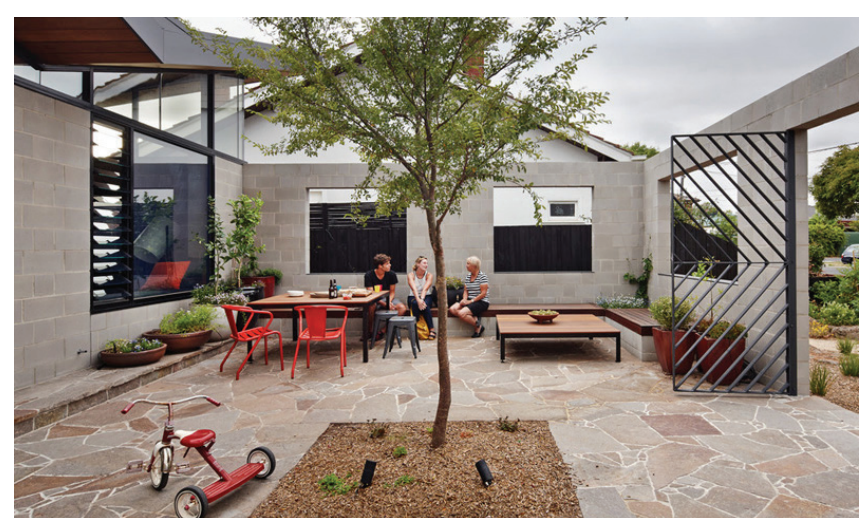

Fig.2.4 Semi-Private Space 


\subsection{PRIVATE SPACE}

According to Madanipour, private space "belongs to, or is controlled by, an individual, for that individual's exclusive use, keeping the public out" (35). It involves the right of privacy as the space is exclusive to the individual. In private property, its owner has the legal right to choose and control who may or may not enter, depending on the owner's preference. Private property, as officially defined by the City of Toronto, refers to "any land owned by individuals or corporations other than the government" (City of Toronto, Public). In this policy, anything that is not owned by the government would be considered as private. The

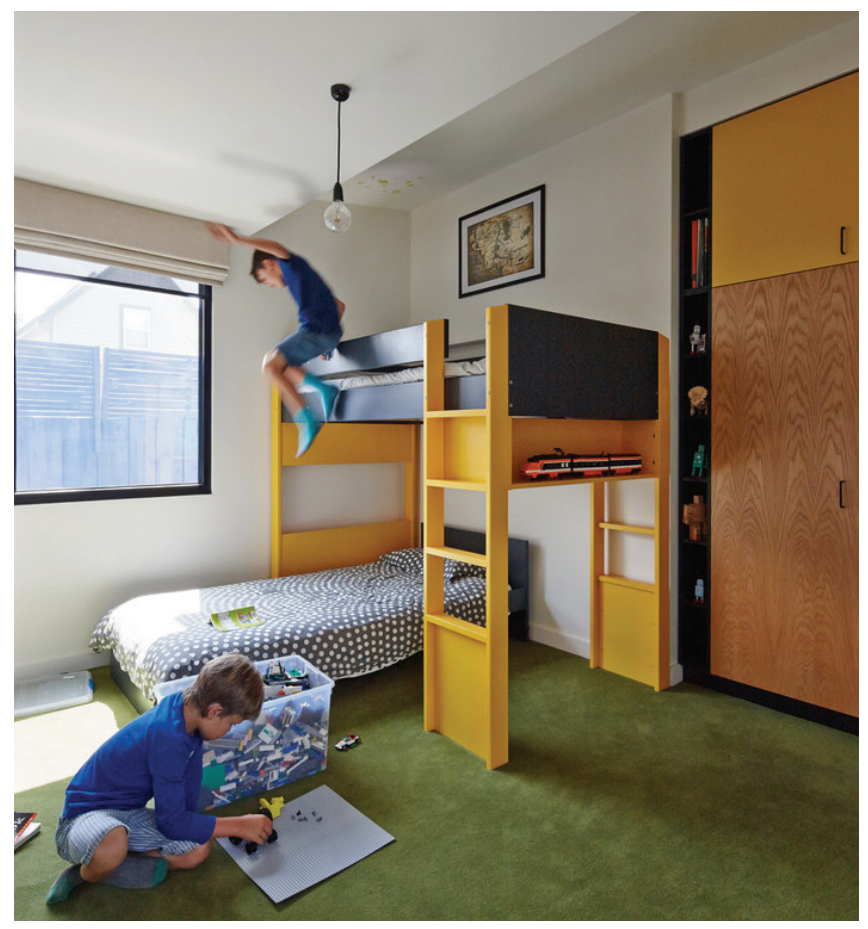
official website of the City of Toronto indicates that commercial and residential properties are considered of private property (City of Toronto, Public). It should be noted that although roads are often perceived as public property owned by the government, there can be exceptions, such as Highway 407, which is privately owned and operated by 407 ETR. Thus, ownership provides the legal right of possession of property and space.

Fig.2.5 Private Space 


\subsection{APPROPRIATION OF SPACE}

People appropriate space if the conditions are favourable to their uses. As mentioned earlier, people tend to set up their territory and perform activities in a space that is unintended for those uses, but are 'allowed' informally provided they do not disrupt the normal functioning of the space. The pattern of how people use such spaces may suggest the type of activities or any design elements that trigger such behaviour. Although this thesis is not studying the psychological behaviour of people, observing how people appropriate space does provide some ideas of what people are looking for in a space and what makes a space work.

It was observed that at the food court in a local Chinese plaza in Markham, elderly men would set up a few tables of Chinese chess to play and others would gather to watch their games. It became a natural social activity for these people. From observation, they did not purchase any food items at the food court, but still appeared to use the facility for their own leisure purposes. It seems that such a place, although it is privately owned, has the conception of 'publicness' where people are free to stay and play. The focus is not about whether or not the food court is strictly guarded by security, but this pattern may suggest that perhaps the local neighbourhood needs this type of gathering space for leisure purpose, where people can gather together to enjoy an afternoon of game play.

Another form of appropriating space that was observed is that people would sit on ledges. As Whyte mentioned, sitting should be socially comfortable, such that it offers choices for people to choose whether in a group or alone (28). Sitting plays an important role in making the social life in urban space work and as Whyte pointed out in his findings, "people tend to sit most where there are places to sit" (28). Sitting to rest also becomes an activity of people watching. This leads to a form of social interaction, which is passive contact, where there is no direct conversation between the observer and the observed. This also suggests that architectural design can integrate sitting as a strategy to allow people to stay, socialize or rest.

There are many scenarios in appropriating spaces, but the above observed incidents prove that architectural features should accommodate these factors in the creation of good social spaces. 

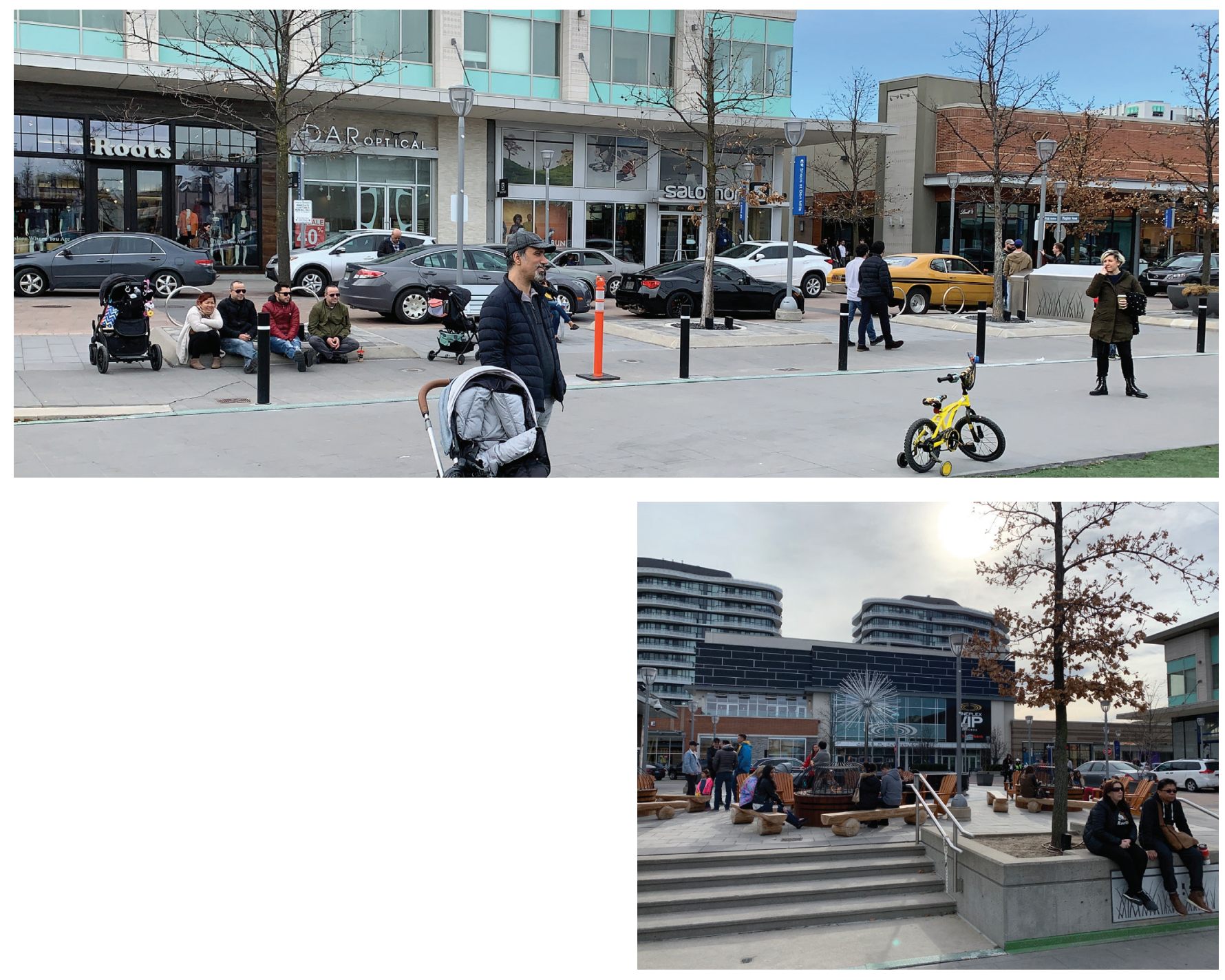

Fig.2.6 People Sitting on Ledges

Fig.2.7 People Sitting on Ledges

Fig.2.8 Chess Playing at Foodcourt, Markham

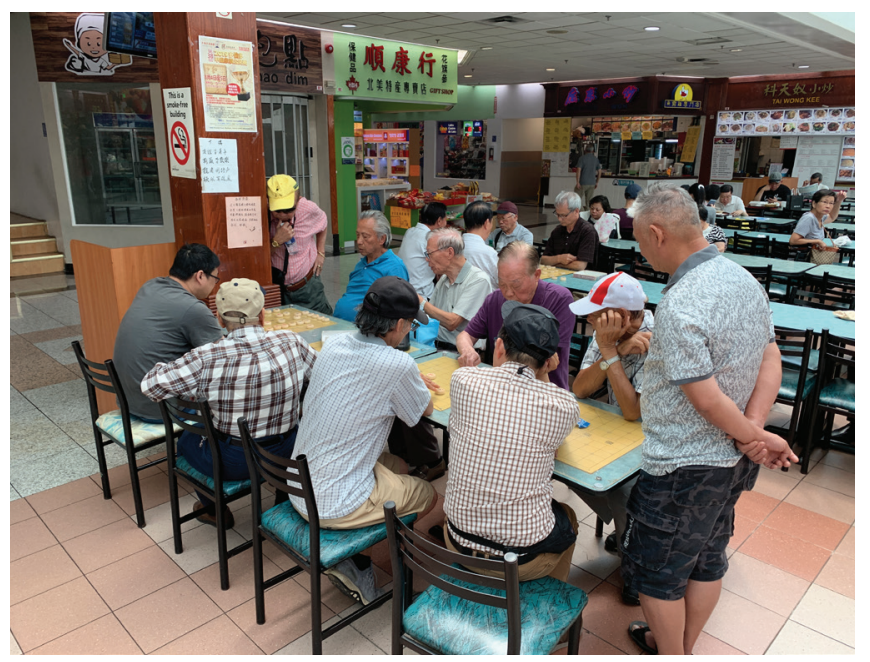




\subsection{OBJECTIVES OF PUBLIC SPACE}

There are two objectives of public space: one is to serve the human needs in terms of sociability, and the other is to serve the political conception of democracy. Since public space can be an ambiguous subject, it is crucial to define the scope for this thesis exploration. The focus of this thesis will be on the social aspect.

As Carr et al. found, there are five ways in which public spaces serve to meet people's needs, which include comfort, relaxation, passive and active engagement with the environment, and discovery (231). Comfort here refers to how one can find relief from the elements, rest and seating (Carr et al. 238). This serves the physical needs of humans, which allows people to regain energy in a physical sense. This can be addressed by providing seating. Relaxation, as Carr et al. noted, is the "developed state of body and mind at ease" (232). This is where people can have a pause from their daily routines, like a small escape. Passive engagement is where people are not actively involved in any social participation, and yet are present to observe others. Meanwhile, active engagement refers to a more direct experience with others and the place they are in. This is where people are actively engaged and interact with other beings, be they strangers or friends. Discovery is part of the human desire for stimulation and the need to explore, which results in satisfying experiences (Carr et al. 238). It provides an opportunity for people to observe what others are doing as they move through urban public space (Carr et al. 238). These are the main reasons that Carr et al. have discovered in their research for which people go to public space and hence, these are generally what people are looking for in terms of sociability in public spaces. It is vital to have public space serving the neighbourhood, especially when the human needs of sociability can easily be neglected in a rapidly growing environment. 


\subsection{WHAT IS LOST SPACE AND PLACELESSNESS?}

\section{LOST SPACE}

Roger Trancik defined lost spaces as "the undesirable urban areas that are in need of redesign - antispaces, making no positive contribution to the surroundings or users" (64). The examples he lists include the leftover spaces at the base of high-rise towers, unused sunken plazas, surface parking lots, edges of highways, abandoned buildings, vacant sites and residual areas (Trancik 64). He adds that the lost spaces "fail to connect elements in a coherent way" (Trancik 64). The core idea to his definition is that lost spaces are the spaces that exhibit the loss of connection with other elements, and they do not make a positive contributions to either their surroundings or the users. Usually these are the places people do not want to go since they are undesirable. It can be argued that the absence of people-oriented vision in design causes the creation of lost space.

Trancik identifies some causes for the creation of lost space, and one of them is due to dependence on the automobile (64). He raises the point that a lot of urban land is dedicated to the storage and movement of automobiles (64). Although automobiles are essential modes of transportation in the 21 st century, the issues created by automobiles should not be ignored in the urbanistic perspective. For example, the parking lot may be located underground, which allows the space at grade be dedicated for other meaningful activities for the public. This can minimize the segregation of land caused by surface parking lot from a planning perspective.
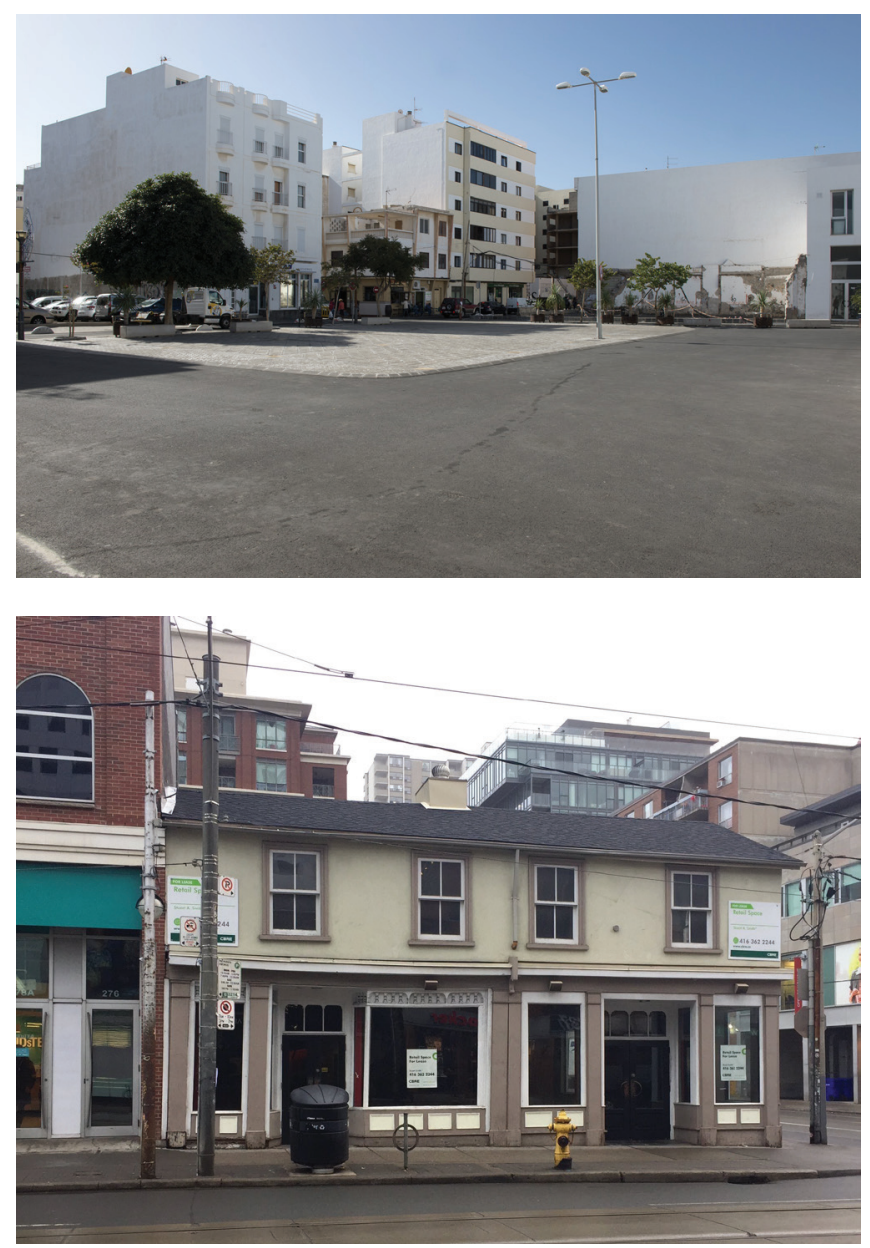

Fig.2.9 Unused Plaza, Arrecife Fig.2.10 Empty Building 


\section{PLACELESSNESS}

Relph argued that at present people subject themselves to the forces of placelessness as the norm and as a result the sense of place is lost (79). He maintained that placelessness is an attitude, which makes it harder to have authentic places as this attitude becomes dominant (80). Relph defined placelessness as "a weakening of the identity of places to the point where they not only look alike but feel alike and offer the same bland possibilities for experience" (90). This homogenized experience does not make a place significant or distinct, and it is arguable that as a result people are brainwashed with this homogenous experience that continues the inauthentic attitude. There is no recognition of the significance of a place anymore. Furthermore, Relph summarized some components of placelessness as "uniformity and standardization in places" and "formlessness and lack of human scale and order in places" (118119), which are the results of globalization and economic development. He raised the issue of how planning that concerns itself with efficiency in the end results in uniform places that can be interchangeable or replaceable by multinational corporations, authoritative central governments and uninvolved planners (143). Places then can easily be replaced, which would lose their diversity or significance. If this continues, the environments will look more alike, and people will not be able to identify a place without external identifiers. Indeed, shopping malls are very similar as they are mostly composed of chain stores. There is not much authenticity found in typical malls.

Relph mentioned that "the meaning of places may be rooted in the physical setting and objects and activities, but they are not a property of them - rather they are the property of human intentions and experiences" (47). It is based on what people want to experience in a space at a personal level. He also noted that physical setting, activities and meanings are inseparable, which are the basic elements that make up a place (47). It can be interpreted that the physical settings must allow intended activities, which provide the users some sort of meaning as they experience it, whether at a personal or collective level.

After understanding lost space and placelessness, though they represent different perspectives on the existing places of society, there seem to be common elements between both perspectives: absence of connection to community and significance to people. They revolve around how places should connect people and the need for significance, in this case, the value of places or what they offer to the people as sense of place for gathering.

Although these dead spaces may serve a simple 
function for everyday life, some of these spaces are underutilized and could accommodate more uses, especially today when land is so valuable. According to Carr et al., "places that do not meet people's needs or that serve no important functions for people will be underused and unsuccessful" (231). This makes a good case for planning an alternative to underutilized mall sites that can be reinvigorated into places for people, both publicly and privately. 


\section{SUBURBAN DEVELOPMENT AND PLANNING}

\subsection{URBAN PLANNING OF SUBURBS}

The sprawl began after World War II as people began to move outside of the city centre looking for bigger homes. Don Mills was the first corporate suburb that was influential in Canadain the twentieth century (Sewell 80). Its planning consisted of neighbourhoods in quadrants established by the intersection of Lawrence Avenue East and Don Mills Roads, with elementary schools, churches and local stores at these centres, surrounded to a ring road. (Sewell 80). Within the ring road, regional functions such as a shopping centre, community and recreation centre and library were located, while the working area was located at the outer edge of the site (Sewell 80). The central area of regional uses often becomes a social gathering node for the neighbourhoods that surround it. The idea of this planning was to create a self-sufficient community in the suburbs, where people can work, live and relax.

However, for most suburbs the dispersion of functions creates a dependency on the automobile that makes the streets too spread out which results in a less intimate scale for pedestrians (Gehl, Life 89). When communities are spread out and the everyday destinations are beyond the reach of a walkable distance, encounters with others become minimal (Montgomery 56). In order to reproduce the intimacy and better-used public spaces of the city centre, a more concentrated street network is required (Gehl, Life 89). This street network is what creates this sense of a walkable community. Although most of the roads in the suburbs are not pedestrian-friendly as blocks are too far apart, it may be reasonable to say that new community planning most likely can achieve this network of walkable street. People walking on the street is what animates the streetscape, and by bringing this concept to planning, it promotes a more sociable experience in the suburbs where people can engage with their streets at a slower pace on foot. An example would be The Shops at Don Mills, completed in 2009. The Shops at Don Mills' new plan incorporates many small internal streets that are focused on sidewalks where people can walk safely. Cars are allowed to navigate inside the new plan as well, but due to the small scale of streets and many pedestrian crossings, cars must maintain at a slow speed, which helps keep the neighbourhood safe for walking. 

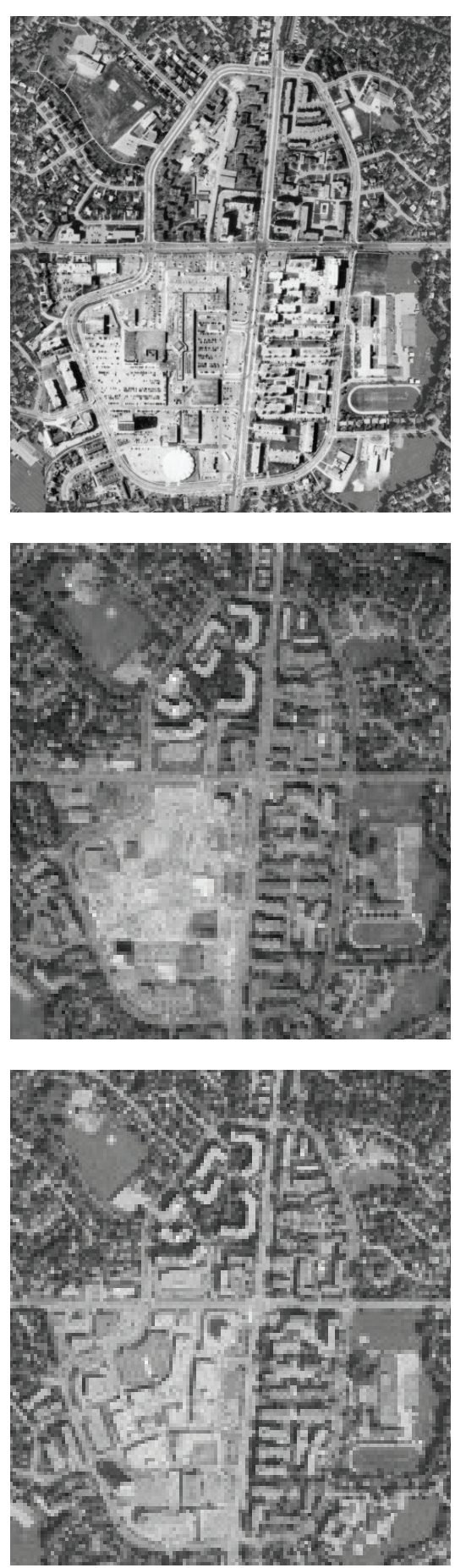

Fig.3.1 Shops at Don Mills, 1983

Fig.3.2 Shops at Don Mills, 2007

Fig.3.3 Shops at Don Mills, 2009 


\subsection{SHOPPING MALL AS NODE}

As Robert Fishman mentioned, the shopping mall should not be viewed as single-minded space, but rather an open-minded space (10). In this sense, single-minded space refers to the sole purpose of shopping as the single function. It requires a new multipurpose model, which attracts more investment and prevents further sprawl. Indeed, the mall is a perfect location to counter decentralization in the suburbs, by intensifying its capacity to become the suburban downtown.

According to Lynch, an important element that makes up the image of the city is the node, which he defined as "points, the strategic spots in a city which an observer can enter, and which are the intensive foci to and from which he is travelling" (47). He further noted that nodes can be concentrations "which gain their importance from being the condensation of some use or physical character, as a street-corner hangout or an enclosed square" (47). In order words, they are identifiable anchor points within the cities that have a certain level of importance. This sets up the case for why a node is needed in the city, as it acts as an important recognizable central point, shaped by its physical environment, for people to remember and interact with. This image of a place is how a city can be understood and where the neighbourhood residents can perceive it as a place for them. This is when the node becomes meaningful to the residents and then becomes useful to them.

If the mall has to be redeveloped with the conversion of an introverted mall into extroverted hub, the mall has to be split up in order to create more internal streets. However, in this redevelopment, it is crucial that a central point, the node, is to be developed in order to become a meeting point, just as the mall has been acting as one. This justifies this transformation of a mall into a hub; if downtown has city street life, then suburbs can have active square life. Gehl also pointed out that most city centres measure one square kilometre, so that most city functions are within this one kilometre (Cities 121). This can be translated to the idea that people should be able to walk one kilometre to important functions. Therefore, shopping malls should serve those living within one kilometre radius by walking. With this idea in mind, the new intervention should also cater but not limited to those within this one kilometre if it is to promote a sense of walkability to this new node. 

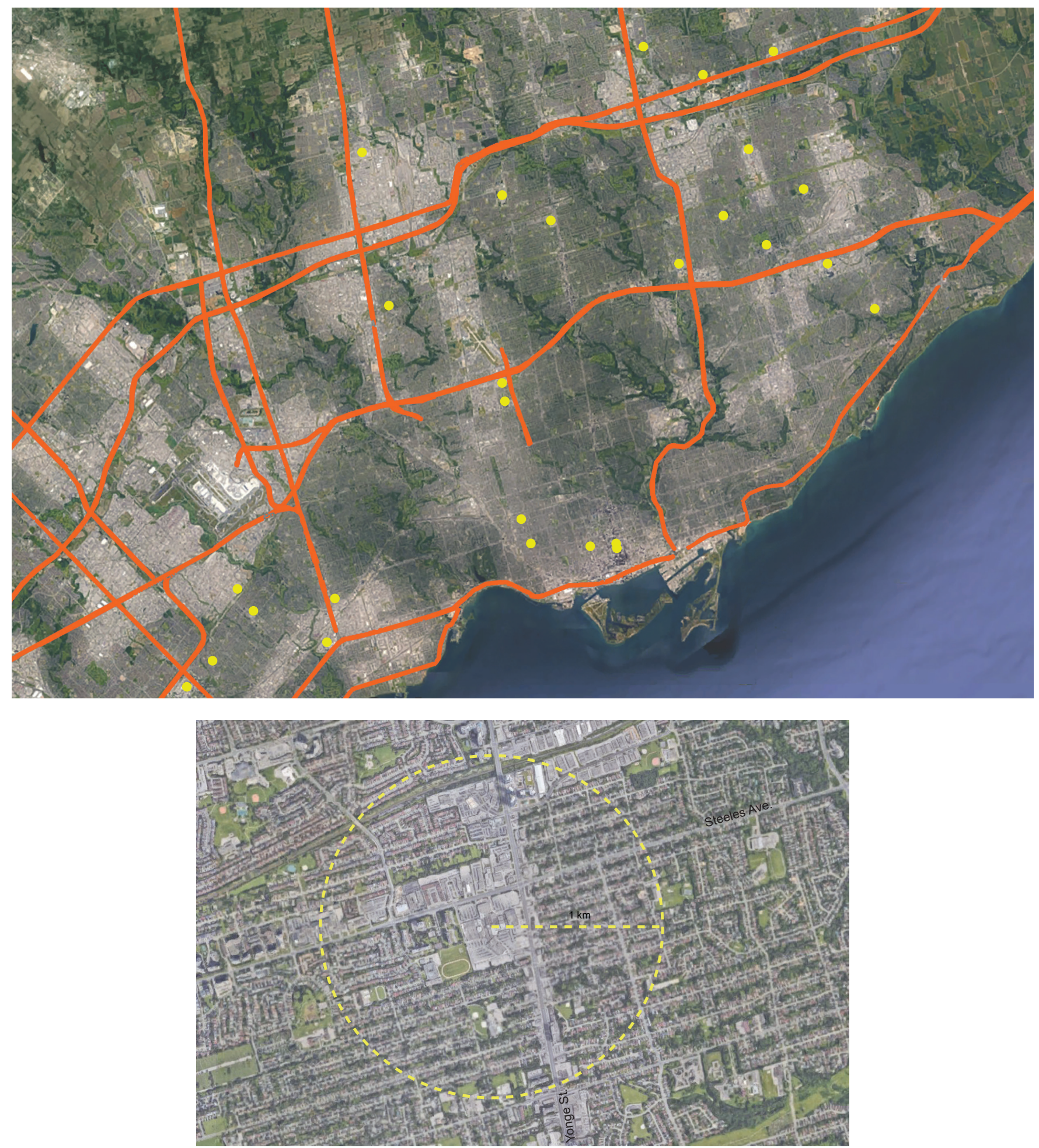

Fig.3.4 Mall Distribution in GTA

Fig.3.5 1 km Radius Around Centerpoint Mall 


\subsection{ECONOMIC MODEL OF SHOPPING MALL}

For the malls to succeed, they have various strategies to attract their customers. In terms of economics, some malls would go for the upscale model by attracting high-end brands so that the idea of branding and status help create a high level of luxury experience for both the brands and the mall, like Yorkdale Shopping Centre. Some malls target the local demographics by finding a niche that attracts the suitable income level group of the neighbourhood, an example would be Centerpoint Mall for the low-to-middle class. Another category of the mall would be the ethnic mall, such as Pacific Mall, which caters to the specific group of Chinese customers, but later became an attraction for a diverse group of customers.

Pacific Mall has been an attractive place for many people for the past two decades and it can be viewed as one of the successful malls in the Greater Toronto Area. Pacific Mall is an Asian mall located in Markham opened in 1997. It was promoted to be the largest Chinese mall in North America, which consists of many small tenants that sell a variety of products. What differs from the mainstream mall is that Pacific Mall first began to cater to the surrounding Chinese community that, with its stores mostly selling Chinese products. Also, "the concepts for Chinese malls were born out of Hong Kong models, which are condominium-style" (Bascaramurty). This means that the store units can be purchased rather than leased, an economic model that differs from the mainstream North American mall. This model allows the investors to either start up their own businesses or lease them as an investment property, which is also why the store units tend to be small and modular. It should be noted that this mall does not have any anchor store, so the success of Pacific Mall can be argued to be driven by the authenticity that the mall offers, from cultural aspect to the variety of products.

The location of the mall is at the border of Markham and Scarborough, where large numbers of Chinese immigrants settled in the late 1990s. The ease of accessibility from the neighbourhood via public transportation, cars or on foot makes the mall an attractive place for the Chinese community to gather.

The layout of the mall consists of a grid of modular retail units that could be combined into larger units, which provides flexibility for tenants. The grid layout creates internal "streets" inside the mall. There is a performance stage located in the heart of the mall, which accommodates different Chinese cultural events, such as Chinese New Year, press conferences with Chinese artists, contests or fashion shows. The stage is located 
within an atrium, which allows people to observe the events from above. These cultural activities promote Chinese culture while becoming a tool to attract more customers to the mall.

From tenant leasing to scheduling of events, the operation of Pacific Mall is maintained by a management team that oversees all the activity planning. This ensures that cultural events or celebrations can happen in an orderly manner, which keeps the mall lively.

Pacific Mall has become a tourist attraction, and as such is open all year round. Later, as the shopping phenomenon shifts, Pacific Mall may no longer cater to Chinese shoppers, as it requires a diverse group of customers (Bascaramurty).

Perhaps, ethnic malls cannot just cater to a specific ethnic group, but will need to serve a diverse group of customers for survival. The economic strategy of the mall helps the mall thrive at one point, but its strong cultural aspect is what makes it distinct from the standardized North American malls. By learning the lessons from the success of Pacific Mall, it enables a clearer understanding of what the new transformation would require, which is to incorporate a more diverse cultural dimension of the public, if it is to serve the neighbourhood and bring people together.
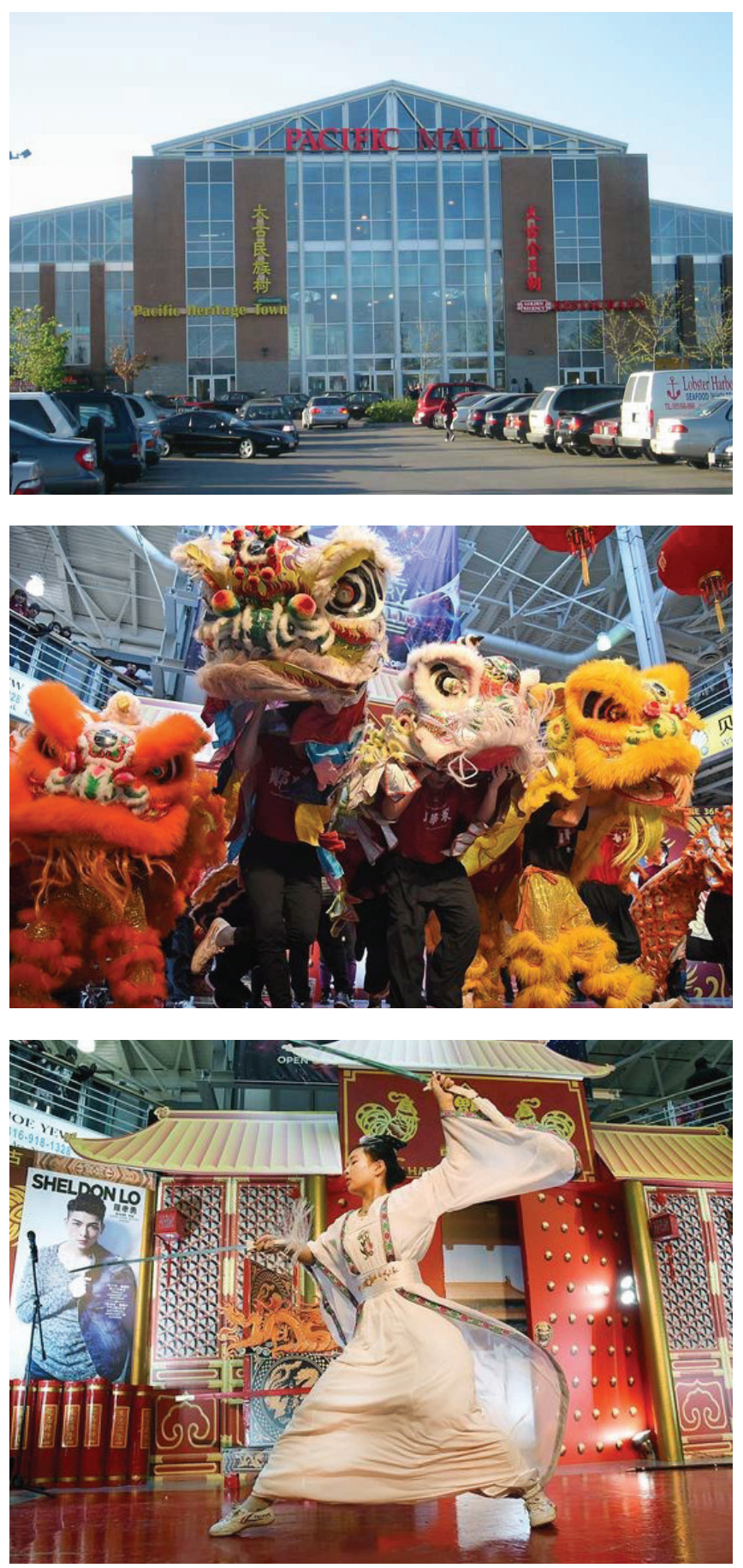

Fig.3.6 Pacific Mall, Markham

Fig.3.7 Chinese New Year Celebration at Pacific Mall Fig.3.8 Chinese New Year Celebration at Pacific Mall 


\subsection{VISIONS FOR THE MALLS AND CURRENT PROPOSALS}

Shopping malls often take up a vast amount of land on huge lots and are often only one to two storeys in height. Developers are beginning to revisit these lands that can potentially expand to generate a higher profit. In Toronto, there are a few proposals that look at the direction the malls can take. To prevent the future of the mall from becoming another Junkspace, as Koolhaas puts it an air-conditioned container with just layers of matter piling on top (176), it is critical to reintegrate public life into the privatization of land, in order for it to become a space that is socially activated for the community. Although most of these proposals are focused on the economic aspect, some do exhibit potential 'publicness' on these privately owned lands. The mall has its 'publicness' in that allows the public to enjoy the space for social interaction with others. It is very important that the new transformation of the mall can retain this 'publicness' for the greater goal it serves. It is crucial to plan for the next development carefully as the future development may not incorporate this 'publicness' into the scheme. Thus it is vital to have this concept in mind now so that inefficient dead space or lost space can be avoided and the public space is not designed as an afterthought to satisfy the public and government for approval. 


\section{YORKDALE SHOPPING CENTRE}

Recently there has been a redevelopment proposal at Yorkdale Shopping Centre, which will add a new neighbourhood of around 680,000 square meters and 1,500 residential units to the existing north parking lot (Smee). This strategy is to first establish a network of private internal roads, and intensify the existing lot by filling the void of the parking lot with new development of a mixture of residential, commercial and public park, and relocating the parking underground. The new buildings will range from 2 to 28 storeys. This strategy is to keep the existing mall with the additional expansion to it, while a dense neighbourhood is created at the periphery. This proposal seeks to infill these voids within the property.

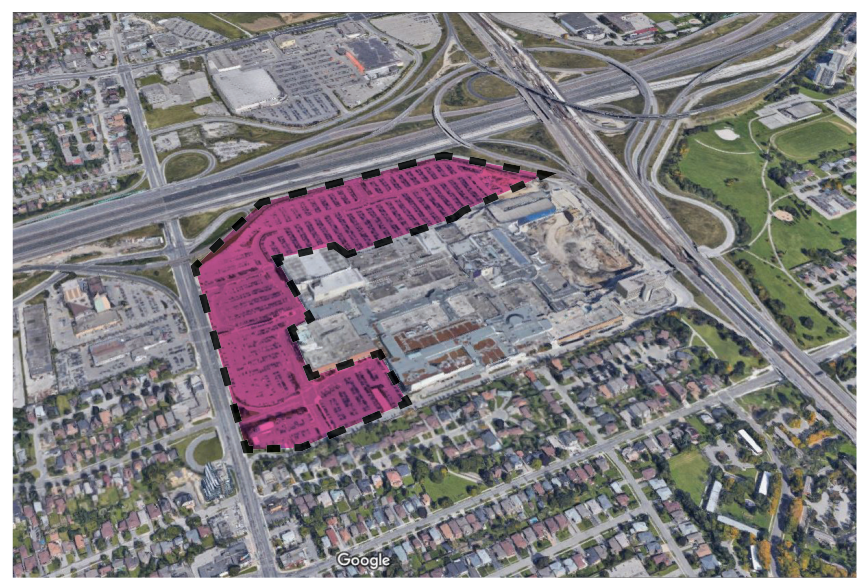

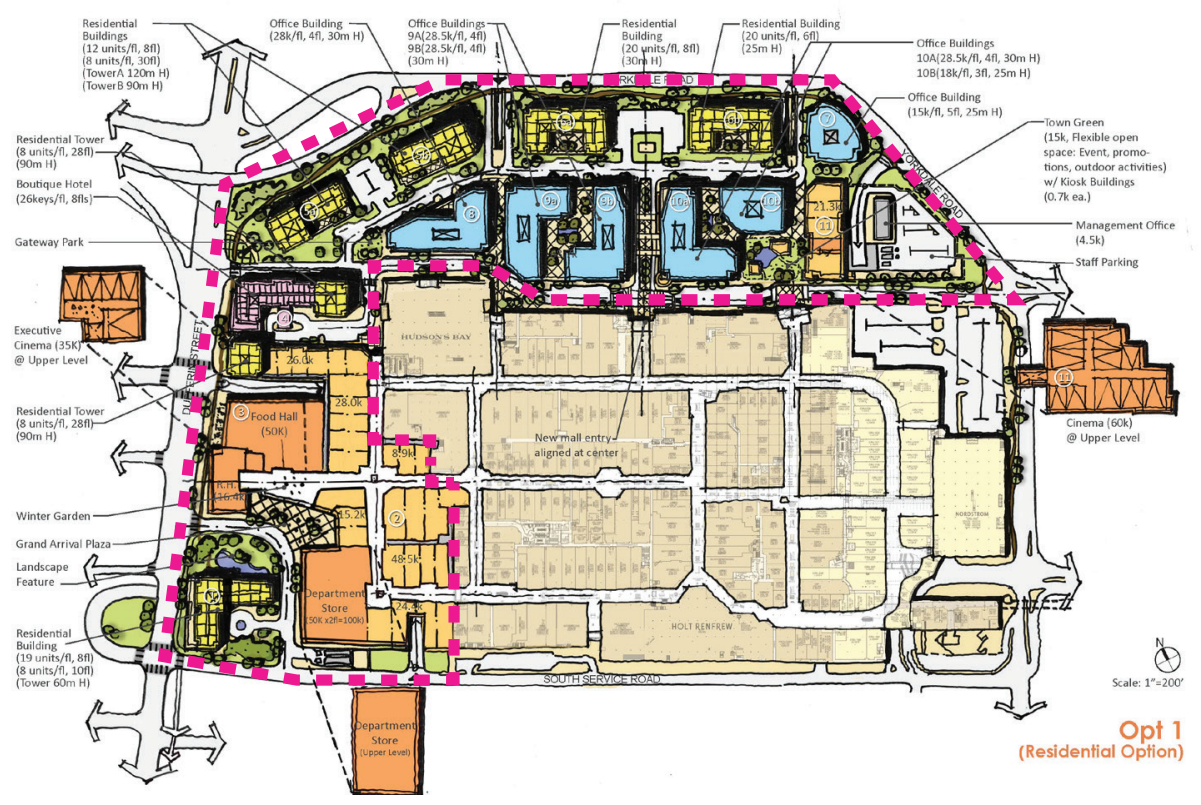

Fig.3.9 Yorkdale Shopping Centre Aerial View

Fig.3.10 New Expansion Proposal at Yorkdale Shopping Centre 


\section{GALLERIA SHOPPING CENTRE}

Galleria Shopping Centre, located at Dufferin and Dupont Streets, is set to close for a major redevelopment that will happen in the near future. The idea of this redevelopment is to create a mixedusecommunitythatis morecohesiveforitsresidents, the public and the private sector. The proposal seeks to organize the large site by introducing new arterial streets that connect other major streets to the site, dedicating parkland for public uses, creating many internal streets that define smaller blocks and establishing a central gathering space.

This redevelopment proposal has demonstrated a successful negotiation between the city officials and the developer providing more public and community spaces for the site. The community plan will include "the creation of internal city streets, pedestrian walkways, a publicly owned park and a rebuilt community centre - with all of these amenities transferred to municipal ownership" (Lorinc). The proposal attempts to give back to the city by creating more public uses on a private mall site. This demonstrates the idea of how private and public sectors can contribute to a neighbourhood development that strive to maintain a balance, where both are beneficial to each other. This proposal seeks to build from scratch, which allows a more refined planning to the site and is not restricted by any existing structures.

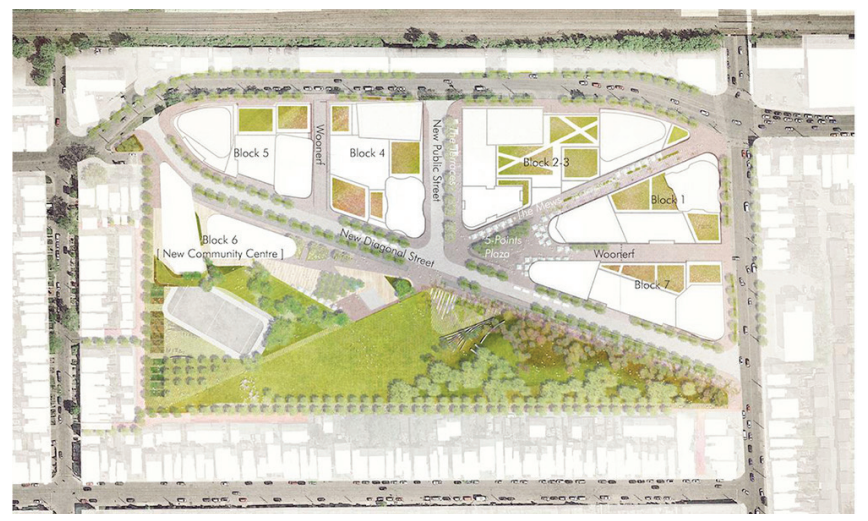

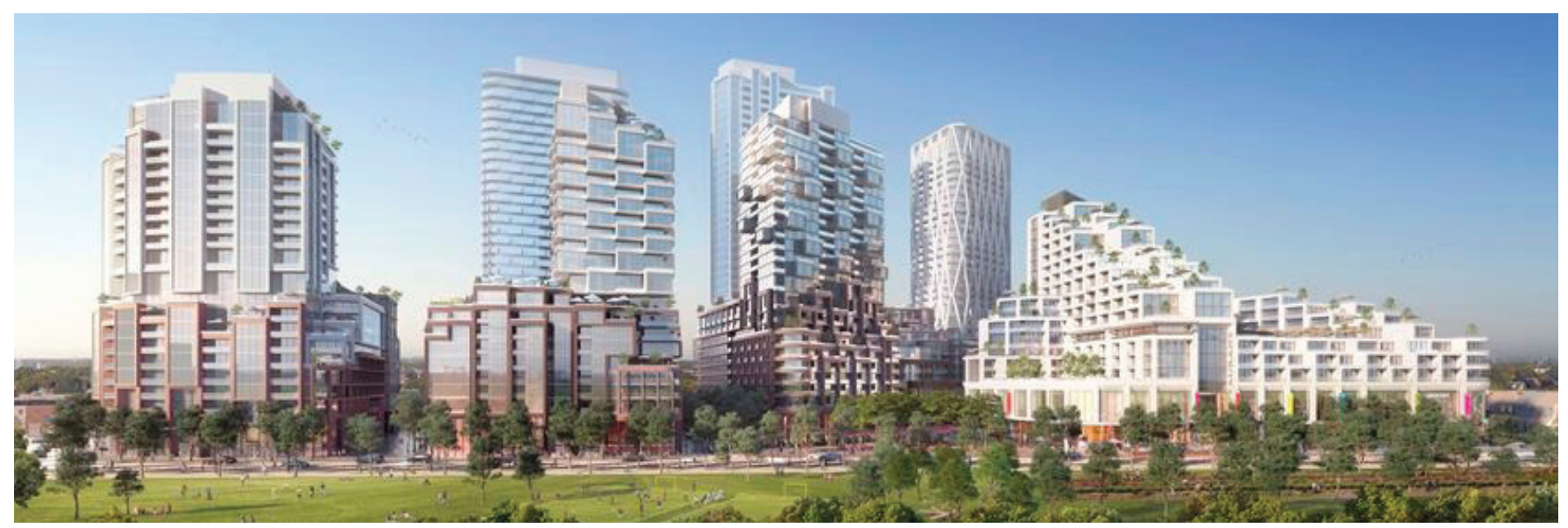

Fig.3.11 New Proposal for Galleria Mall Master Plan

Fig.3.12 New Proposal for Galleria Mall 


\section{NODES AND STRATEGIES}

\subsection{URBAN PLANNING STRATEGY}

In Jane Jacobs' book, The Death and Life of Great American Cities, she mentioned four conditions that would help create diversity in the streets and districts of a city. The four conditions are: a district that has more than one primary functions, shorter blocks with frequent street corners, the idea of mingling with buildings in various ages and conditions and a dense concentration of people (Jacobs 150). However, not all of these ideas are applicable to the modern suburban development. For example, keeping old buildings may not be ideal in redevelopment if they restrict the potential capacity of the land has to offer by their physical structures, such as the case of Galleria Shopping Centre. In the case of developing a new and denser community in the suburbs, old buildings may not be able to support the new influx of people, whether its capacity or functionality, and thus it is not necessary to mix buildings in various ages in order to keep the diversity of the city fabric. The vision of a more self-sustained neighbourhood is the priority in the new suburban strategy in order to prevent further sprawl.

Suburbs are often divided into different functions and thus people would be required to drive to different destinations for each purpose. It would be more efficient if a mix of primary functions were located within an area to reduce the need to travel. Jacobs stated that people need to appear at different times in order to make the streets successful (152). The reason is that the streets can be occupied for longer duration to ensure a safer environment while allowing different groups of people to go. This concept can be applied to a place, or a node, which will create an exuberant environment for people to congregate. Primary functions can be expanded if the idea of multifunctionality is incorporated, which will allow the primary functions to branch out to secondary functions that will complement each other. This allows a place to be adjusted to the changing needs for different groups of users and in different periods of time. This is critical in creating a suburban centre that aggregates functions while fostering conviviality.

When preparing a new master plan for a new community, it is crucial to maintain shorter blocks so that there can be more frequent intersections in an area. People are also given more route options to a destination, allowing one to view different parts of the neighbourhood. It allows for more interactions at different areas within the neighbourhood, and reduces the chance of isolated areas resulting from long blocks that separate people physically. A network of pathways that maximize exposure to 
the public also creates a safer environment. This makes the walking experience more enjoyable and thus encourages one to walk and explore.

The large site of a typical mall has lots of potential development that can help the neighbourhood to grow. The concentration of people is what generates the diversity or liveliness on the streets or the district. Thus, residential development is an ideal addition to the redevelopment of a mall site to increase the concentration of people that helps generate the diversity of the neighbourhood, in addition to the existing population of the neighbourhood. It helps to encourage variety in the neighbourhood. When a district has an increased concentration of people, many activities are able to occur, and it leads to the idea that a city centre becomes essential for these events to take place where people become the participants who contribute to the vibrancy of public life. Without people, space becomes dull and unsafe.

New suburban neighbourhood in Markham, Cornell, incorporates retail space on the ground floor of townhouses along a local street, which creates a live-work environment. These shops are mainly service providers such as clinics, that cater to the neighbourhood's needs. It is an attempt to recreate a street life in the suburban neighbourhood, though at a very small scale. It seems that new suburban planning looks into a livework strategy that encourages variety. However, this new suburban neighbourhood does not have a recognizable node for the residents to congregate.
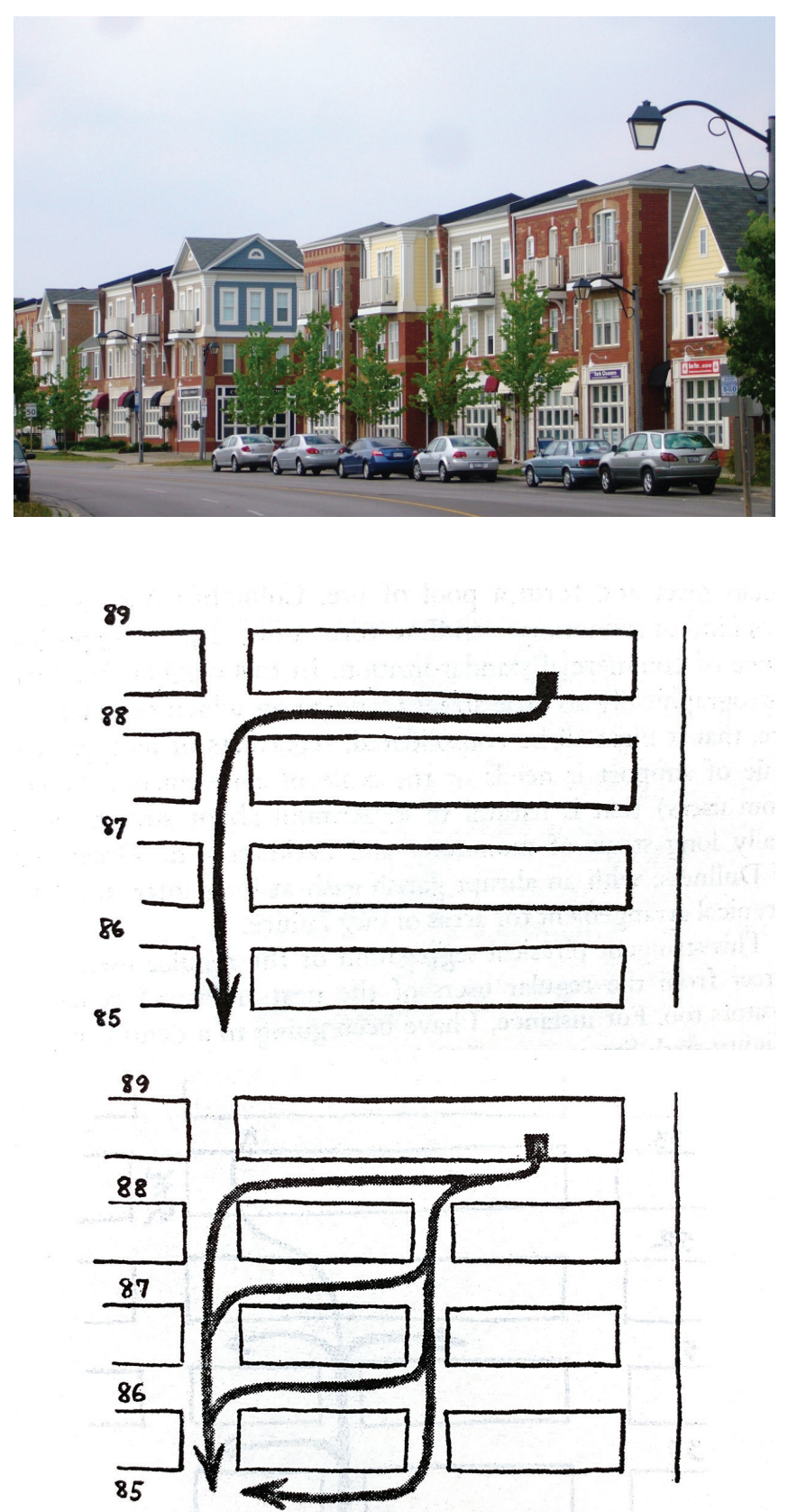

Fig.4.1 Cornell Neighbourhood, Markham Fig.4.2 Jacobs' The Need of Small Block Sketch 


\subsection{PURPOSE OF SQUARES}

Squares are identifiable nodes that can have many functions and different layers of meaning associated with them, politically, economically or culturally. The scope of the square in this thesis is to act as the heart of the neighbourhood and to create a sense of community and a place for meeting, which the mall has been serving since its development in the past decades. The idea of this neighbourhood square is for the local people to sit, to meet others, to enjoy the outdoor environment and to take part in cultural events that celebrate the diversity of the neighbourhood. All of these events have already been part of what the mall has incorporated, but as the need for mall transformation arises, these aspects become apparent to the transformation of such a node for the neighbourhood. An organization, Project for Public Spaces, explains that public squares sustained by community can have many benefits, including fostering entrepreneurial businesses and emphasizing distinct values of the communities (Project for Public Spaces). Although public squares are supposed to serve the community, community involvement nevertheless helps to build the unique experience at these squares. It should be kept in mind that this type of square is not intended for any political protest as it is not on public land owned by the government, but provided as a courtesy by the property owner.

Night It Up in Markham is a great example of an annual cultural event, an outdoor market that celebrates Asian street food and entertainment for the local community. It is currently hosted at the Markham Civic Centre parking lot, and every year it attracts many visitors, especially where a lot of Markham residents are Asian. This type of event is both economic and cultural; the vendors can promote their stores, or startup businesses with friends, it has a strong cultural value that promotes the essence of Asia market to the public.

A square can also act as a celebration place that is not limited to specific ethnic events but also for community or city-wide celebrations. In June 2019, an outdoor square in Downtown Markham had transformed into Jurassic Park North which hosted NBA Finals viewing parties. Instead of congregating at Jurassic Park in Downtown Toronto, some communities set up remote viewing parties at various places, such as Mississauga's Celebration Square (Vuong). This strengthens the point of what suburbs need, which is local meeting points for suburbanites. These suburban 'Jurassic Parks' became places where the diverse community gathered at and celebrated with their neighbours. 

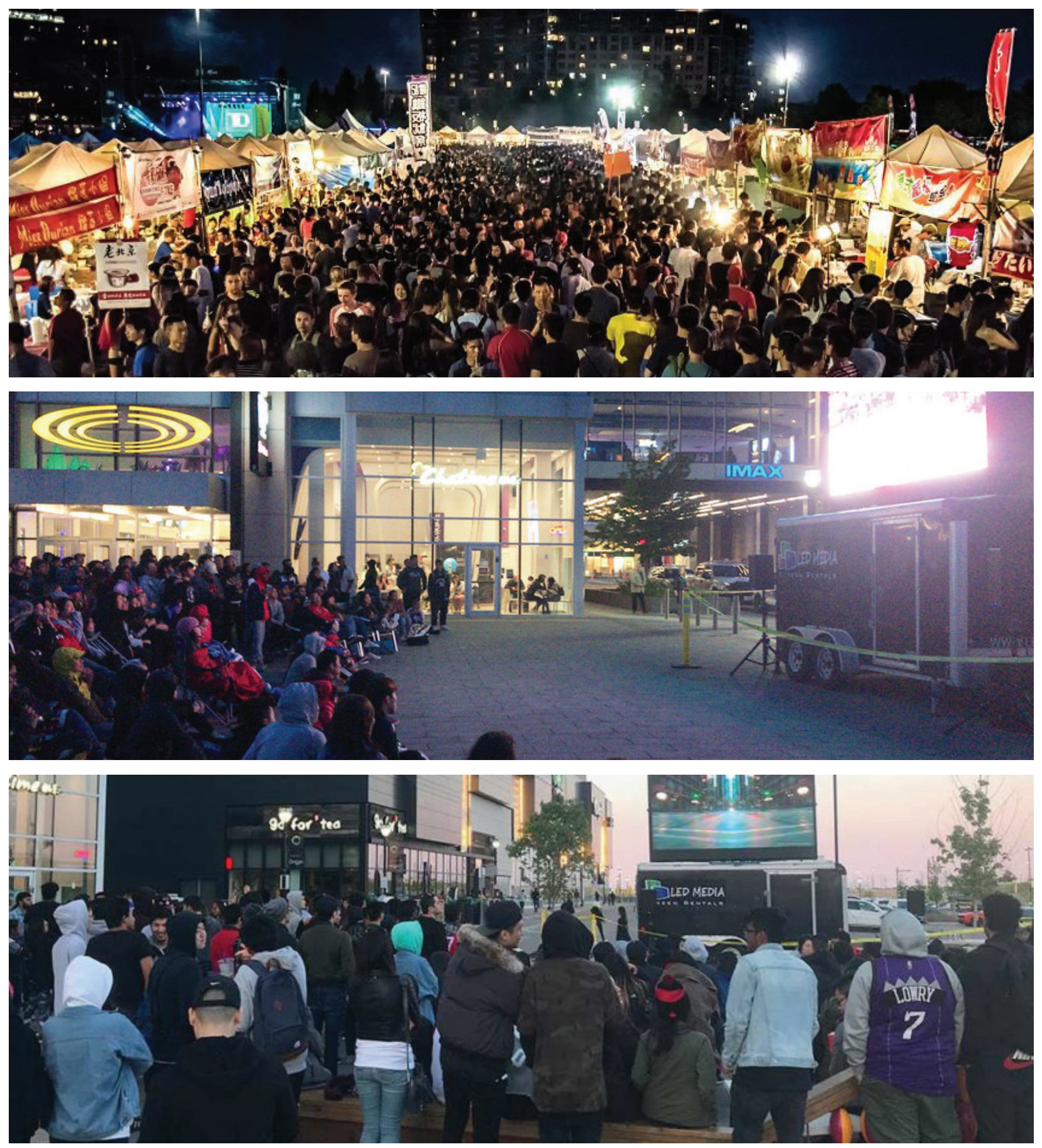

Fig.4.3 Night It Up, Markham

Fig.4.4 NBA Viewing Party at Markham Downtown

Fig.4.5 NBA Viewing Party at Markham Downtown 


\subsection{APPROPRIATE SIZE OF SQUARES}

Human scale is an important factor in square designs, as it relates to how a person reacts to the environment based on the visual perception of space. It determines an appropriate capacity for a space to hold activities. A square can be felt as empty or over-crowded, based on the size of activities it holds within the given space, which influence the behaviours of people in that space. In terms of human scale this is related to "concepts of appropriate levels of privacy" (Lang and Marshall 109).

Although there is no absolute and correct size of square, based on the observation of how squares function and the way people use them, it is possible to make an educated guess as to what an appropriate size of square is, depending on the intended use in the design vision for the specific location. The idea is not to change the behaviour of people, but through observation and comparison of precedents, to understand how architecture can frame the square appropriately for certain types of activities to occur.

According to Lang and Marshall, there are two variables which help determine the appropriate size of the square, which are the activity the square is to accommodate and the height of the surrounding elements (109). The sense of enclosure relates to the surrounding building height. Some may argue that the surrounding buildings should not be too low in height which makes this sense of enclosure disappear (Lang and Marshall 110). As Lang and Marshall referred to Gehl's findings, a square should not be more than 30 metres to 35 metres across, so that the person is able to recognize another person at the other side of the square (111112). This is not an absolute measurement but only serves as a reference. Given this reference, it can be argued that it is an appropriate size of a neighbourhood square that allows people to visually engage with others. Design elements or change of materials can help outline the size of the square. 


\subsection{BOUNDARY}

Boundary can have tangible and intangible dimensions. It creates limit that becomes a divider between two entities. In terms of tangibility, boundaryis manifested through physical objectsthat separate an area into two parts. In an architectural context, it can be created by the use of planes such as floors and walls, or use of materials. Boundary can also be created by intangible elements that affect people's perception through their senses, such as light, or by that invisible property line hinted by the change of materials. Boundary can be broad, and it should be clearly defined.

Aquestion that arises is what makes the boundaries of public and private spaces. In city planning, the property line is what governs and demarcates this boundary. A survey is a dimensioned plan of one's property, which documents the ownership of property on paper as a form of control, thus holding the responsibility for that land. In an urban context, this invisible boundary line can either be manifested by the physical fence or wall, or buildings surrounding the property, planted vegetation, change of ground planes or materials. These are all visual cues for people to visualize the invisible line that demarcates the different lots. As Madanipour mentioned, a boundary is "part of both sides of the divides" and thus it forms threshold (55).
The city's boundary lines are fixed, and the uses within these boundaries are determined by the zoning of the city. However, recent trends have shown that mixed-use development is on the rise, where multiple functions can coexist within property boundaries. Thus, grey areas in private and public spaces, the in-between zones of semi-public and semi-private spaces, become apparent where the concept of publicness can be inserted that can attract the public to use on a privately-owned site, which is the core idea explored in this thesis. This new 'public' space can benefit the neighbourhood while allowing the private sector to operate and captures this influx of people, which aims to maintain a balance within the public-private spectrum. It is this publicness that becomes the 'anchor' of the new intervention that draws people together.

The design approach begins with understanding what constitutes boundary and design elements that can separate or potentially create connections. Boundary study leads to the design principle of a place that might invite and welcome people to use the space more. Gehl mentioned that the selfreinforcing process between people and events is a key driver for growing together towards a larger and meaningful sequence of events (Life 75). If activities cannot stimulate other activities then the place becomes lifeless. This synergy 
is what makes a place work better. Gehl also pointed out that how the public environment is placed in relation to private space determines whether the place invites people or not (Life 113). Thus it is important to unite the two spaces to make them function collaboratively, through flexible boundaries and a mix of programs. The idea of permeable and transparent area blurs the boundary of the public and private spaces, which distinguishes the idea of border from barrier. Typical mall envelope is composed of solid wall without many windows, which does not allow the public to see from the outside and vice versa. The blank walls become a barrier and disengages the mall from the surroundings and thus prohibits any activity to stimulate one another between indoors and outdoors, resulting in less engagement and minimal public life in the community.

On the other hand, Gehl mentioned some principles in determining whether a place can assemble or disperse people and activities. In order to assemble, in this case of creating a gathering point, the circulation flow needs to assemble and integrate many functions that are inviting, with the help of the building opening up for these events to assemble and operate successfully (Gehl, Cities 233). Instead of blank and boring walls acting as barriers, openings are essential tool in assembling people to various activities. city planning principles: to assemble or di
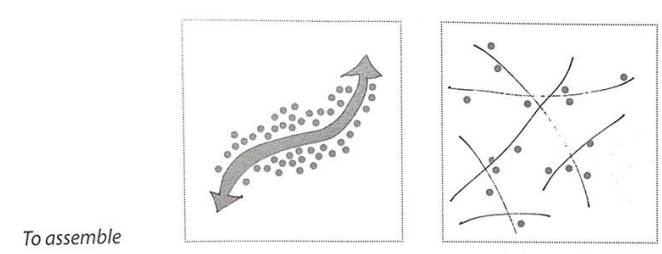

To disperse
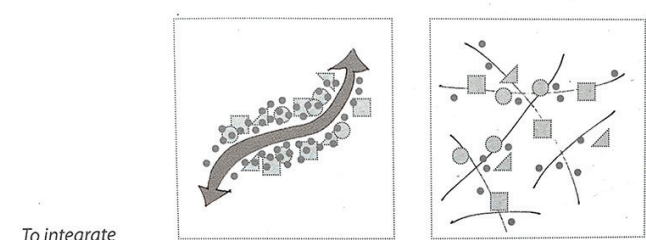

To segregate
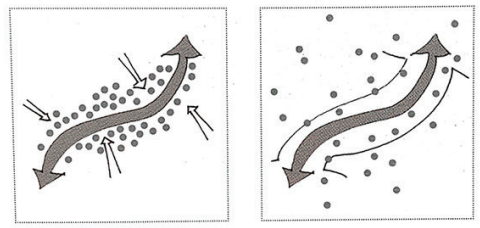

To invite
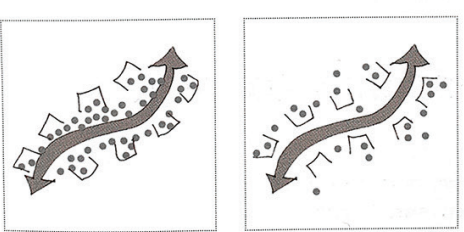

Torepel
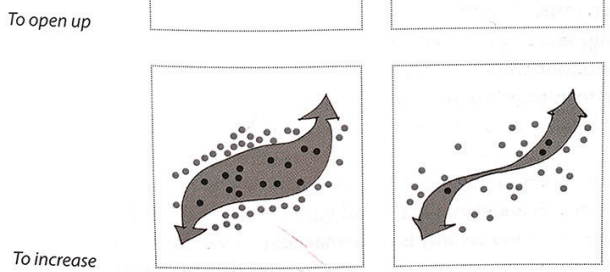

Toclose in

To increase 


\subsection{SOFT EDGES AND EDGE EFFECT}

\section{SOFT EDGES}

Gehl mentioned that to define the "character of life between buildings, the conditions offered to longlasting outdoor activities play the decisive role" (Life 183). This soft edge becomes a transitional zone between the street and the building, where opportunities for staying outdoors are provided. This is similar to the front yard of a dwelling, where the private meets the public side of the house and allows various activities to take place, such as playing, resting or other activities. Good connections between outdoors and indoors along with good resting places next to the building are crucial in establishing these soft edges that promote lengthy outdoor stays (Gehl, Life 197). This extension of outdoor stays enhances the existing daily activities on the street and between buildings, which is an important factor that creates lively streets and squares since people attract people. The idea of transition can first be achieved by the visual connection between indoor and outdoor, so that one is conscious of the surroundings to make decisions regarding to where to go. There should not be any changes in level between indoors and outdoors in order for events to easily flow in and out (Gehl, Life 187). This ease of 'popping in and out' allows people to observe and engage in other activities happening elsewhere, which draws attention to these activities and allows the event to grow. The easier people can get to these events, the easier these events will grow. This strategy suggests that there should be an easy flow on the ground floor between indoors and outdoors, which gives people freedom of choice to stay where they desire to be. Thus, the idea of soft edges is to enhance the quality on the ground level, where one can see others as most activities of the street and square happen at this level.

An architectural approach is to allow a free flow on the ground floor whenever the activities require it by introducing a series of big opening doors such as sliders or folding doors. By doing this, the wall is no longer a physical barrier, as it caters to the situation by having flexible opening. This flow provides choices for people, which can invite them in or out depending on the location of activity that interests people. On the other hand, this soft edge allows the activity from within the building to spill out to the exterior as a strategy for flexible expansion. All of these would not happen if long and hard edge is provided.

$$
\text { SOFT EDGES }
$$
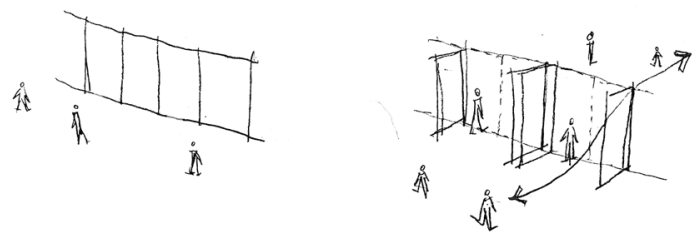

Fig.4.7 Soft Edges Sketch 


\section{EDGE EFFECT}

Edge effect illustrates the phenomenon where popular zones for staying occur along the facades or in the transition zone between spaces where one can look at both spaces, since it provides the best surveying spot in a space without the disturbance of others (Gehl, Life 149). The edge offers a desirable area for people to stand and observe, where it becomes the starting point of interaction. As a pattern, Gehl mentioned that the events would grow inwards to the centre of public space (Life 150). With this in mind, it can be argued that the edge effect can be one of the criteria which can determine whether the public space is successful or not. Thus, it explains why activities will begin on the edge first, as observed at Nathan Phillips Square near the elevated walkway, though the large scale of the square does not generate much activity in the middle. In order to generate activities at the square, first the edges around the square must allow for lengthy outdoor stay, which can be achieved by temporary or permanent seating.
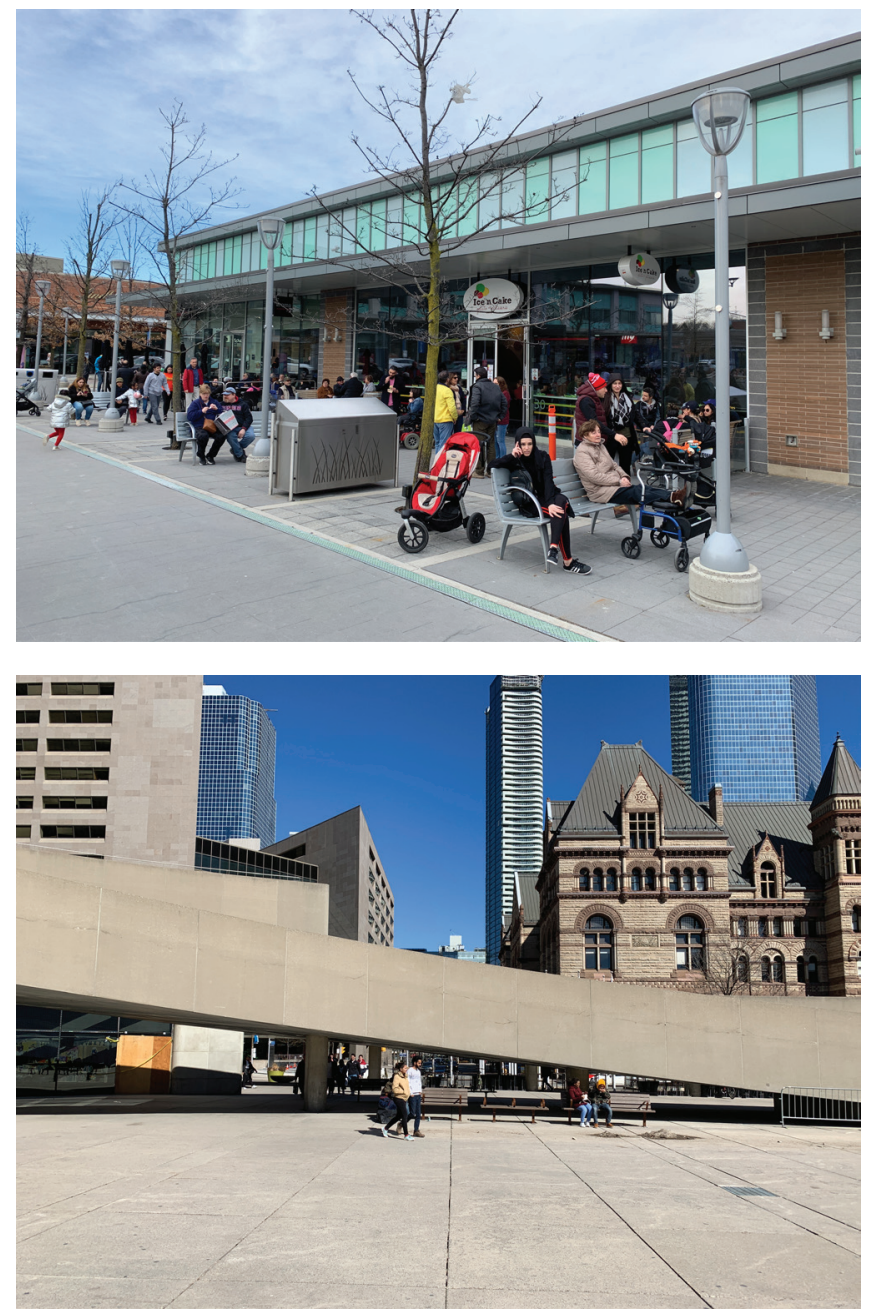

Fig.4.8 Edge Effect at Shops at Don Mills Fig.4.9 Edge Effect at Nathan Phillips Square 


\subsection{TYPES OF OUTDOOR ACTIVITIES}

Outdoor activities define the public life on streets and squares. Gehl defined three types of outdoor activities found in public life, which include necessary, optional and social activities, that are influenced by the quality of the physical environment and the exterior conditions (Life 9). Necessary activities are those that people must perform without a choice to go about their everyday lives, such as walking or shopping, and they happen under nearly all conditions regardless of the exterior environment (Gehl, Life 9). Optional activities refer to the activities that take place under favourable exterior conditions and the place is inviting to do so (Gehl, Life 11). They can include sitting, sunbathing, relaxing or recreational activities that are closely tied to a favourable physical outdoor environment. Social activities are the resultant activities that evolve from necessary or optional activities (Gehl, Life 12). This category depends on the presence of other people, such as children at play or watching street performances, and thus they occur when other people are in the same space. Passive contacts, such as seeing and hearing others, are also considered as social activities even though there is no direct interaction. It is common for people to initiate passive contacts before larger events can develop and thus places that offer observation opportunities can greatly stimulate other social activities.

The reason why outdoor activities are important is because they make up the public life on the street and square. "Integration of various activities and functions in and around public spaces allows the people involved to function together and to stimulate and inspire one another" (Gehl, Life 101). These activities, activated and experienced by people, are the essential components that can make these places vibrant. The presence of people is the critical factor that influences others' activities in public space, and social activities are what makes neighbourhood residents unite together. Thus, architecture becomes a tool that generates these meeting opportunities in hope for different forms of contact to develop. Also, outdoor activities allow a direct connection with the surroundings, in terms of visual and social connection.

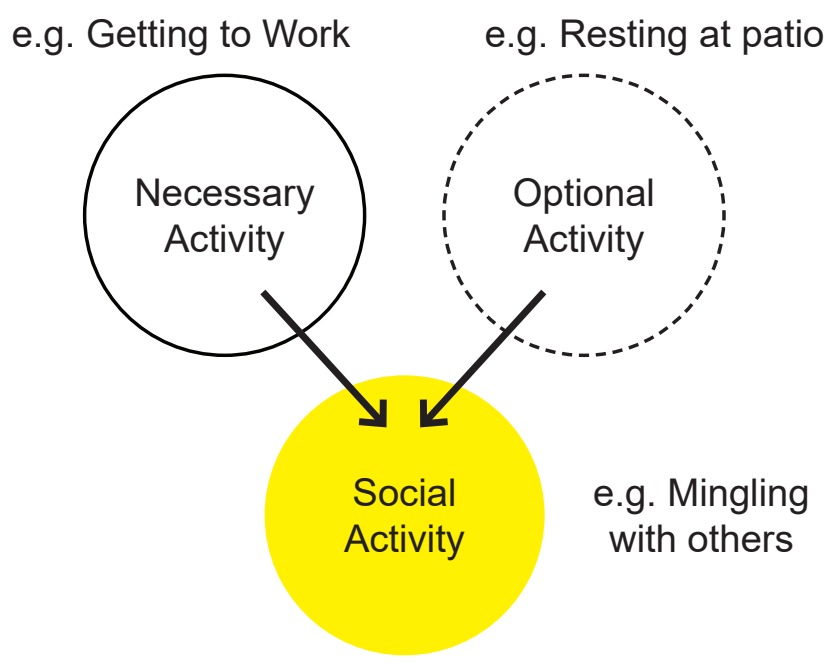

Fig.4.10 Activity Relationship Diagram 


\subsection{THE HUMAN DIMENSION}

Gehl has described a few principles concerning how people can promote contact with others, which include no walls, short distances, low speeds, one level and face-to-face orientation (Life 72). All of these are attributes to the physical environment that allow people to come into contact. Slow pace and short distance allow people to perceive their surroundings because there is more time for them to look around. When people can spend more time observing, it is more likely for them to be attracted by these surrounding activities. Especially in the case of the suburbs when many people travel by cars, it becomes difficult for them to observe the surroundings in details. $\mathrm{He}$ also studied the distance at which one can perceive others. Around 30 metres is the limit at which one can recognize others and at around 20 to 25 metres is when one can perceive the feelings of others, which begins the initial meeting (Gehl, Life 65). The social distance, at a distance of 1.3 to 3.75 metres, is when people can develop ordinary conversation with friends (Gehl, Life 69). This data serves as a reference when designing areas for social interaction, especially for a neighbourhood square. Nonetheless, oversized dimensions will eliminate these opportunities for social interaction. The scale of the building and area also influence the presence of people or activities. 
It is important to note that building height affects people's perception of their surroundings. In order to maintain a visual connection, Gehl suggested a threshold height of $6.5 \mathrm{~m}$ at which people can still view the activities on the ground plane (Cities 40). This is normally about two to three storeys and allows people to follow the life of the city. The higher the building, the harder for people to engage with the street activities and thus any sensory, especially visual, connection dissipate. In downtown, it is almost infeasible to develop low-rise where land value is so valuable. However, when developing a gathering point in the suburbs, the idea of low-rise is feasible especially when fostering social interaction is critical.

In this sense, the public space acts as a bonding agent for its surroundings where people can come together. Although it is impossible to find a solution that works for everyone, the idea is that when designing spaces for interaction, the human factor plays a dominant role. The height of buildings should not be overwhelming when the goal is to develop social interactions in public space. It is only the best hypothesis that architects can make to envision a possible successful design.

senses and tall buildings
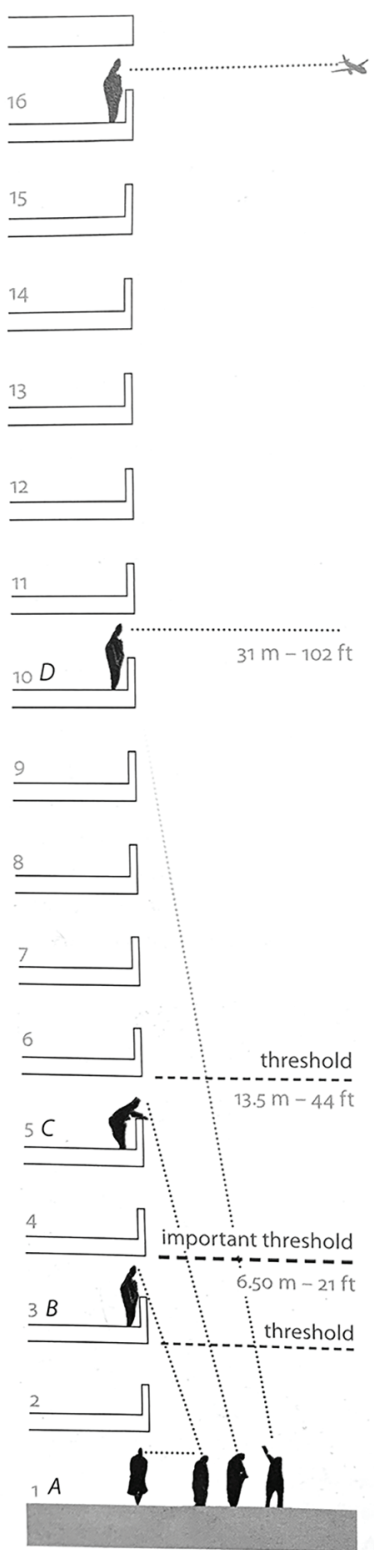


\subsection{CASE STUDIES}

Public life in the suburbs is a key component in the future of suburban development when it currently lacks a sense of centrality for neighbourhoods. It is believed that the activities of public life must be considered early in the planning stage in order for suburban public life to thrive. It is best to examine and learn from existing squares for a comprehensive understanding of the elements that make squares function. Squares consist of many elements which can be compared using case studies analysis. Scale, solid and void, material, seating and activities are properties which can determine the success or failure of squares. Case studies from Toronto are selected, as they best relate to the area of study. 


\section{NATHAN PHILLIPS SQUARE}

\section{SCALE}

The scale of Nathan Phillips Square is large enough that it becomes an ideal space for citywide events. Due to its massive size, the sense of scale becomes difficult for intimate gatherings to occur. The distance between activities at the square is too great to encourage any social activities, such as seeing and hearing others present at the square. Without any planned public events, the square becomes cold. As a result, there are not many people lingering at the square on a normal day. The square becomes a shortcut.

\section{BUILDINGS AND OPEN SPACE (SOLID AND VOID)}

The elevated walkway helps frame the square boundary, and since it is elevated, there is a visual connection without any physical barrier between the square and its periphery at grade. The centre of the square has become wide open after the revitalization plan of clearing the clutter to host large city events. There is an one-storey pavilion for amenities that provides washroom, snack bar and skate rental facilities, which supports the activities at the square. There is a covered stage which allows for concerts and performance opportunities while its amphitheatre allows people to sit and watch the urban life taking place at the square. The pavillion and the amphitheatre are connected to the existing elevated walkway to help bridge between different levels and zones within the square.

\section{MATERIALS}

The main square is paved with concrete pavers and most structures are exposed concrete. Material choices are kept minimal and no distinct colour is visible, thus the place is very monochromatic. Softscape is minimal near the edges of the square, where planters and trees are planted in landscaped islands. Without much shade available on site, the square can become very hot during the summer.

\section{SEATING}

There is some permanent seating located around the square below the elevated walkway, and around the pond. The amphitheatre also provides permanent seating for resting and people watching. A few portable picnic tables are present in the middle of the square for people to sit and eat.

\section{ACTIVITIES}

The square has a pond which turns into a skating rink during the winter season. This activity attracts a lot of people to gather and use the facility in winter. In the summer, the pond becomes a calming element that suggests for a retreat from the busy downtown life as it is setback from the main street and the elevated walkway. There is no cafe or shops at or 
near the square, but there are food trucks parked on the street that cater to the workers nearby or visitors to the square. The square mostly hosts large scale city-wide events, but on a daily basis without many activities during normal days, the square is not vibrant as a downtown public space.
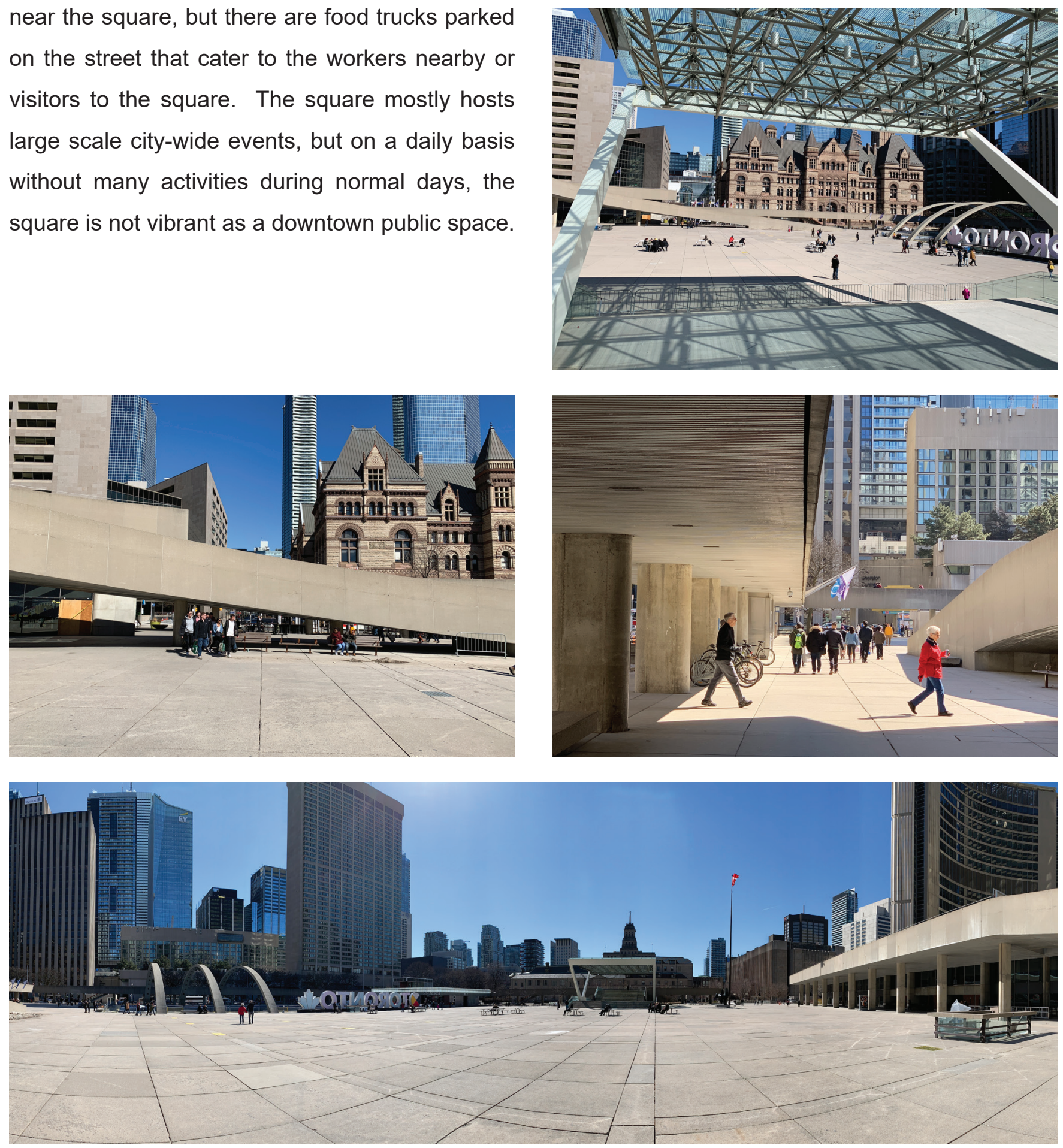

Fig.4.12 View of Nathan Phillips Square from Stage

Fig.4.13 Ramp as Threshold

Fig.4.14 Elevated Walkway as Boundary

Fig.4.15 Nathan Phillips Square on a Normal Saturday Afternoon 


\section{SHOPS AT DON MILLS}

\section{SCALE}

The site of Shops at Don Mills is large, but the scale is relatively small as it mainly focuses on the scale of the pedestrian. The buildings are mostly one to two storeys in height, which do not overwhelm the streetscape thus promoting street life. Due to its small scale, it helps to create a community that strives for pedestrian life, where places are within walkable distance. The central square is also small in scale.

\section{BUILDINGS AND OPEN SPACE (SOLID AND} VOID)

The buildings at Shops at Don Mills are low rise and in blocks which create many internal streets within the site. The streets are intended to slow car traffic, which permits safe and pleasant streets for people to walk. The buildings frame a square that is suitable for intimate gatherings, where people can sit and chat comfortably without feeling too distant from everything and everyone else. The square is enclosed on the sides by retail, while the opposite ends are opened to internal streets. Due to the relatively low rise buildings nearby, the square receives a lot of sunlight.

\section{MATERIALS}

The square has two components. The central part is an oval shape that is landscaped, and it is surrounded by pavers. This change of materials demarcates the different activities happening at the square. This ring of hardscape turns into a skating rink in winter.

\section{SEATING}

Most seating is temporary and is located on the edges of the square. Some are part of cafes and restaurants that are next to the square and some are owned by property management. Also, people tend to find informal seating, such as the steps or the planter edges at the side of the square, or they will sit on the grass during warm seasons. There are many options for people to find seats at this square.

\section{ACTIVITIES}

There are many activities at this square. First, there are a lot of cafes and shops next to the square for people to eat, drink, rest and shop. In the summer, kids play on the grass, while others will sit and watch them play. People tend to sit outdoors on the patio during nice weather to mingle with others. At times, there are seasonal farmers market and performances on a temporary stage. In the winter, the square transforms into a skating rink for the public. In summary, there are a lot of optional and social activities. 

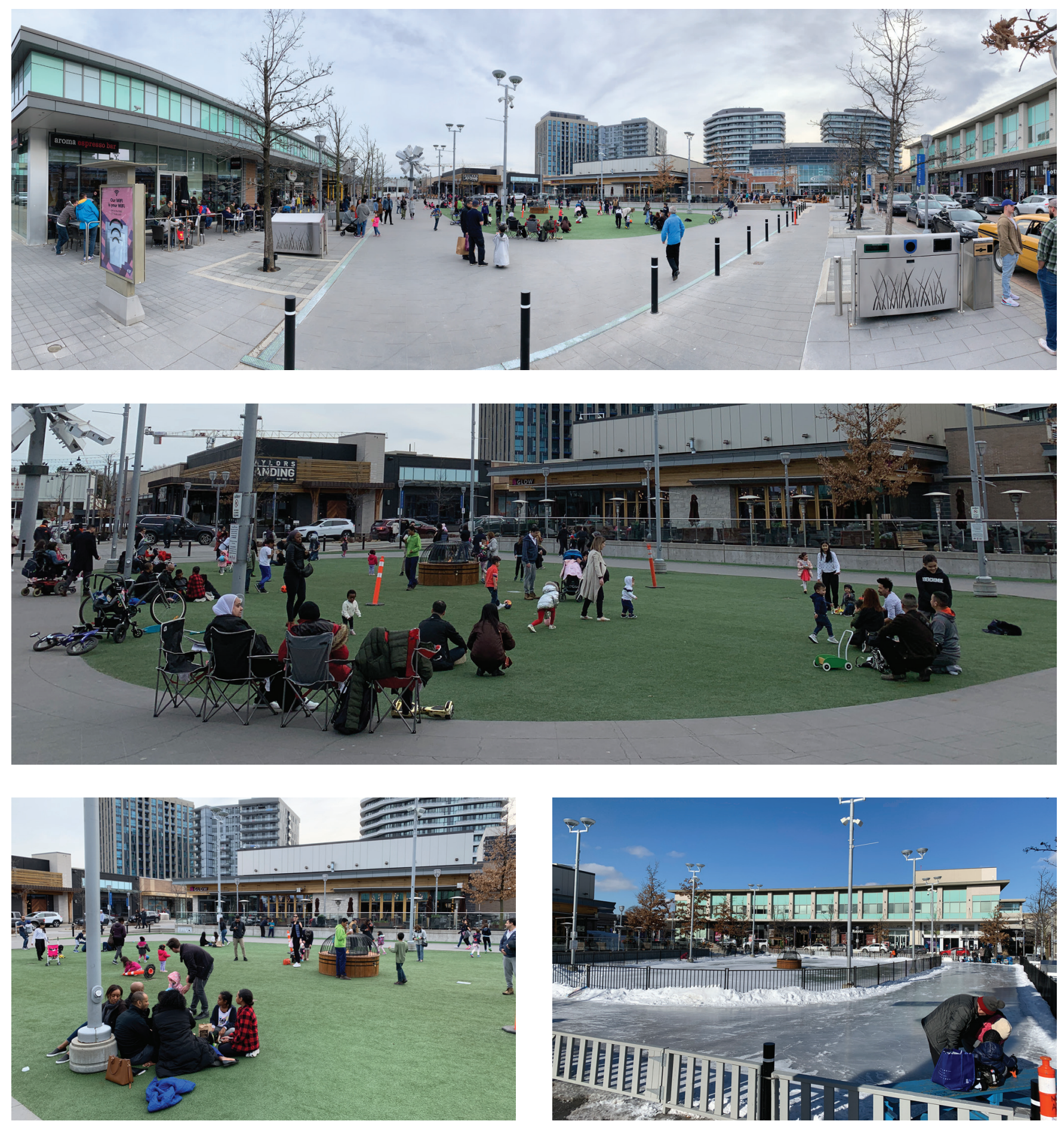

Fig.4.16 Shops at Don Mills Square in Summer Fig.4.17 Families at Shops at Don Mills Square

Fig.4.18 People Gathering at Shops at Don Mills Square

Fig.4.19 Shops at Don Mills Square in Winter 


\section{DISTILLERY DISTRICT}

\section{SCALE}

The site of Distillery District is similar to Shops at Don Mills, which is a large site. However, the scale of it is medium as it maintains the scale of the pedestrian while having buildings with varying heights - low, medium and tall. On the street level, one does not feel too overwhelmed because the streets are wide enough for pedestrian flow. This medium scale helps to create a street life established by the number of street activities at grade. The high number of patios and seats diverts the medium scale to focus on the street level, and thus a strong sense of street life is achieved despite the existence of towers and mid-rises. The site is connected by a network of internal streets, which creates the perception of walkability and intimacy, and helps maintain the pedestrian scale. Despite the medium scale of the buildings, the square is in small scale for the public to gather.

\section{BUILDINGS AND OPEN SPACE (SOLID AND VOID)}

The buildings at the site are a mix of low, mid and high rises. These buildings have created many internal streets and laneways, most of which are for pedestrians only, and thus a safe street life can be achieved. The buildings also frame a few squares that are nodes within the site as relief.
The main square is framed on three sides with its south boundary open, and there is ample amount of sunlight during most of the time. As a result, people sit comfortably in the sun at the square.

\section{MATERIALS}

The street and square are paved with cobblestone. This aged material creates a unique walking experience not found in many places in Toronto, as the ground is unevenly paved. There is no landscape found on site.

\section{SEATING}

Seating is mostly temporary and located on the main square. Cafe and restaurant patios make up a lot of seating along the streets and laneways. There are also some permanent benches along the streets for people to rest. No informal seating is observed at this location, perhaps because there are not many ledges for people to sit on. Although there is not much informal seating, most of the seats are provided by the property management or cafe and restaurant patios.

\section{ACTIVITIES}

There are many activities at this square. First, people like to sit and chat on the patios as there are many cafes next to the square. Visitors tend to stay to people-watch. There is a small temporary stage located in the centre of the square for 
performances and people would stay to watch. No kids were observed playing at this square perhaps due to the unevenly paved surface. There is Artscape, which allows the public to meet with the artists and their studios for arts and craft. There are workshops which engage the public to participate. There are some retail shops that are small brands or start-ups and many restaurants for food options. In the winter, the streets and lanes are filled with a seasonal Christmas market, which draws a lot of people to the site. People come here for the vibe that Distillery District offers with its available activities. Without doubt, the heritage components also play an important role in creating this vibe. Due to the high volume of people present at the location, there is a chain effect to draw more people into the location, and as a result, it creates a vibrant district in this neighbourhood. In summary, there are a lot of optional and social activities at this location as well.

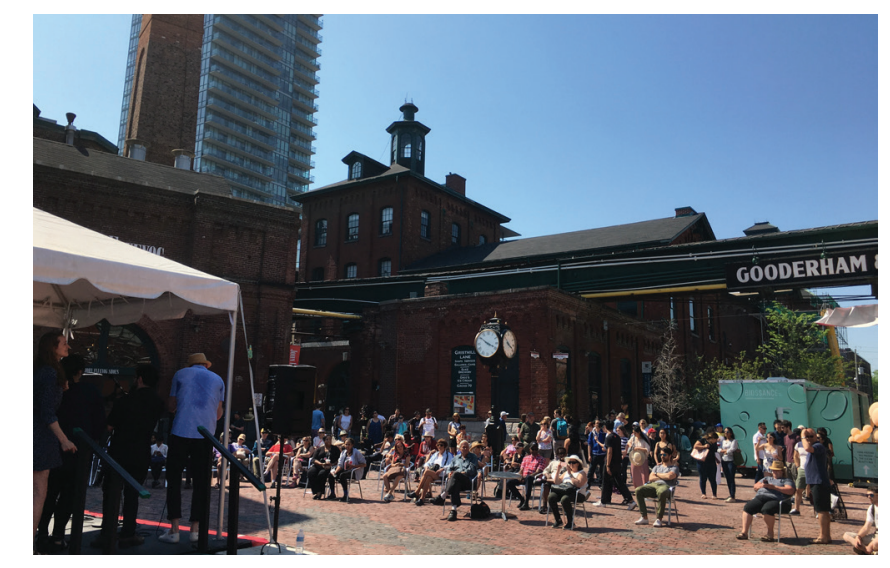

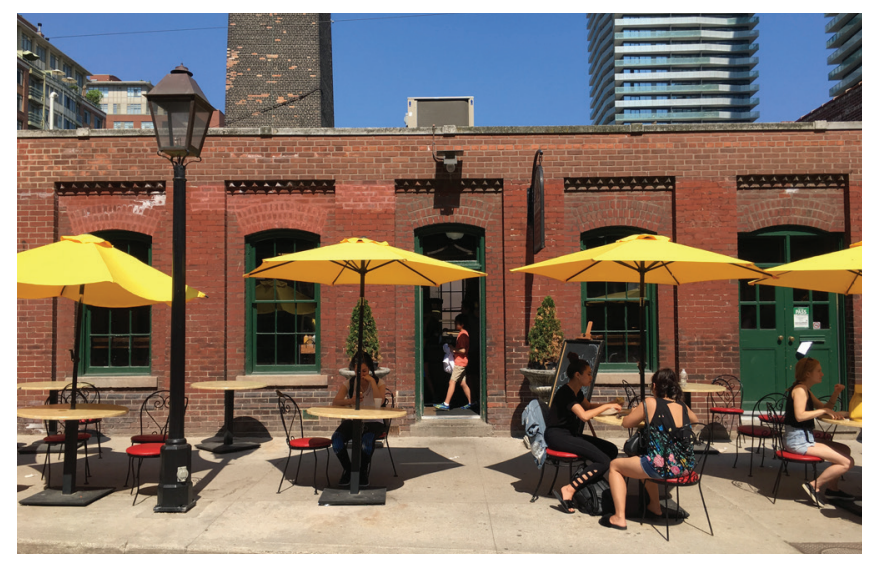

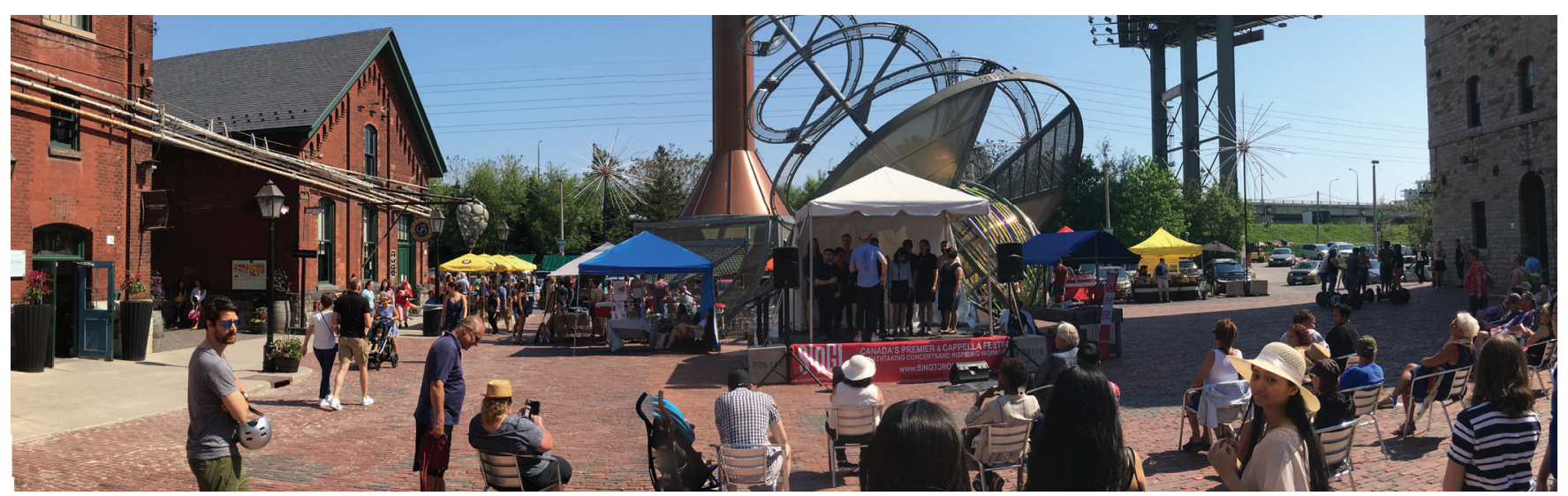

Fig.4.20 Distillery District Streetlife

Fig.4.21 Square at Distillery District

Fig.4.22 Distillery District Performance Stage 

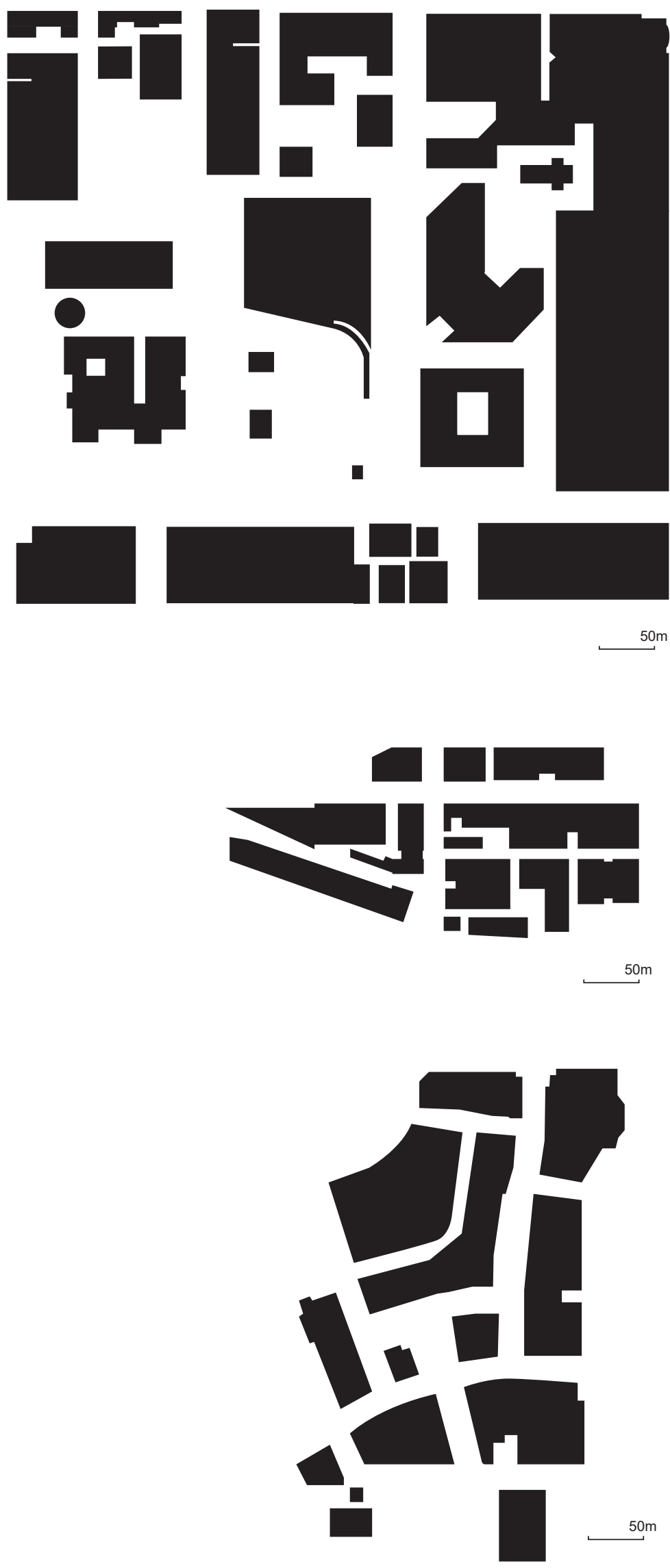


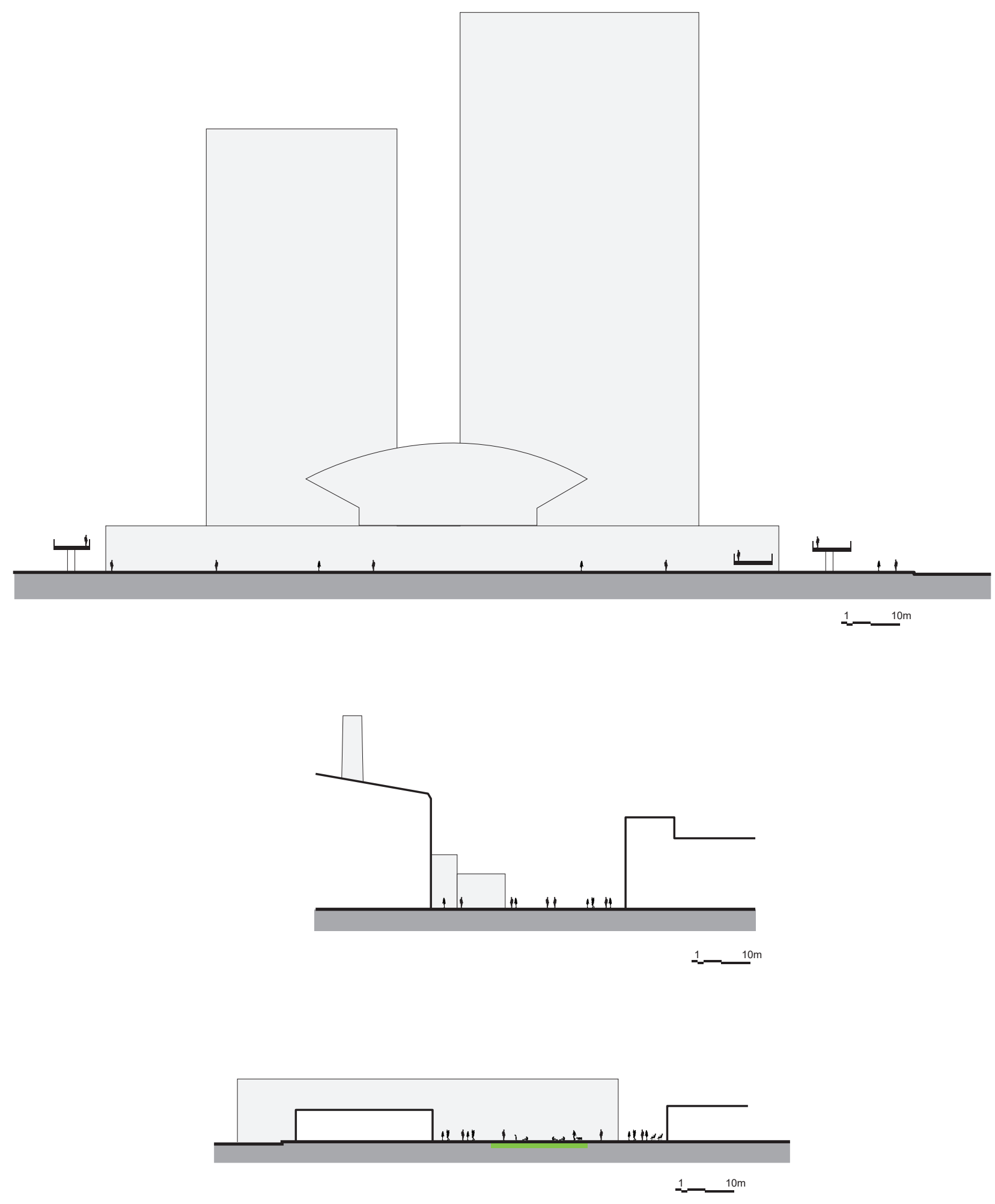

Fig.4.26 Nathan Phillips Square Section at Square

Fig.4.27 Distillery District Section at Square

Fig.4.28 Shops at Don Mills Section at Square 


\section{FINDINGS}

These squares exhibit a variety of components that make some of them more successful than others. Both squares at Shops at Don Mills and Distillery District exhibit many activities, including optional and social activities, where people do stay and interact with others. Their sizes are appropriate for their contexts as the buildings framing them are low to mid rise and their scale does not result in the squares feeling overcrowded or empty. Also, their scales create a sense of intimacy, which makes the streets and squares more lively and safely. The square at Shops at Don Mills seems to allow kids to play with the addition of softscape,

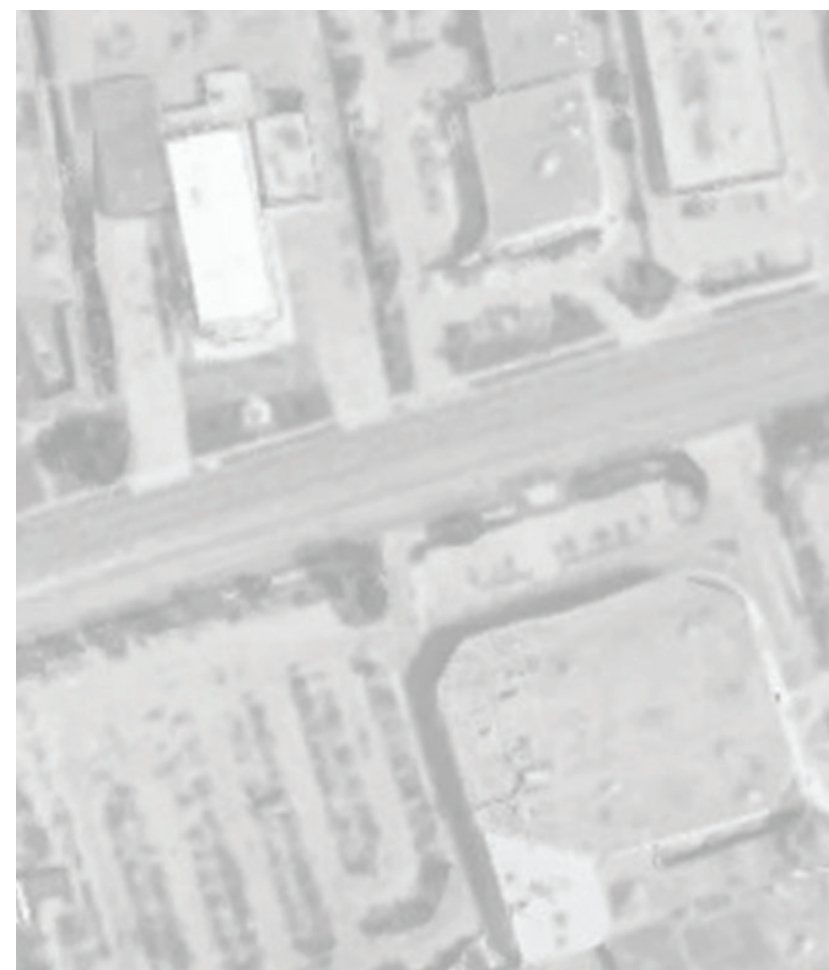

resulting in a more neighbourhood-friendly gathering point. Since the square at Shops at Don Mills is deemed to be the most appropriate for suburban neighbourhoods, from materials to size to amount of activities, this model will be used as a reference for this design project. It should be noted that a unique feature Nathan Phillips Square has is that its elevated walkway creates a threshold that invites one to enter through. This form can denote a strong entrance of the design project.

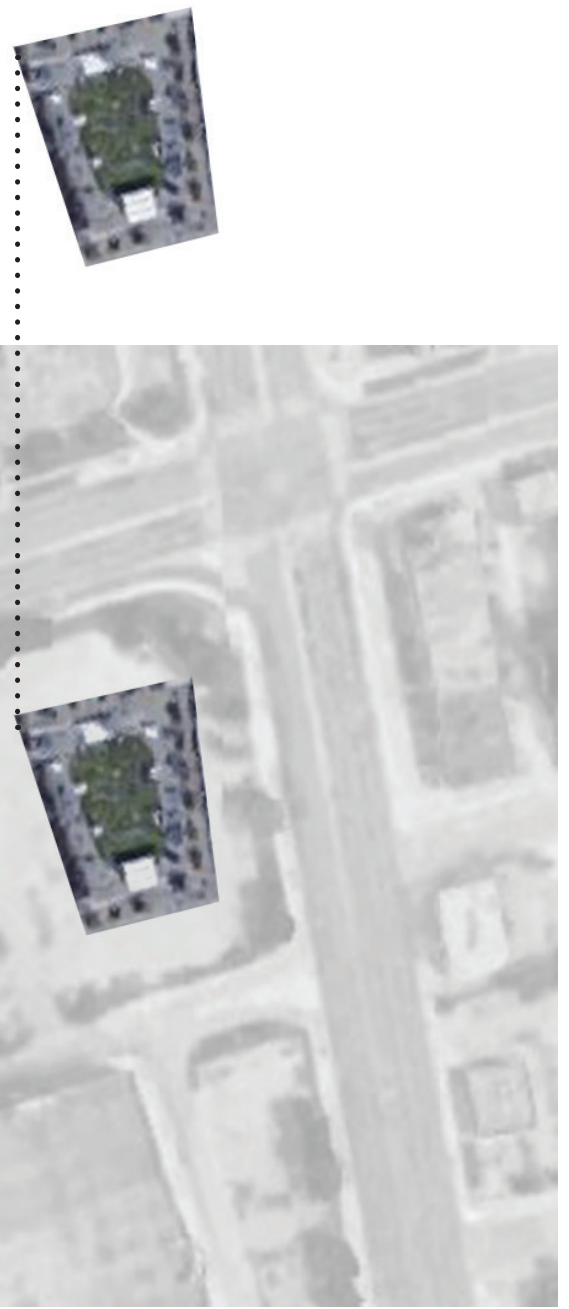




\section{DESIGN PROJECT}

The design intent for this thesis exploration begins with an understanding of the composition of typical malls and to understand what types of services they provide for the neighbourhood. Although there can be retrofitting done to the existing malls, retrofitting may not allow for the density that the city requires because keeping the old structure of the mall becomes restrictive for the new growth that the city demands. While this thesis explores a new intervention at the sites of the malls, it first requires a new master plan that incorporates necessary elements of a 'downtown' neighbourhood. While the old mall takes an introverted approach, the new intervention needs an extroverted approach to open up more spaces for the public, such as streets and squares for social interaction.
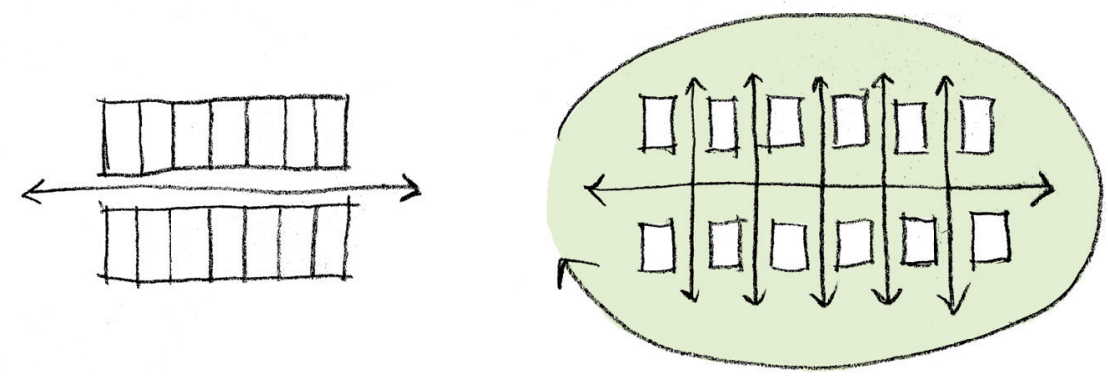
Replacing the shopping mall requires an understanding of what the neighbourhood needs so that the new intervention can cater to the neighbourhood. Referring back to Fishman's idea of an open-minded space and Pacific Mall as a successful model for the Markham neighbourhood, the new intervention requires three categories of programs, which are cultural, social and economic. This formulates the idea of a cultural hub for neighbourhoods, where people with different cultural backgrounds can learn about other cultures, while the economic aspect helps maintain the cost of the building. Most importantly, these aspects tie into the social aspects of people uniting and socializing at this hub.

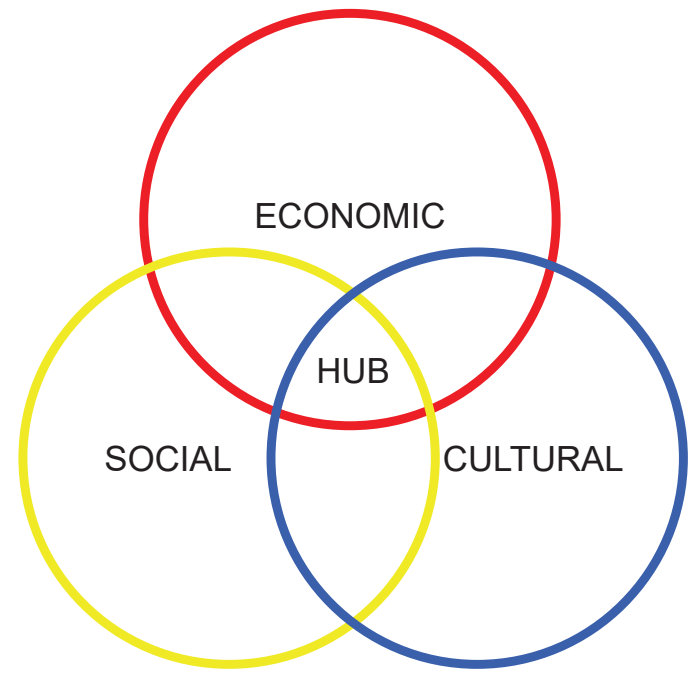

Fig.5.2 Hub Program Category
The architectural intervention should accommodate and promote public space for outdoor activities where the public can gather. It generously turns a private space into a public space while the private sector can densify elsewhere as a trade-off allowed by the amendment of zoning by-laws. The main goal is to revitalize a lost space, currently the old decaying mall and its parking surface, and reintegrate this area into the suburban fabric by creating a vibrant place in which the community can use and engage. The concept of publicness becomes essential in creating such a vibrant hub, where people feel welcome to use. 


\subsection{SITE - CENTERPOINT MALL}

The site proposed for this intervention is Centerpoint Mall, which is located in Toronto, in the former city of North York, on the southwest corner of Steeles Avenue and Yonge Street. Its location is at the border between North York and Richmond Hill at a busy corner between the two municipalities, especially when there is a high volume of commuter exchanges between TTC and York Region Transit. Centerpoint Mall is a typical suburban mall built in the 1960s, surrounded by a surface parking lot. It is designed under the principle of an introvert design approach, in which the exterior walls are blank facades. People would have already made up their minds to go straight into the mall as there is nothing to do outside. One of the four anchor stores in the mall has closed down recently, after having transformed from Zellers to Target, and to Lowe's, which reaffirms the hypothesis that anchor stores will continue to reduce in number in the near future. The mall itself has many small businesses, with only a small number of big chain stores, such as Shoppers Drug Mart. There is occasional seating along the corridors inside the mall, and a few empty booths that share the corridors. Without much renovation like at more upscale malls like Yorkdale Shopping Centre, the current condition of Centerpoint Mall shows signs of decay and presents itself as being in need of a new intervention.

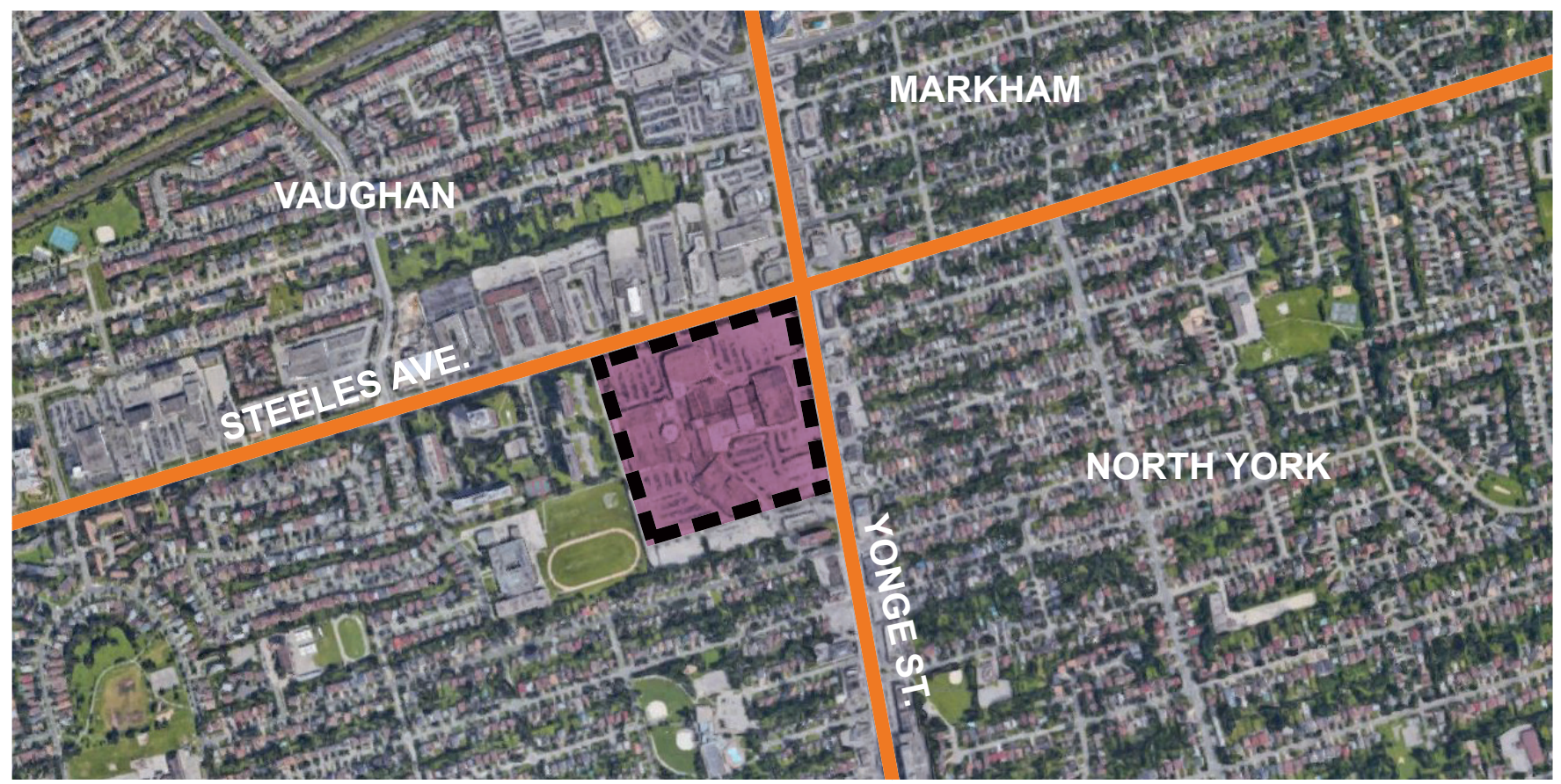

Fig.5.3 Context Map 

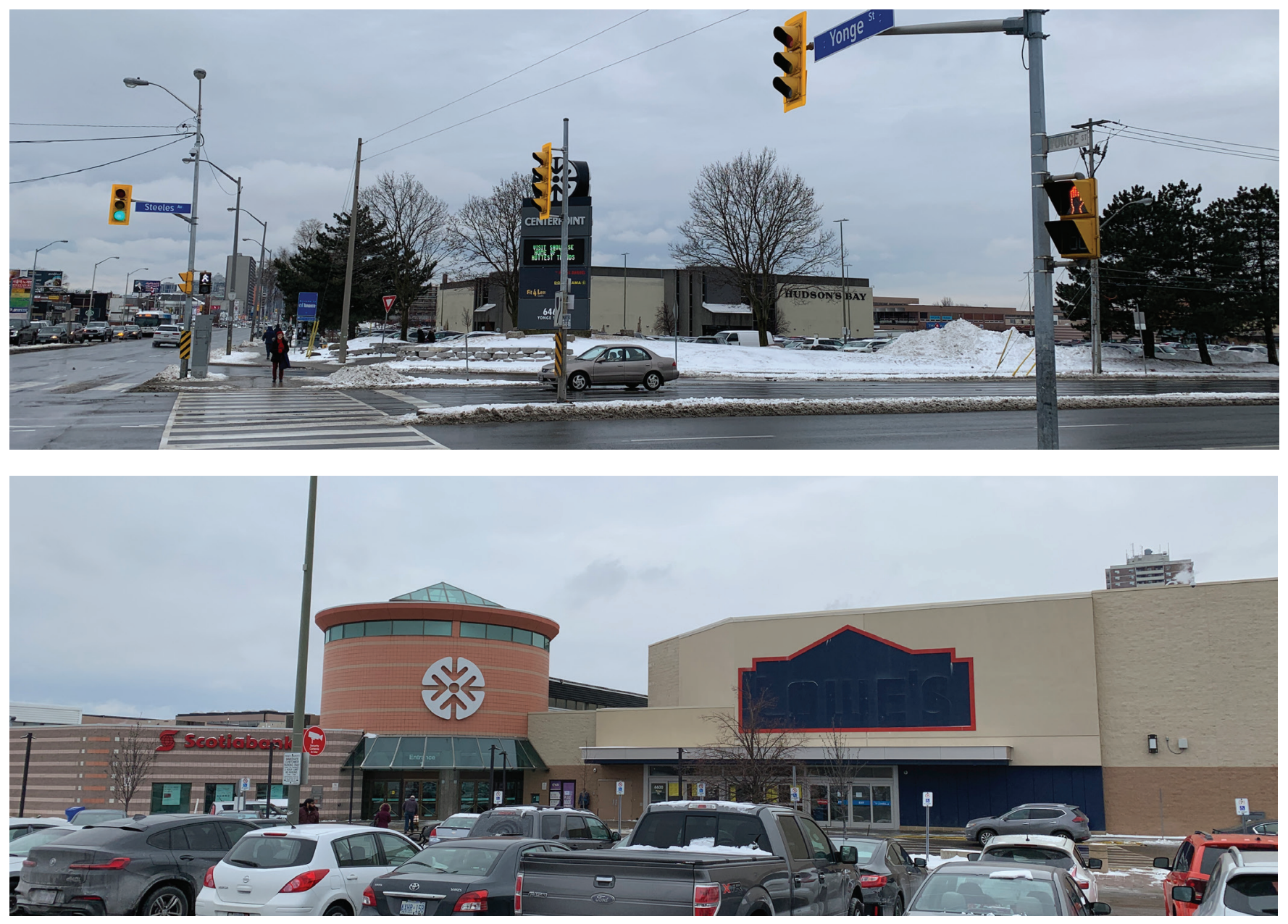

Fig.5.4 Northeast Corner, Centerpoint Mall

Fig.5.5 Northeast Entrance, Centerpoint Mall 

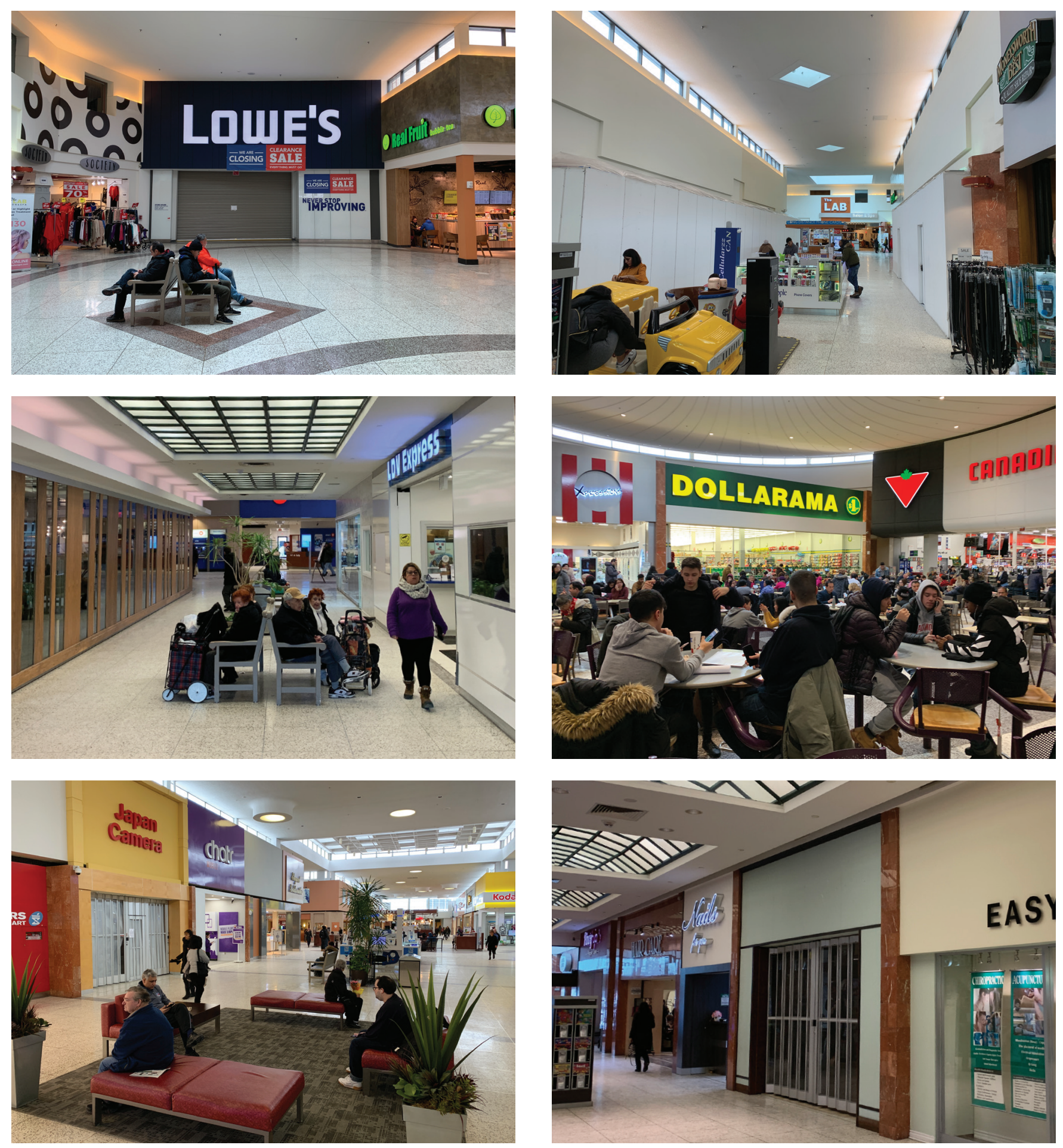

Fig.5.6 People Sitting inside Centerpoint Mall Fig.5.7 People Sitting inside Centerpoint Mall Fig.5.8 People Sitting inside Centerpoint Mall
Fig.5.9 Store Closed at Centerpoint Mall

Fig.5.10 Centerpoint Mall Food Court

Fig.5.11 Store Closed at Centerpoint Mall 


\subsection{ZONING}

The current zoning designation for the site of Centerpoint Mall is CR, which stands for commercial residential zoning. However it currently has a density of 1.0 , which means that the total density of the building allowed is one times the area of property. This poses an unrealistic or dated limitation for the city, as it may be ripe for densification as the mall is undergoing the process of decay. Based on other mall redevelopment proposals in Toronto, it can be argued that this site can and will be rezoned by the city for future redevelopment with increased density. 


\subsection{SITE ANALYSIS}

Surrounding Centerpoint mall is an area of mostly single detached houses, with a few residential towers. North of Steeles Avenue is a row of strip plazas fronted by parking lots, while along Yonge Street the sense of street from Finch Avenue begins to fade as one approaches Steeles Avenue because the street is fronted by discontinuous blocks of small buildings and parking lots. This makes Yonge Street not too pedestrian friendly with a lengthy rolled curb for cars to drive into these small shops, which makes the pedestrians very cautious as they walk on the sidewalk. It seems that there is currently not much street life at this intersection.

Centerpoint Mall is within the neighbourhood of Newtonbrook. According to the neighbourhood census profile from the City of Toronto, more than $60 \%$ of the residents of Newtonbrook are identified as immigrants, of which more than $70 \%$ are first generation immigrant and the top ethnic origins found are Chinese, Filipino, Iranian and Korean (City of Toronto, Newtonbrook East; City of Toronto, Newtonbrook West). It should be noted that in Newtonbrook West, the working age of 25-64 dominates, but the youth age group of 15-24 and the senior age group of 65 and above both present higher percentage than the city average, which means these age groups should not be neglected (City of Toronto, Newtonbrook West). Financially, $29 \%$ of residents fall within the income bracket of $\$ 20,000$ to $\$ 49,999$, which is higher than the city average, then followed by $20 \%$ of residents earning the income bracket of $\$ 50,000$ to $\$ 79,999$, (City of Toronto, Newtonbrook West). This illustrates that the neighbourhood is a low-to-mid income community.

Since the mall is located at the border of two municipalities, there is a high degree of public transit servicing this intersection for transit exchanges. As a result, there are a lot of pedestrians at this corner most of the time. The northeast corner of the site is currently a parking lot for the mall, but it is observed that many pedestrians walk across this parking lot to get access to and from the mall.

During lunch time, many would gather at the food court. The usersobservedincludeteenagers, elderly and office workers. Since there is a secondary school nearby, it can be understood why there are students hanging out at the food court during lunch hour, as a place of meeting and socializing. On the other hand, it was observed that there were shuttle buses that bring in the elderly from nearby senior homes. The mall becomes a place of daily routine for the elderly to exercise or to hang out.

There are a few condominium proposals just north 
of Centerpoint Mall, with the closest one at the northwest corner of the interestion. The proposed project consists of a 7-storey podium with two 52-storey and one 65-storey residential towers. The podium consists of retail at grade and 6-storey hotel. This intersection will soon be redeveloped into a higher density residential project, which encourages gentrification in the neighbourhood.
The fact that there is a hotel may suggest that there will be tourists or business travelers who may require additional amenities. It can be assumed that the mall may become a destination place for new condominium development.

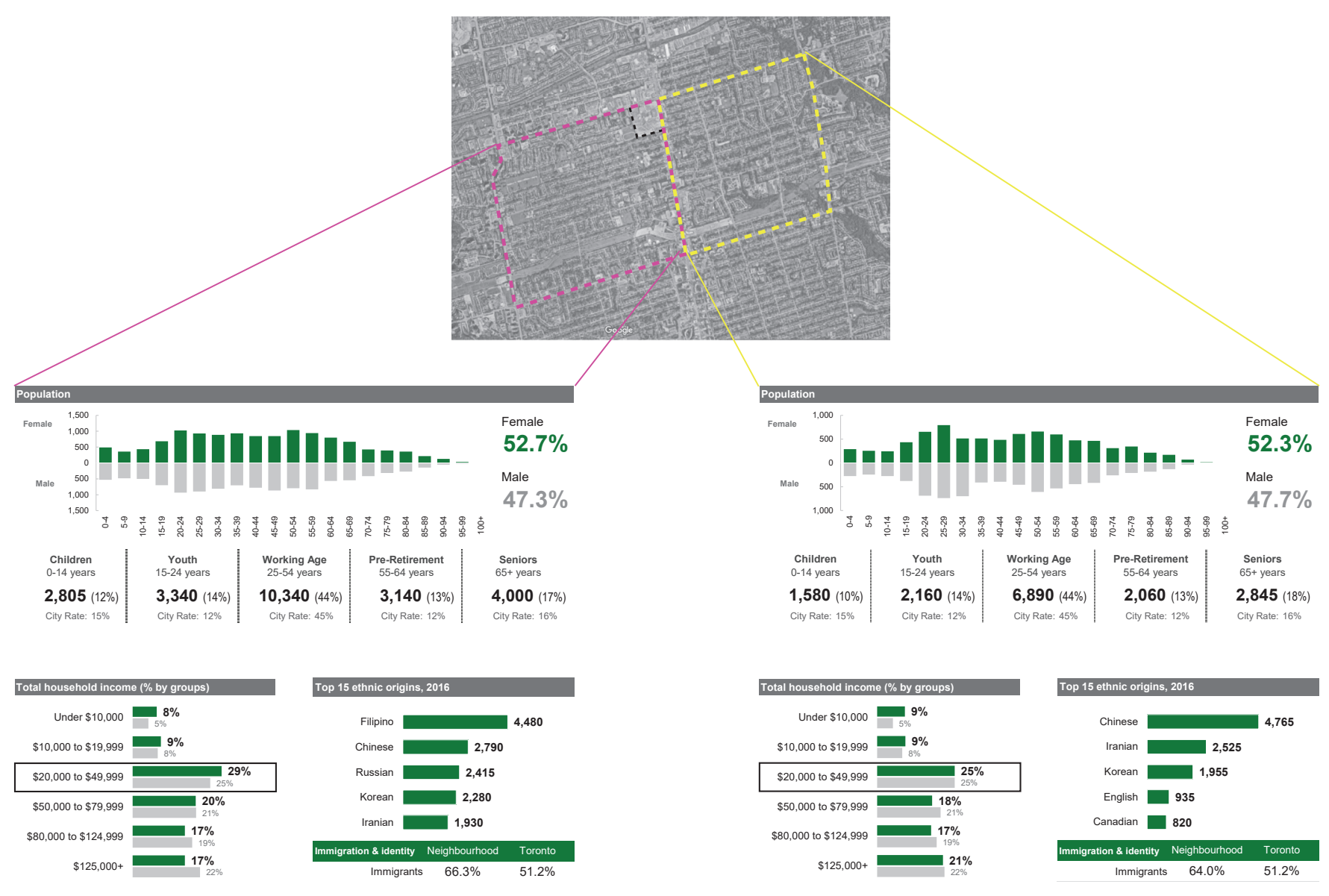

Fig.5.12 Neighbourhood Demographic 

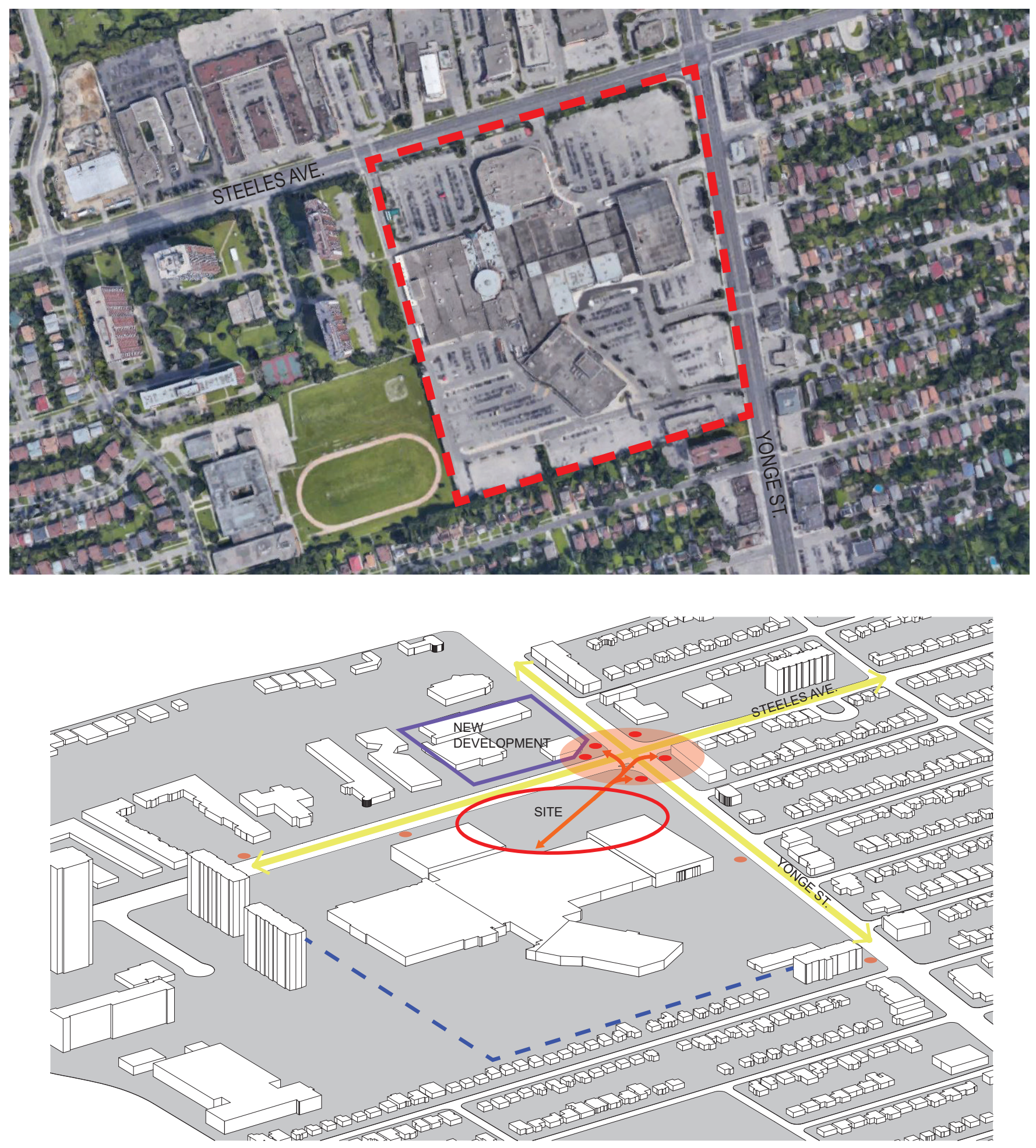

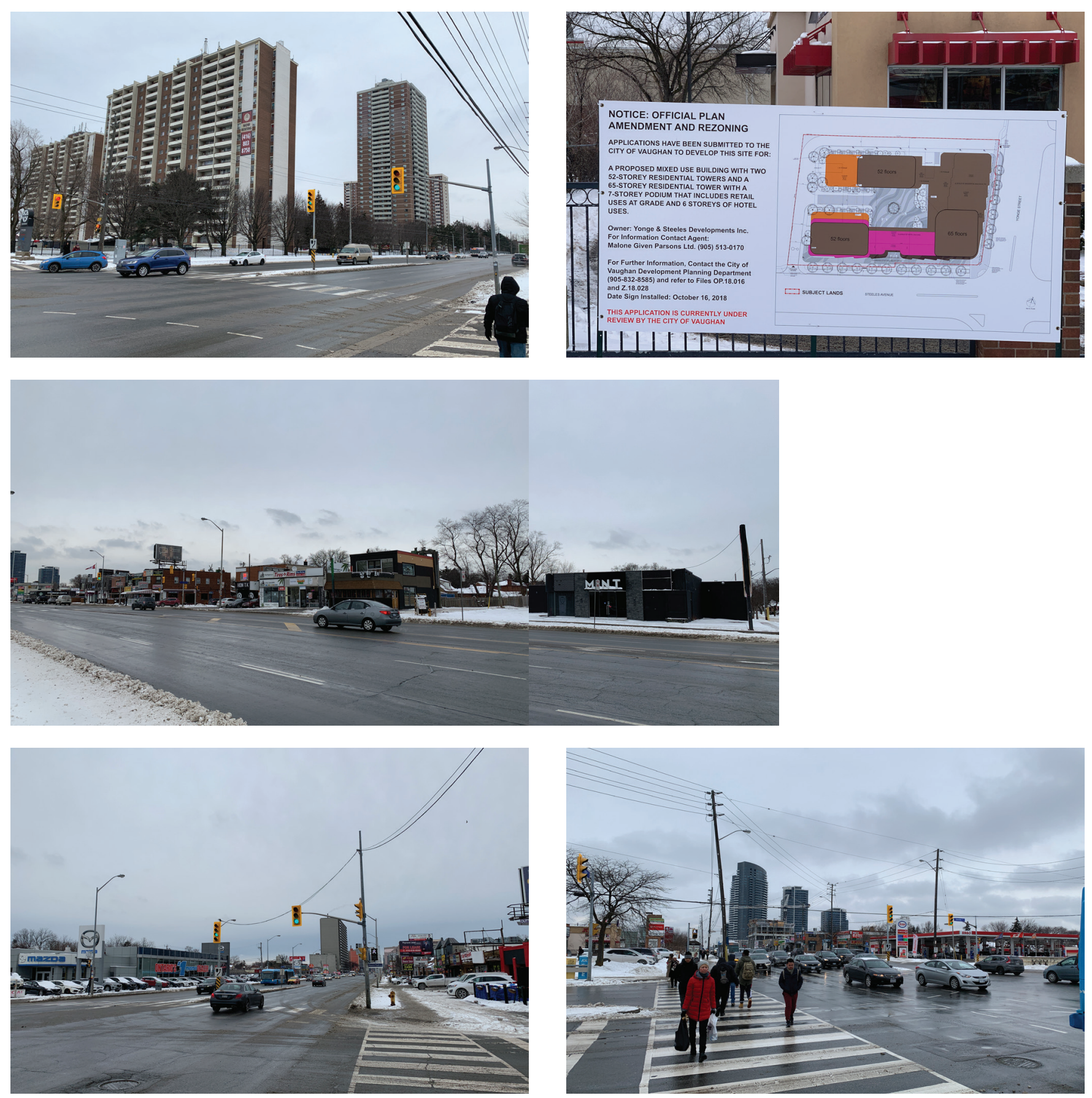

Fig.5.15 Rental Apartment Nearby

Fig.5.16 New Development Notice North of Steeles

Fig.5.17 Pedestrian Unfriendly on Yonge Street

Fig.5.18 View Facing South on Yonge Street

Fig.5.19 View Facing North at Major Intersection 


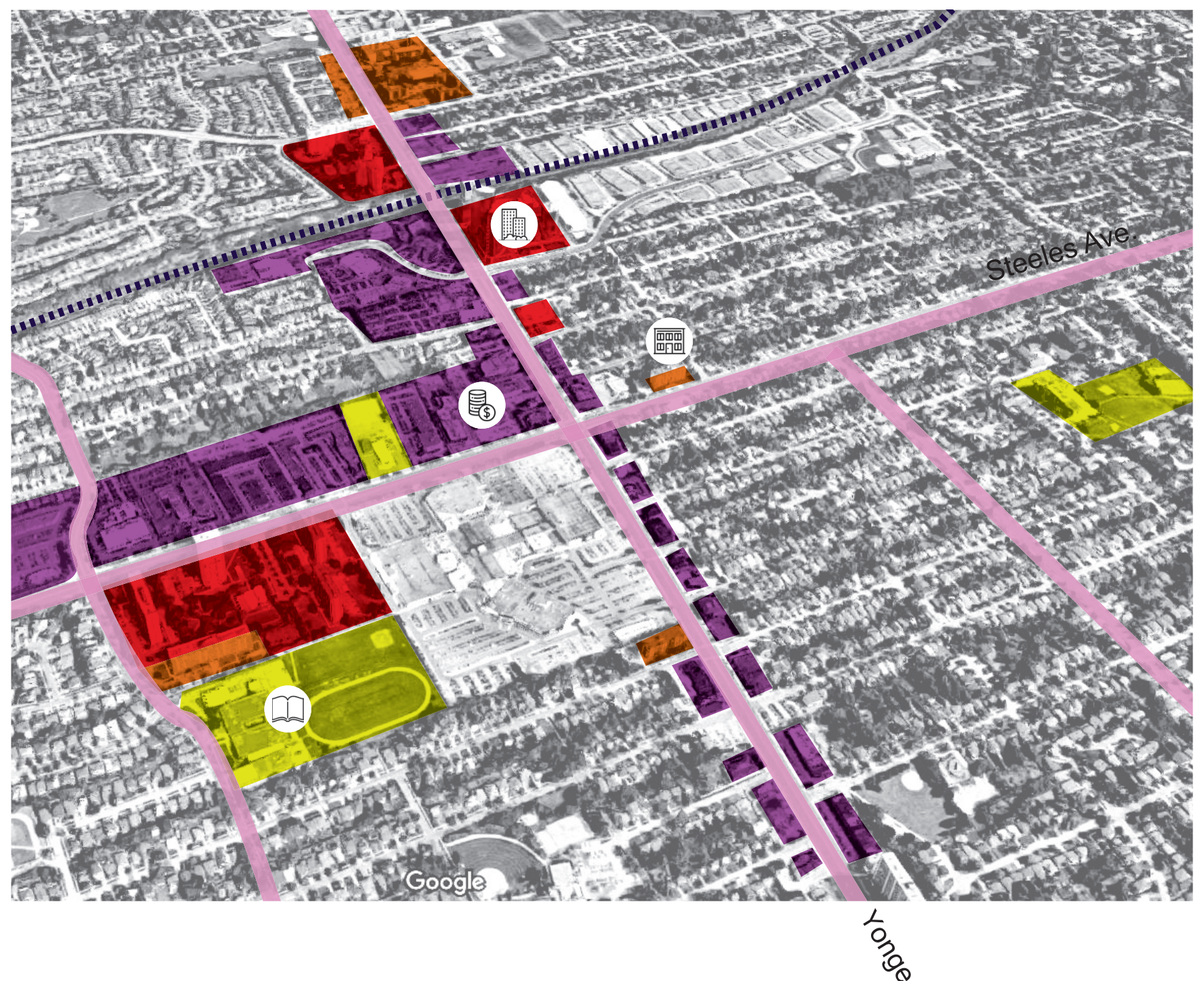

低,

- Institutional

- Mid-rise

- Towers

- Commercial / Retail 


\subsection{MASTER PLAN}

Following some of Jacobs' ideas about city conditions, it is believed that some of the conditions can be applied to suburbs as well. Although suburbs may not have the same degree of population density as downtown, these ideas nevertheless can be applied to suburbs where they lack a central point for public engagement. While a typical mall site usually consists of an outer ring of parking surrounding an enclosed mall, it displays a visual disconnection with the nearby neighbourhood. In order to re-establish a connection with the neighbourhood, the building forms and programs of the new development will need to relate to the existing urban fabric.

The site of the new development should be guided by nearby streets, and so the circulation should be extended into the site. This will help bridge from neighbouring area onto the site and create a framework. The addition of internal streets helps to break up the large site into smaller blocks, which generates a network of car traffic and pedestrian pathways, making the site more accessible from multiple directions both on foot or by car. It is important to connect any existing pedestrian paths into the new pedestrian network as part of continuous foot traffic. This helps to bridge between the old and the new areas, and more importantly connects the existing residents with the site. Using the circulation system as a guideline to subdivide a site allows clearer and more logical planning of the site in an orderly fashion.

At the Centrepoint Mall site, in order to increase the density, various housing models are suggested, including townhouses, mid-rise and high-rise residential. Townhouses and mid-rise residential are mostly planned so that there is less shadow cast by high rise towers, and also the human scale can be maintained that relates to the ground level in the neighbourhood. The site is programmed in rings starting from the southwest corner of the site. Low-rise townhouses are located along the southern part of the site, which relates to the existing neighbouring detached houses on the south. Towards the middle ring is the mid-rise residential, which will not block the sunlight for the townhouses on the south. A few high-rise towers are located along the west side of the site that relate to the existing rental towers adjacent to the site. It is logical that the outer ring, or the street edges, are programed for commercial and office purposes as the extension of commercial activities along Yonge Street and Steeles Avenue. This strategy ensures the continuation of street activities are maintained in hope of reviving the liveliness along these major circulation axes. This helps to animate the streetscape so that it encourages more people to 
walk along major streets, which brings in the public life with people on suburban streets. In the end, it is rational to locate the meeting point at the northeast corner of the site, where it is adjacent to the street intersection. This location illustrates that a node should not be hidden within the new development, which might lead to the public misconception of exclusive use for the new residents. It needs to be located at a visually prominent spot that strives to connect both new and existing neighbourhoods.

Vehicular Path

- Pedestrian Path

O Point of Neighbourhood Entry

Fig.5.21 Master Plan Diagram
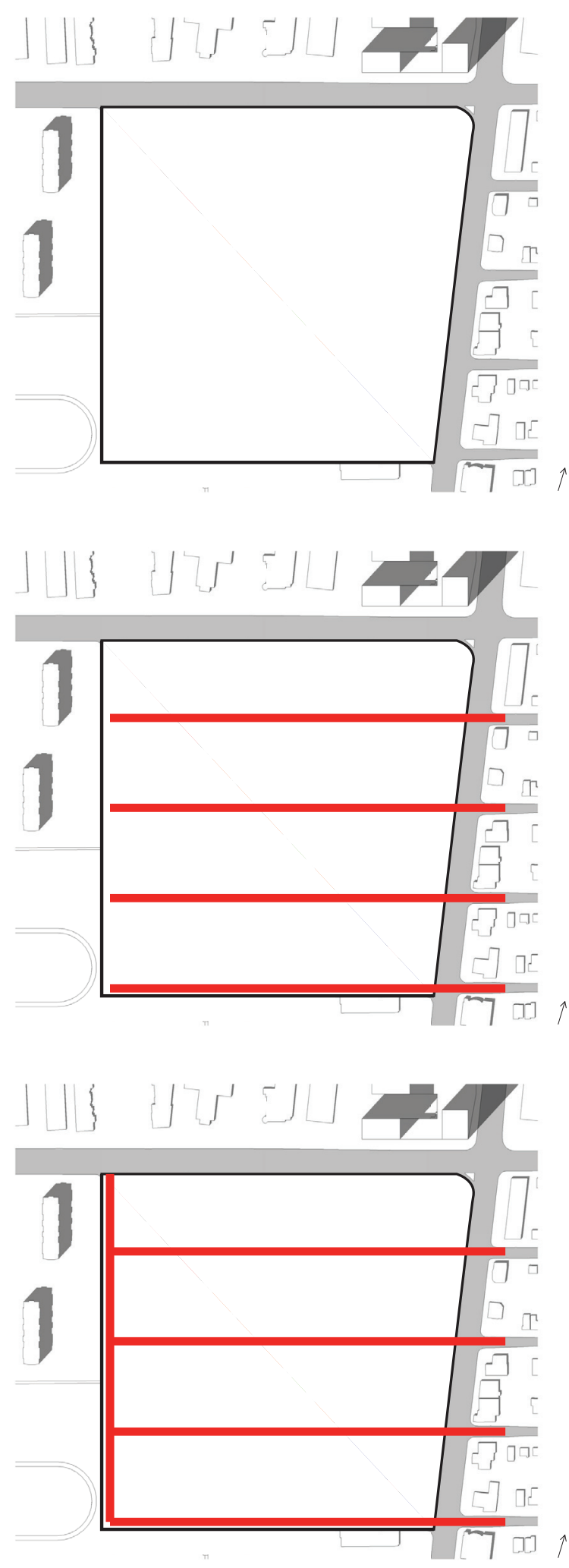

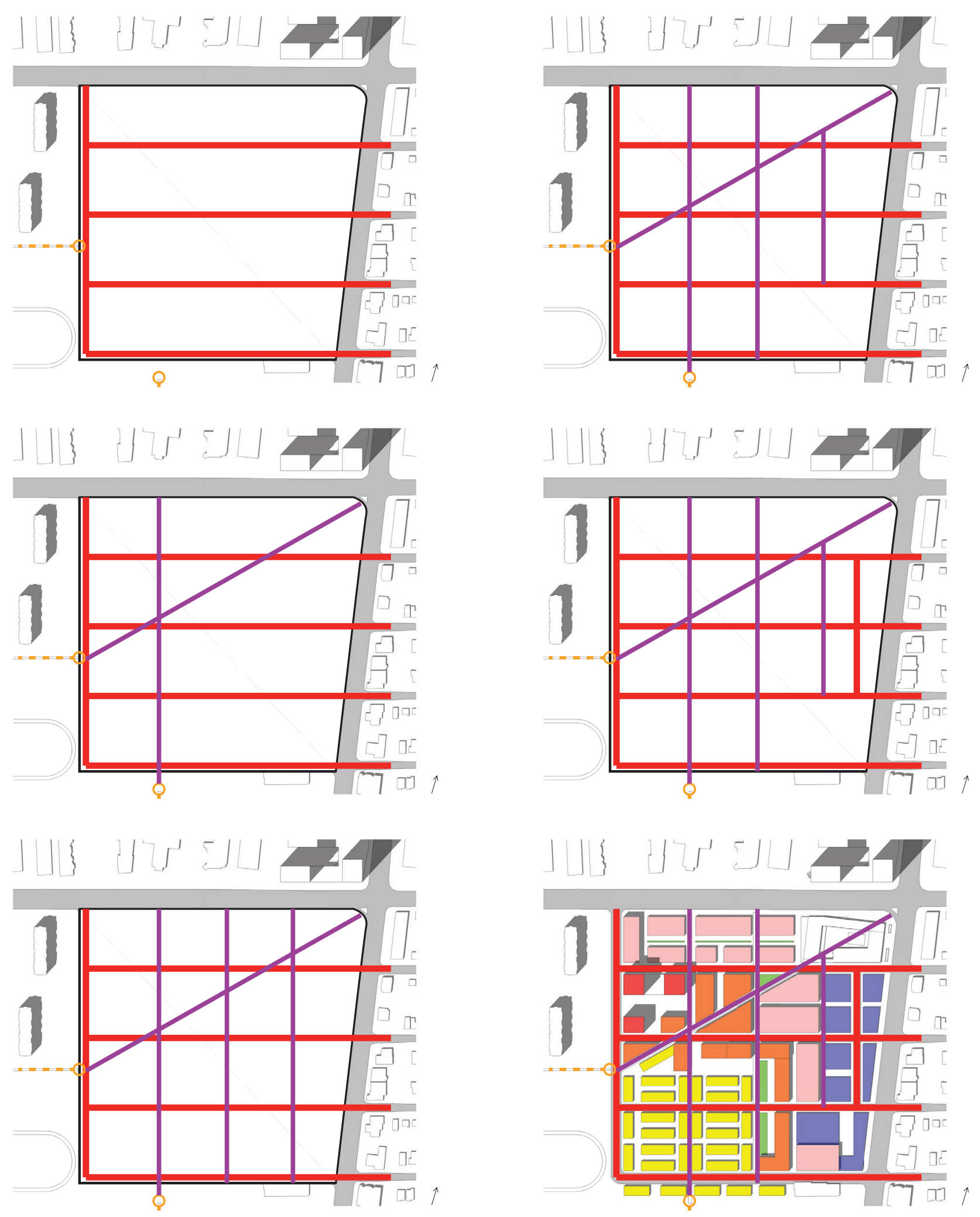

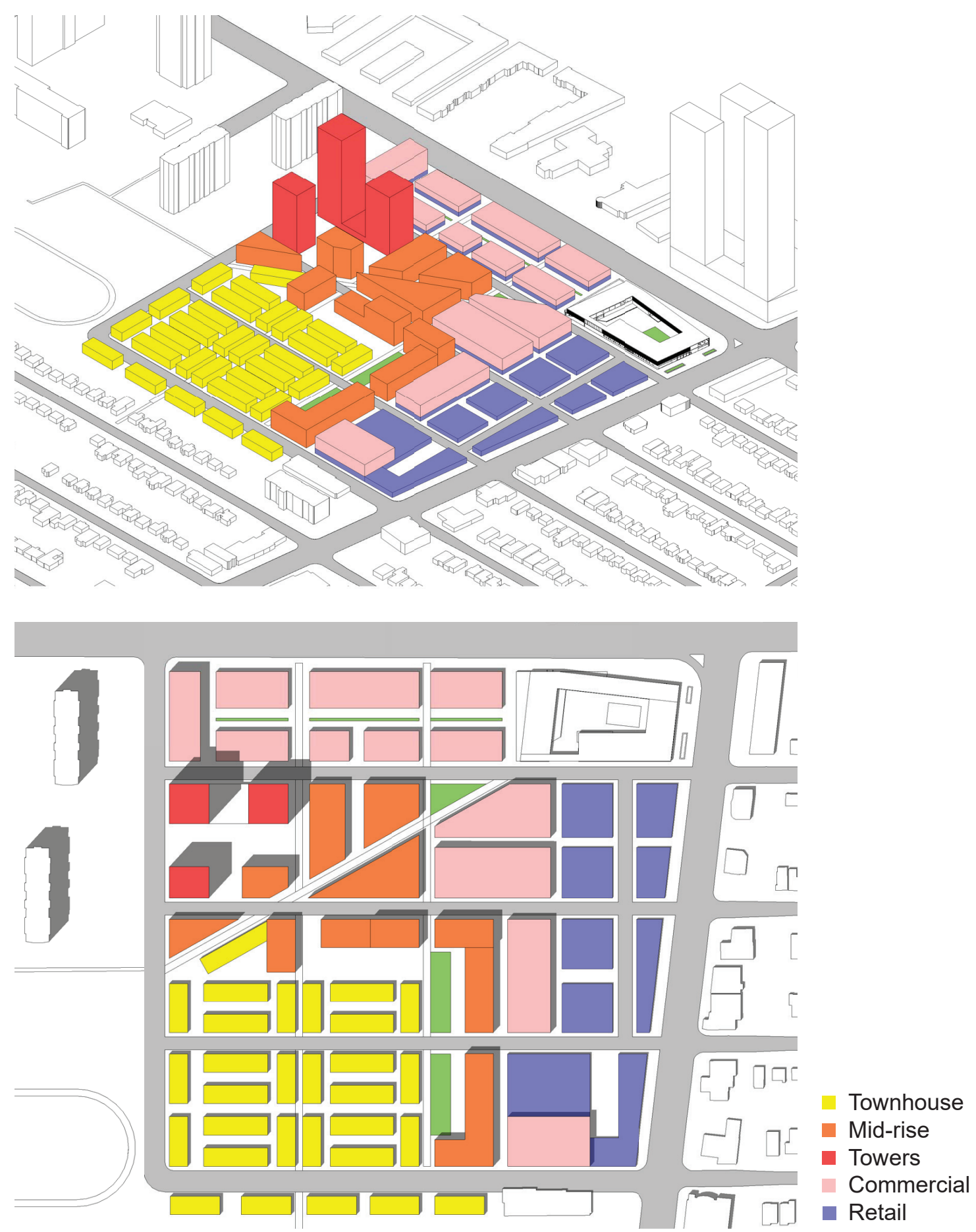


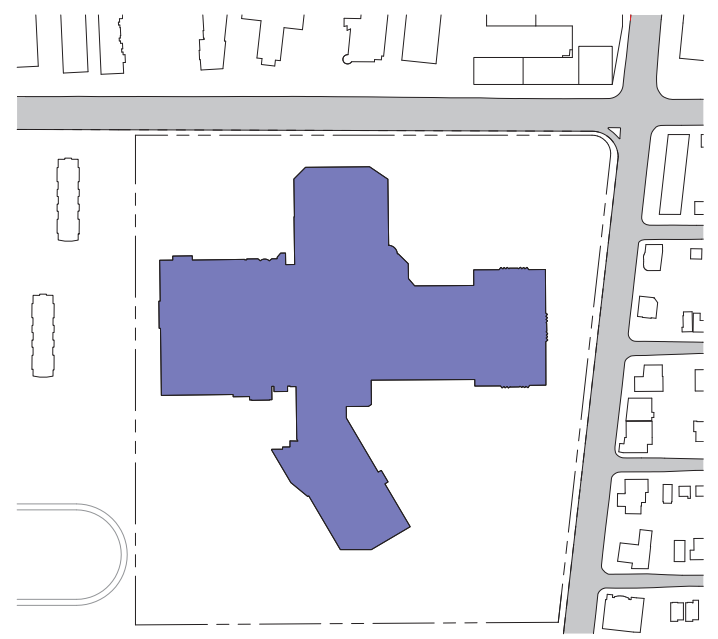

Existing

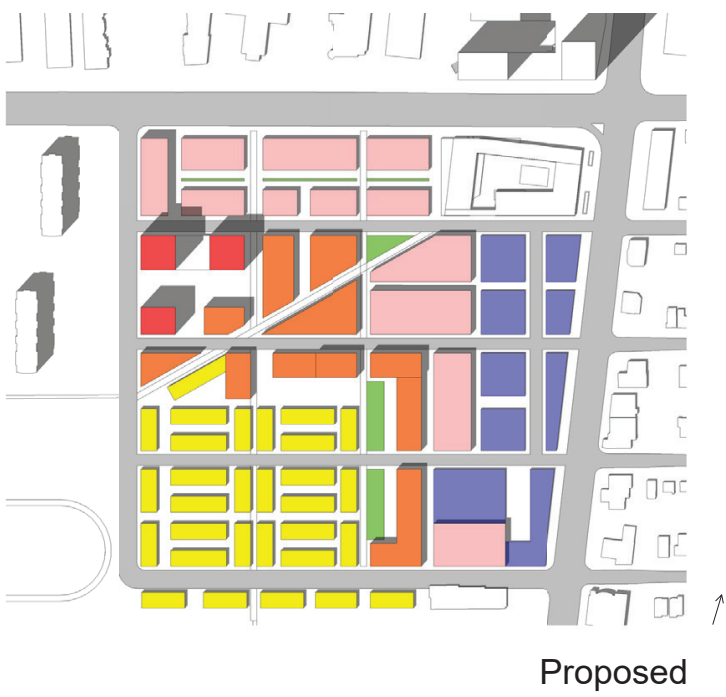

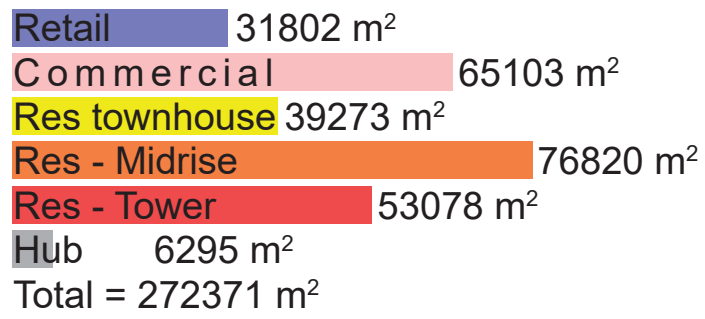




\subsection{THE MIXED-USE HUB}

As identified earlier, the three categories of program are necessary to create a hub for the neighbourhood. Bringing a variety of functions together allows an opportunity for social interaction among different users, who are otherwise segregated in a typical suburban community. Although different ethnic groups tend to occupy certain parts of the suburbs, such as the Chinese living in Markham and creating their own communities, this mixed-use hub intends to provide opportunities for these groups to interact among themselves and also with the general public. Through this combination of functions, spaces can be used efficiently depending on the needs of the neighbourhood, and also provide

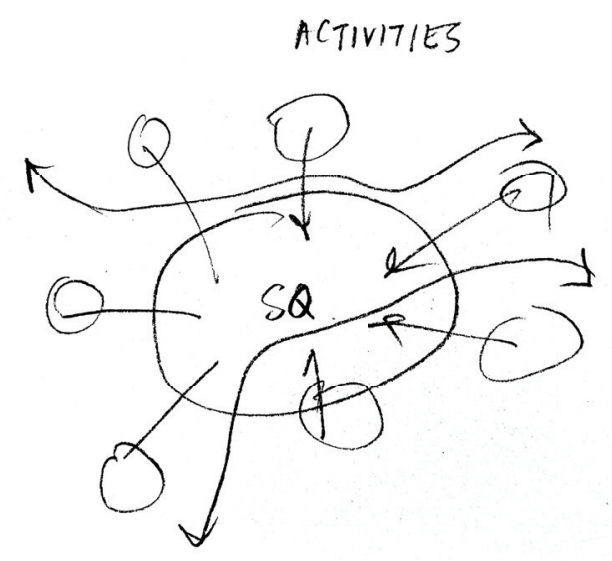

a means to interact with others, especially in a neighbourhood with a diversity of ethnicity. This core idea of mixed-use is driven by Jacobs' notion of a mix of primary functions; the hub can serve different user groups at different times of the day, ensuring that the place is maintained as lively. When this central hub is lively, it creates an image that is favourable for public life to occur. When people can identify this hub to be a place where they can meet others through various programs, there will be meaning associated to this place and will establish an identity within the neighbourhood. When a place has meaning and identity within the neighbourhood, it becomes a destination and thus attracts more people to come and participate. In addition, the insertion of publicness into a privately-owned site blurs the boundary between public and private domains and offers the public a new space to appropriate. This act of generosity by the private sector is essential in improving the community conditions while establishing a new private development at the mall site. This publicness can be achieved first by incorporating an easily accessible public square that invites the public to use. Indeed, the hub shall be established in a public-private partnership which seeks both economic and cultural values in order to sustain its operation while promoting social connectivity in the community. 
While assembling all these programs together, it is critical that the hub is a place for social interaction as a means of promoting cultural diversity as well. An easily accessible public square in the centre of the hub allows it to be a place to pass by or to stay. Architecturally, this square is framed by all the activities that happen around it, whether people are watching or just physically present around it, and this is possible because it is visually and physically connected to them. This connection is what initiates social interaction by stimulating the users visually between outdoors and indoors. Activities are critical factors in creating the atmosphere for public life and thus any visual connection helps capture the public's attention towards these activities, enriching the encounter experiences for the public. Also, it needs to serve as an outdoor area where people can gather to celebrate festivals, similar to the performance stage in Pacific Mall. Toronto is known for its multiculturalism and this cultural hub celebrates this core value by providing many festive experiences for the neighbourhood to engage in, whether they are indoors or outdoors, at the edges or centre. "Urban experience is the collective experience of places and spaces conceived for linkage between people and for social interaction" (Curran 24). All these activities resemble the multi-layers of functions which the neighbourhood needs from public and private realms, from learning, exchanging ideas, playing, chatting to resting; all of these can happen at the hub, which makes this place vibrant as a city centre.

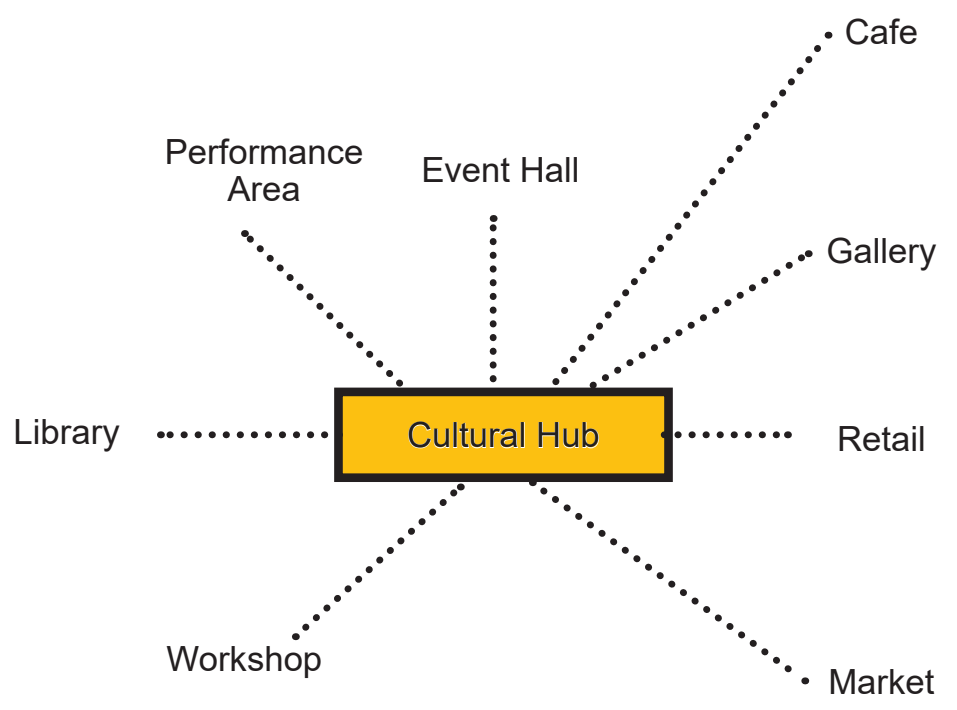




\subsection{PROGRAMS}

Planning the mixed-use programs requires a look at what the neighbourhood needs. The programs should accommodate the future development of the new neighbourhood while also serving the older neighbourhood. It is critical to insert spaces for social interaction, especially for the culturally diverse neighbourhood of Newtonbrook so that the community has a place to come together for various activities.

Although it is hypothesized that malls will die, it does not mean that the need for physical stores will diminish as well. It is envisioned that these retail spaces will be short-term lease since the demand for physical stores may fluctuate in the future if e-tailing continues to thrive. In addition, the sizes of physical stores may also shrink. These short-term, or pop-up retail spaces can be incorporated to allow for quicker turnover or for start-up projects, and these quick changes may spark new interest from the public. Such space should have a flexible enclosure which will allow the retail spaces to expand or shrink as needed. This flexibility allows the retail space to divide into smaller compartment units depending on the changing needs of retail, similar to small tenant units at Pacific Mall. These spaces should be located on the ground floor where foot traffic occurs the most, and the quick turnover allows the window display to change regularly, which will reinvigorate the visual experience at grade.

A market is an active community bonding space that attracts people to explore different cultures and shop for a variety of products. Market usually carry diverse products which specialize in local production, or authenticity which big box does not offer, which is why it can create opportunity to socialize with strangers in the neighbourhood. This market is imagined to host a farmer's market, which brings local food products to the community, to local designers' arts and crafts that promote their cultures. Thus, market not only promote the authenticity of cultures but also support local businesses. This makes the market unique from the standardized chain stores found in suburbs and becomes a destination.

Outdoor space is essential for people to hang out or to rest, since the current condition of the mall does not stimulate or allow any outdoor activities. Thus, a square becomes an important central element in this proposal, which acts as a central meeting point for the neighbourhood. As discussed earlier, public square can serve multiple functions, and if the conditions are favourable, people would stay outdoors and stimulate activities. In the summer, people may enjoy sitting in the sun or kids 
playing at the square. Outdoor performances or movies are great opportunities for neighbourhood gatherings. This outdoor public space is a bonding agent that attracts the residents to get outside of their homes to mingle. In the summer, the square can host many summer festivals in collaboration with different organizations. In the winter, the square may turn into a temporary skating rink or curling rink. It is reported that Toronto Curling Association wants to promote curling to the general public and have partnered with the City of Toronto for two free outdoor rinks (CBC News). Thus, this outdoor space is envisioned to host many types of activities all year round.

Nowadays, libraries provide multiple services for the community. This library can be a small library branch not only designed for reading purposes, but it can become a place for computer usage, studying, meeting, children's programs or tool lending. A report has mentioned that one in five people visited Toronto public libraries at least once a week and $58 \%$ of them have used the library computer or wireless network (Toronto Public Library). This suggests that the library has played an important role for the public. Since there is a high demand for library, different age groups in the neighbourhood can benefit from it.

The new space would require areas for informal

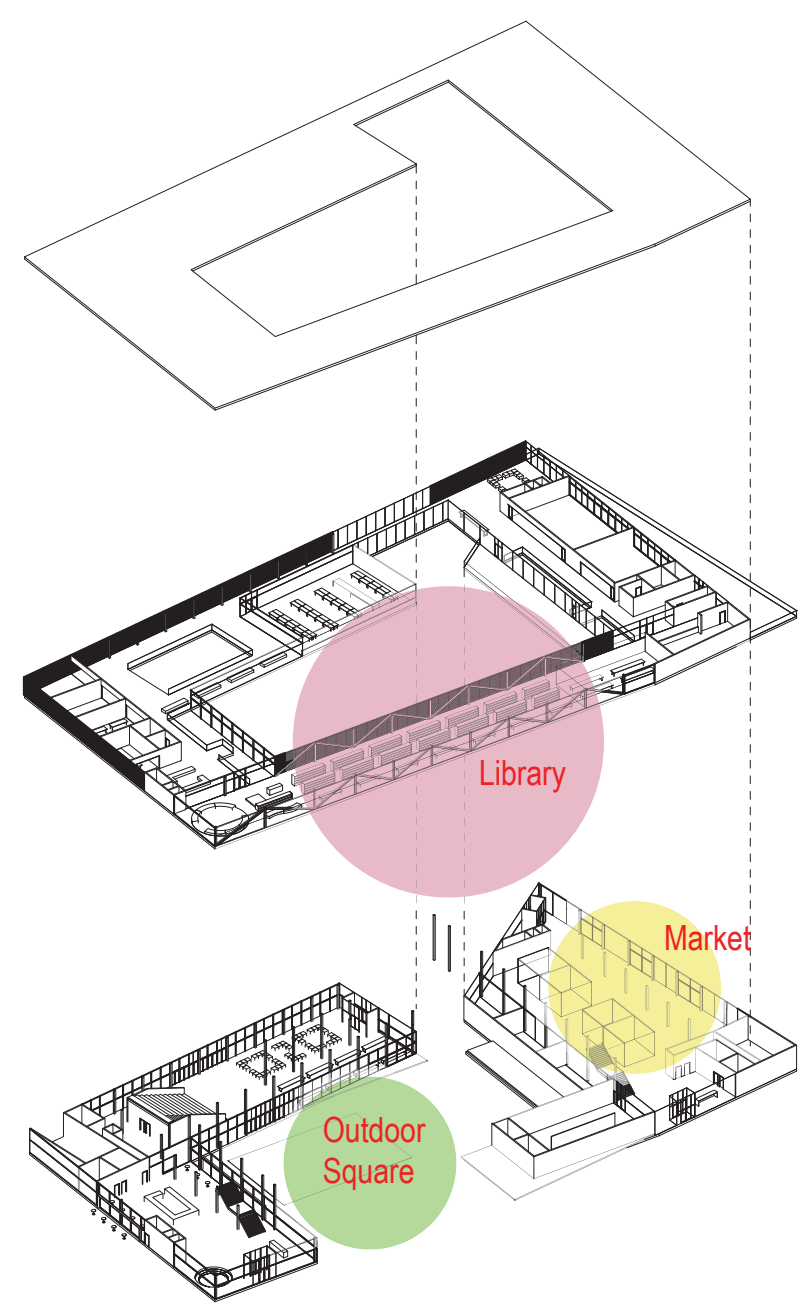

Fig.5.27 Program Diagram 
performances where people may perform spontaneously or enjoy a relaxing show with seating. This should be allowed both indoors and outdoors in order to respond to the unpredictable weather conditions. An outdoor stage can serve outdoor performance in favourable weather conditions. Also, an outdoor cinema screen can be set up for neighbourhood events such as movie night or cultural festivals. An indoor amphitheatre provides informal seating for viewing performances or mingling with others. This amphitheatre is not only intended to encourage people to perform, which can stimulate others to people-watch, but it can also hold information sessions such as new immigrant orientation. Another important function the amphitheatre serves is that it is part of the circulation connecting the floors. Thus, people are able to observe any activities happening at the amphitheatre as they move between floors.

A gallery and exhibition area can allow products or artwork to be displayed. It is intended for local artists or organizations to create exhibitions to educate or to promote their ideas to the community. This area can also display any work created by local children, or any community programs that will inform the public about the neighbourhood as part of the community engagement initiative.

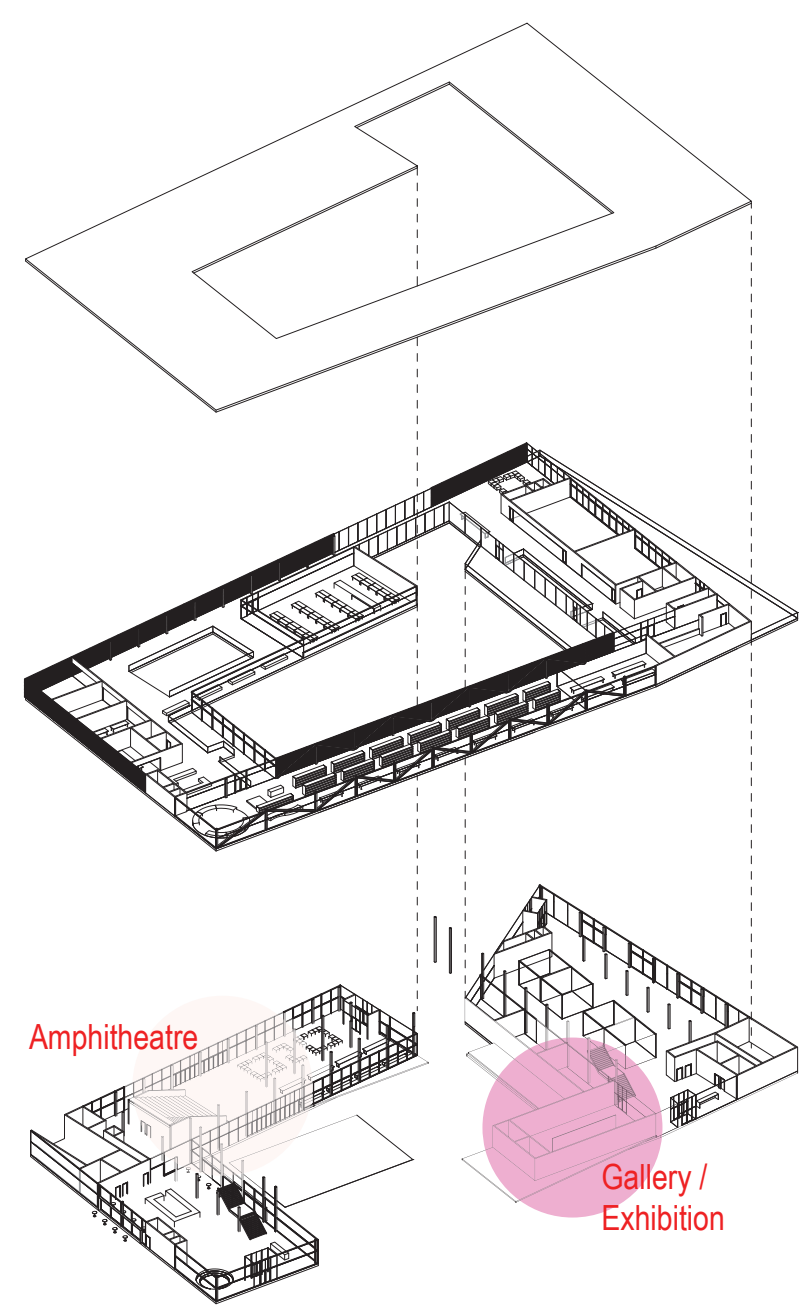


An event hall is an multi-purpose space that offers the flexibility to host any community functions, such as repair club for the community, or any celebratory gala, where there can be an opportunity for exchange and social interaction. It can serve both public or private events, so that the space can cater to different occasions within the community.

Workshop spaces offer more intimate studio spaces for artists or speakers to teach others, whether it is cultural art and craft or wellness. This is a place to educate others with any specialty skills and to share knowledge and experience as part of the community engagement.

Coworking space is on the rise, offering a flexible working environment for those who do not require stationary offices and can share amenities. It acts as a temporary working space where different users will come. It is also a place where people can meet and exchange ideas with others in different disciplines, which makes this place a vibrant and attractive working environment. Having a coworking space allows people to come work in the cultural hub, not only diversifying the user groups of the hub but allowing these workers to meet and exchange ideas with the local neighbours as well. This also ensures different target groups to use the space during the day, while they may be able to rent the market space,
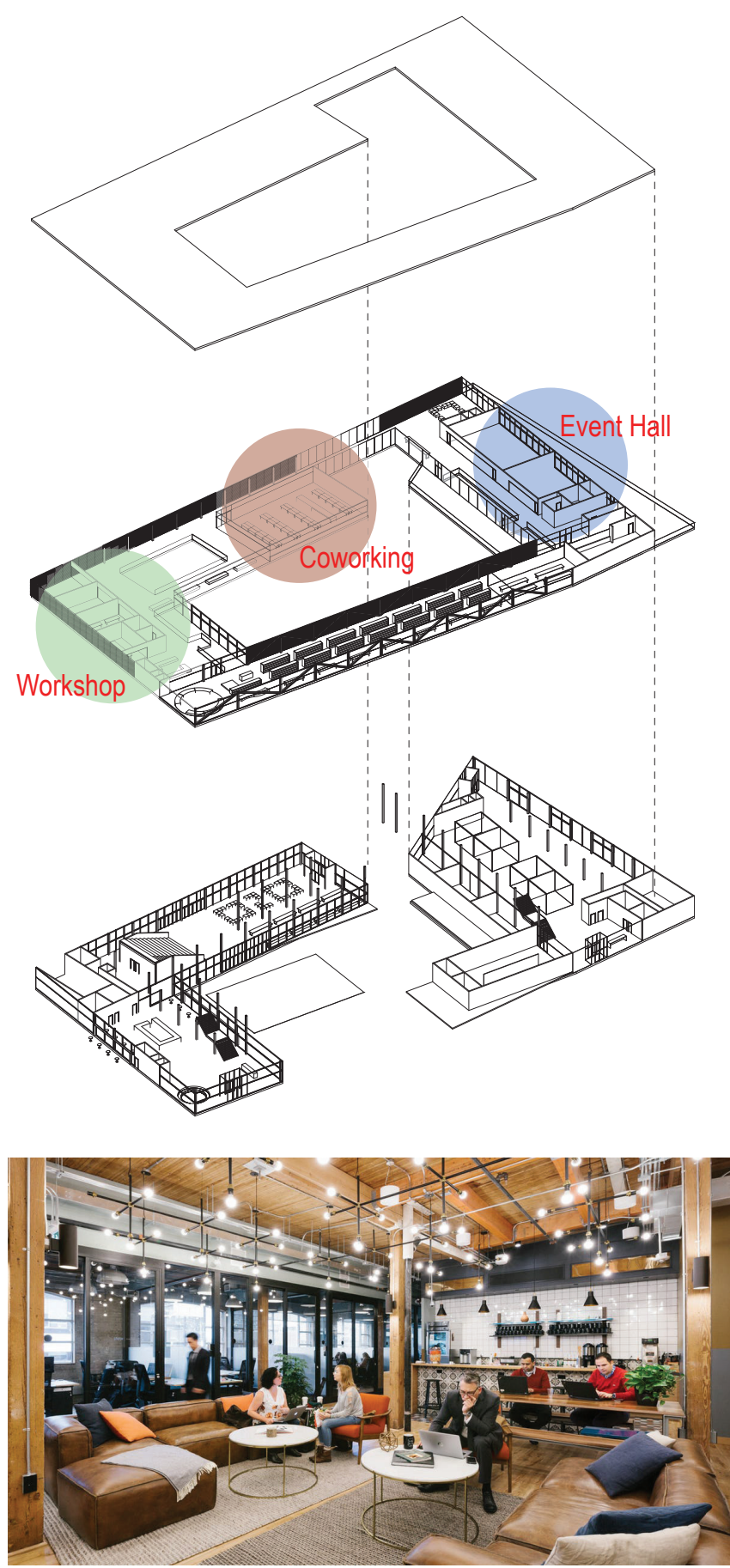

Fig.5.29 Program Diagram Fig.5.30 WeWork, Toronto 
pop-up stores or gallery for their work. These spaces make the hub an incubator, which enables these small businesses to grow and thrive. This mix of user groups helps foster social connectivity between non-locals and the neighbours.

The communal lounge is a place that offers the public a resting place where they can mingle with others. This idea is supported by the evidence that people tend to appropriate spaces for leisure purposes, such as those found in the Chinese plaza playing chess or the elderly sitting on the benches inside the malls. Providing a place to sit and rest is critical in establishing a meeting point in the neighbourhood and drawing the public into this hub.

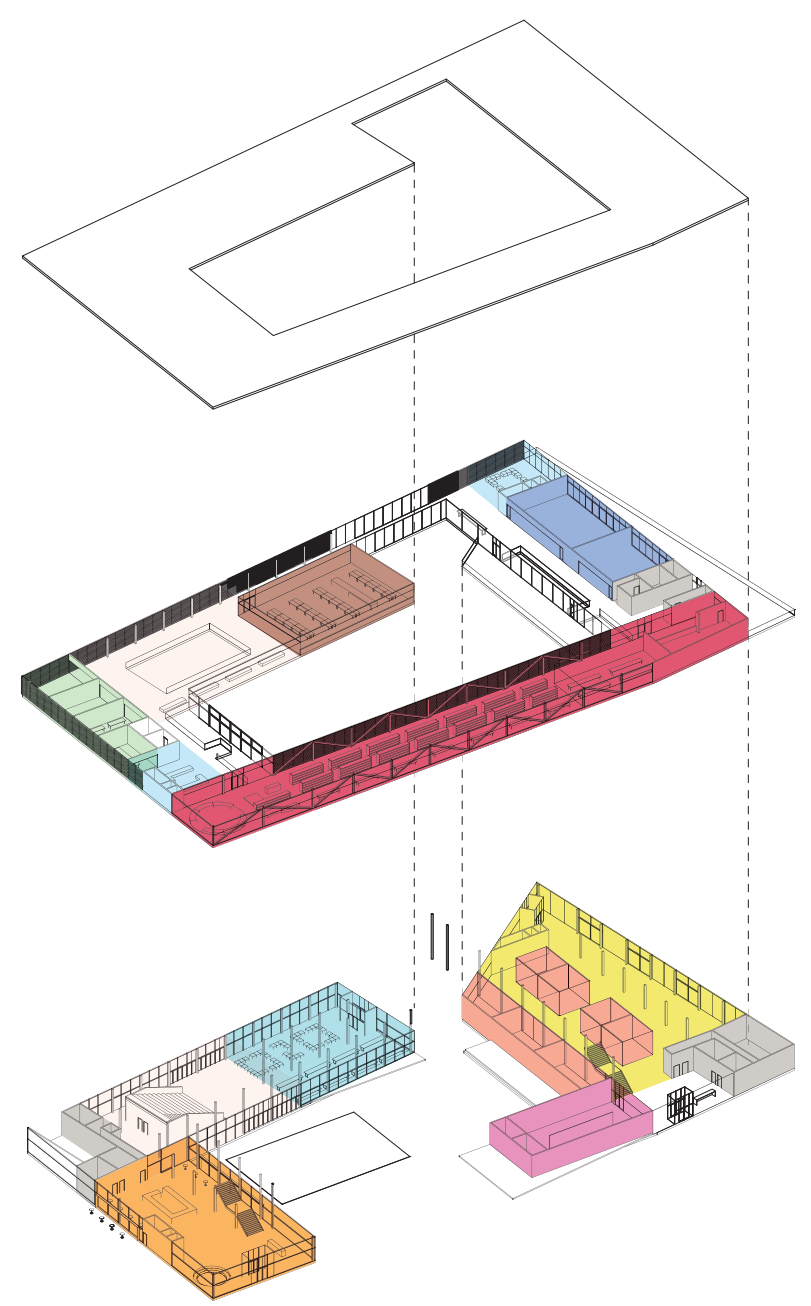

- Cafe Amphitheatre Community Lounge Market Retail / Pop-up Store

- Gallery / Exhibition

- Support

- Library

Lounge

Workshop

Coworking Space

- Event Hall 


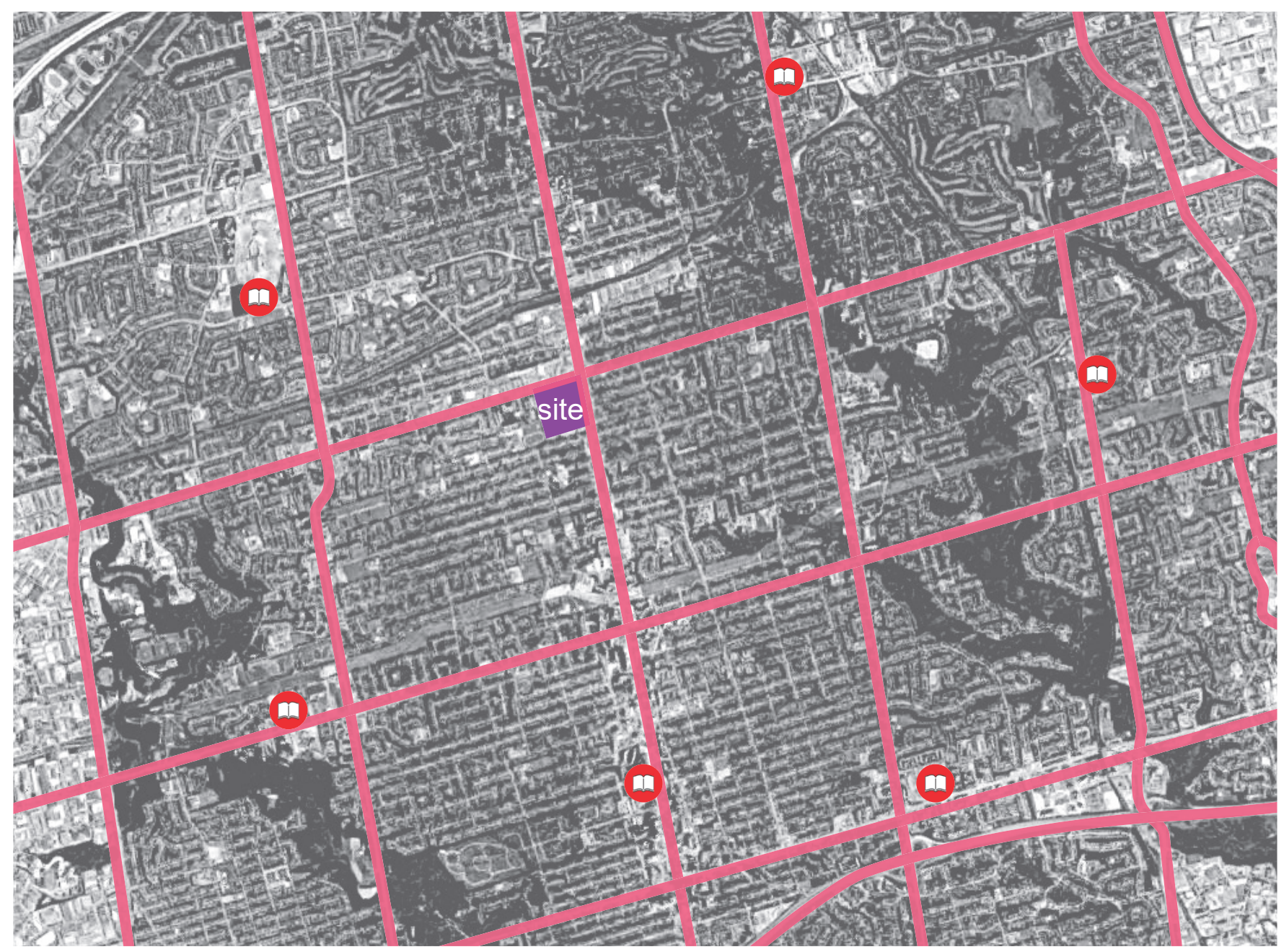




\subsection{DESIGN}

The main core value is to keep the main square in the middle as visible and accessible as possible by lifting up the north side in response to the circulation pattern from the intersection. This lifting becomes a welcoming gesture that invites the pedestrians to flow into the square, which also acts as a link to get to the rest of the site. As such, the square will become a stage of pedestrian flow, enabling the necessary activities while allowing spontaneous encounters for those who stay at the square. This lifting also sets a visual boundary between the busy Steeles Avenue and the square, which will provide an image of a safe zone for the public to use. Also, the envelope of the building is composed of transparent glazing so that the activities inside the building can be seen from the outside, which allows the activities to animate the life of public and private spaces to the outside. At the same time, the street and square life can be observed from the inside. This establishes a degree of transparency which the old shopping mall does not have. While keeping the building envelope as transparent as possible, brick walls will be used to enclose support areas, such as circulation, and the gallery, to protect the display work from the sun, as a design strategy to contrast with the rest of the building.

Retail and market activities are on the first level so that street life remains, while the cafe also allows a place for staying and people watching. The communal lounge on the ground floor also offers the public easy access to seating for rest. All of these are part of the design intent to generate more optional and social activities, which help to animate the street and square life. As identified by earlier precedents of squares, this design also has a stage in the square to host performances as a means to promote different celebration or events in the community.

On the other hand, gallery, market and pop-up stores are located on the first floor for easy access at the street level, where people will tend to pass by. These become the passing-by activities which may attract the public to explore if they are located within easy access. Also, reflecting on Gehl's idea of the soft edge, big sliding doors are placed next to the market, which allows the market to extend out onto the pedestrian street outside. This is to remove the barrier for the public between inside and outside.

An event hall and workshops are placed on the second level to achieve a certain degree of privacy from the main square and the openness on ground level. This allows the community-activated space to have a more intimate area for events to occur without much disturbance from the heavy pedestrian flow on ground floor. There is also a 
rooftop terrace next to the event hall, which allows the events to spill out onto the rooftop terrace, which also serves as a viewing platform overlooking the street life below. This terrace is not exclusive of the event hall, but for the public to enjoy as well if no private event is using the terrace. This ensures that the public can have access to different areas to stay and observe. This terrace is inspired by Gehl's edge effect, which the architecture creates edge effect moments for people to stay, in this case a viewing platform on the second floor.

No formal auditorium is intended in this design because there is no vision for it to be used much in this neighbourhood and eventually becomes a waste of space. Instead an informal amphitheatre allows spontaneous events to occur. Also, this amphitheatre acts as a seating space for the public to restorenjoy any shows. Many operable doors are located north and south sides of the amphitheatre so that they can be opened up to the street and square, which may help attract people outside to come in and watch these spontaneous events. Again, this is to reflect on the idea that people attract people, and this is a strategy which may attract people while reducing the physical barrier of walls.

The cafe serves as both a destination and a transition between the outside street and the internal square by being located on the east side of the building next to Yonge Street. This area can open up on both sides of the building, ensuring that people on both sides can be drawn towards each other and stimulates the encounter experience between outside and inside. As identified in site analysis, Yonge Street currently lacks the street life and this cafe is a great transition that may draw people from the square to the street and vice versa, creating a vibrant circulation flow on the ground floor between Yonge Street and the square.

A library is located on the north end on the second floor, which faces Steeles Avenue, as a prominent destination feature of the building. The glazed facade on the north allows the outside to see the programs inside, so that it may attract visitors to explore, while users in the library can observe the street life on the major road. The library also provides a view to the square, which becomes a viewing platform and also a relaxing area for those who may prefer some quietness while observing the activities happening at the square.

Parking is located in the underground so that more above-grade area can be dedicated to the public. It allows the hub to connect with the street and the surrounding without the disruption of large surface of parking lot, in order to create a more pedestrian-friendly area. Without the rolled-curb parking lot fronting the street, this area can now be 
dedicated to public art, which helps to activate the street life. It is envisioned that the TTC subway line would extend to this location in the future and thus the east side and northeast corner of the hub allocate spaces for this expansion. Although this thesis is not to design a transportation hub, but the design caters to this potential addition in the future, creating an entry point to the subway. 


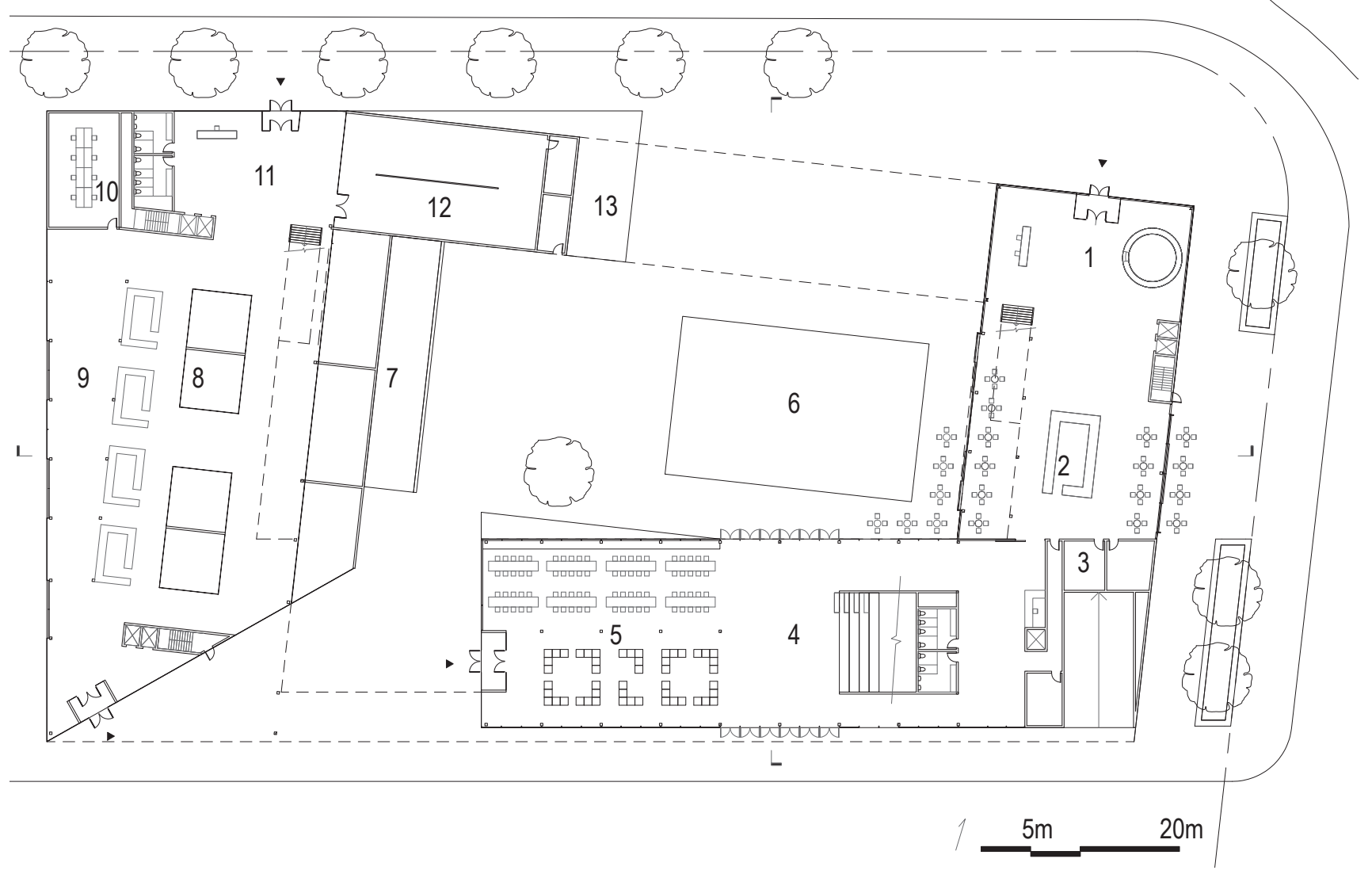

1 Lobby

2 Cafe

3 Support

4 Amphitheatre

5 Community Lounge

6 Outdoor Square

7 Stage

8 Pop-up Retail

9 Market

10 Administrative

11 Lobby

12 Gallery / Exhibition

13 Platform 


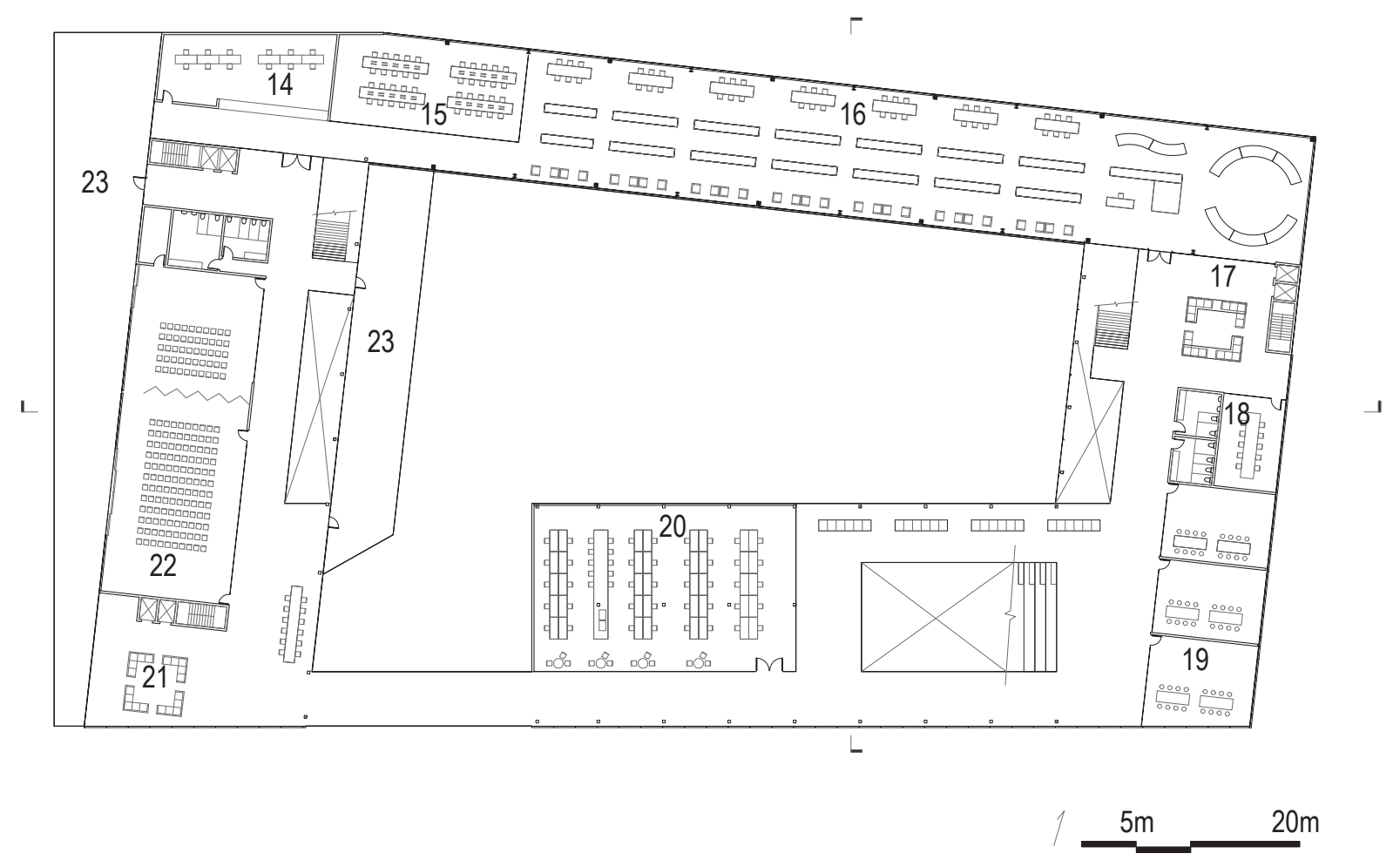

14 Library Office 15 Computer Room 16 Library 17 Lounge 18 Meeting Room 19 Workshop 20 Coworking Space 21 Lounge 22 Event Hall 23 Outdoor Terrace 

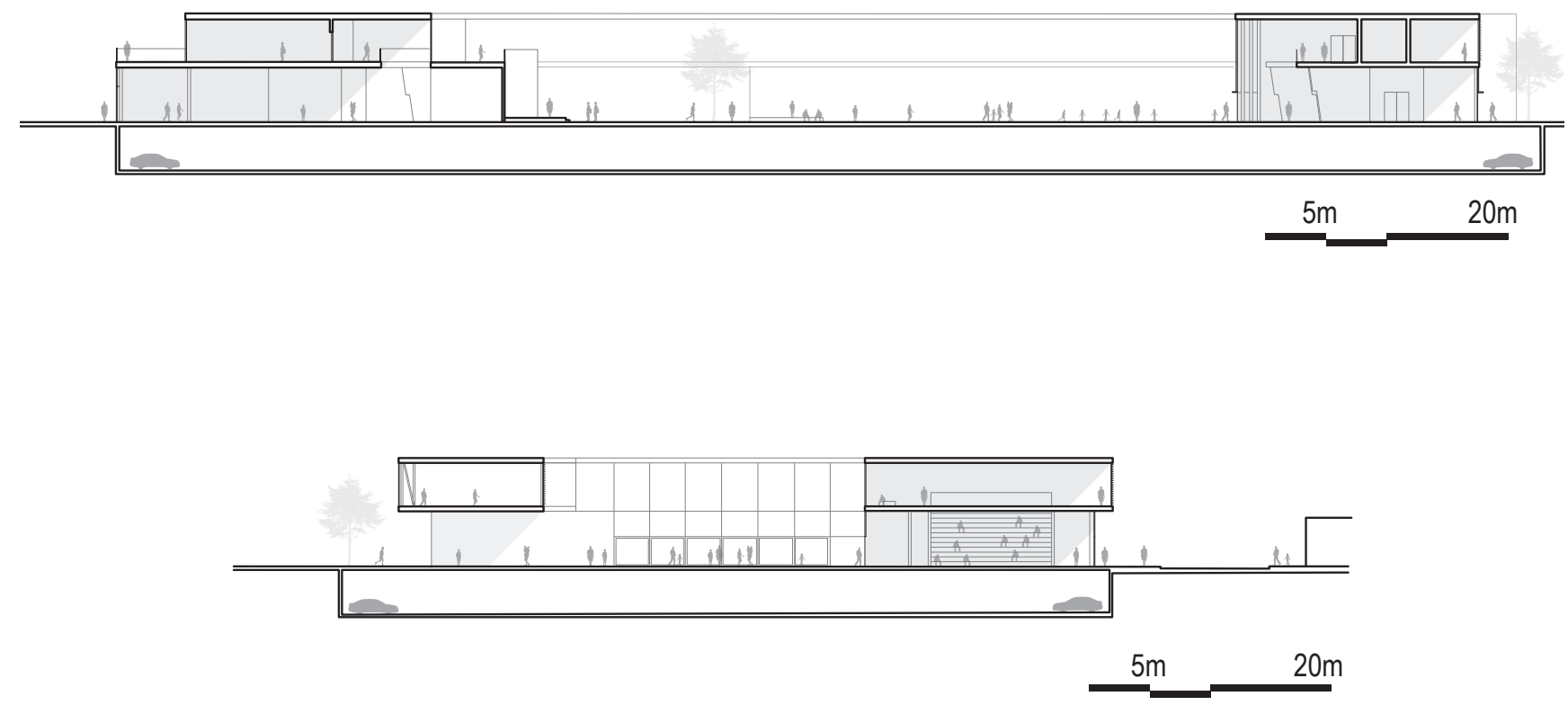

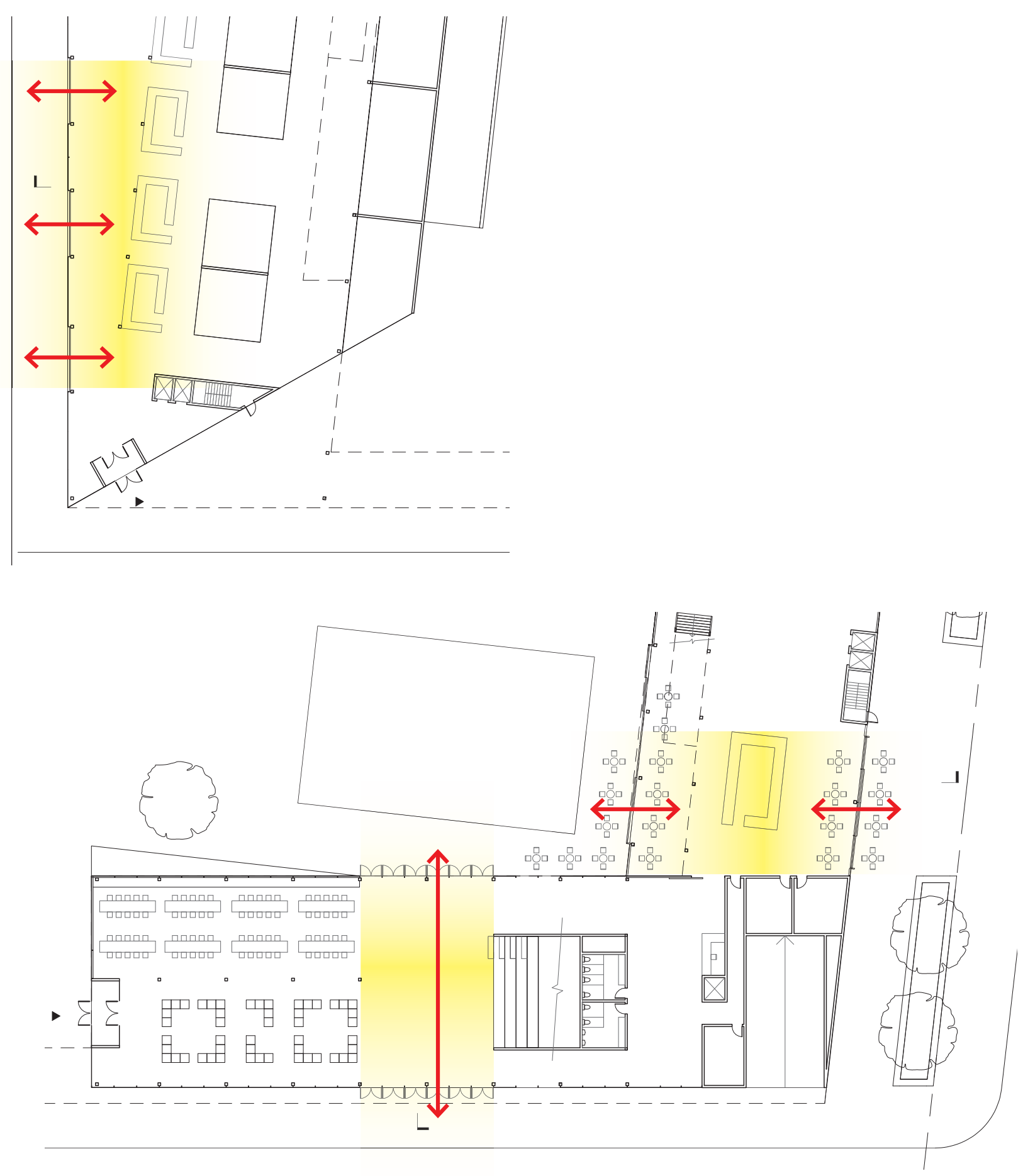

Fig.5.37 Connecting Streets and Square on Ground Floor Through Openings 

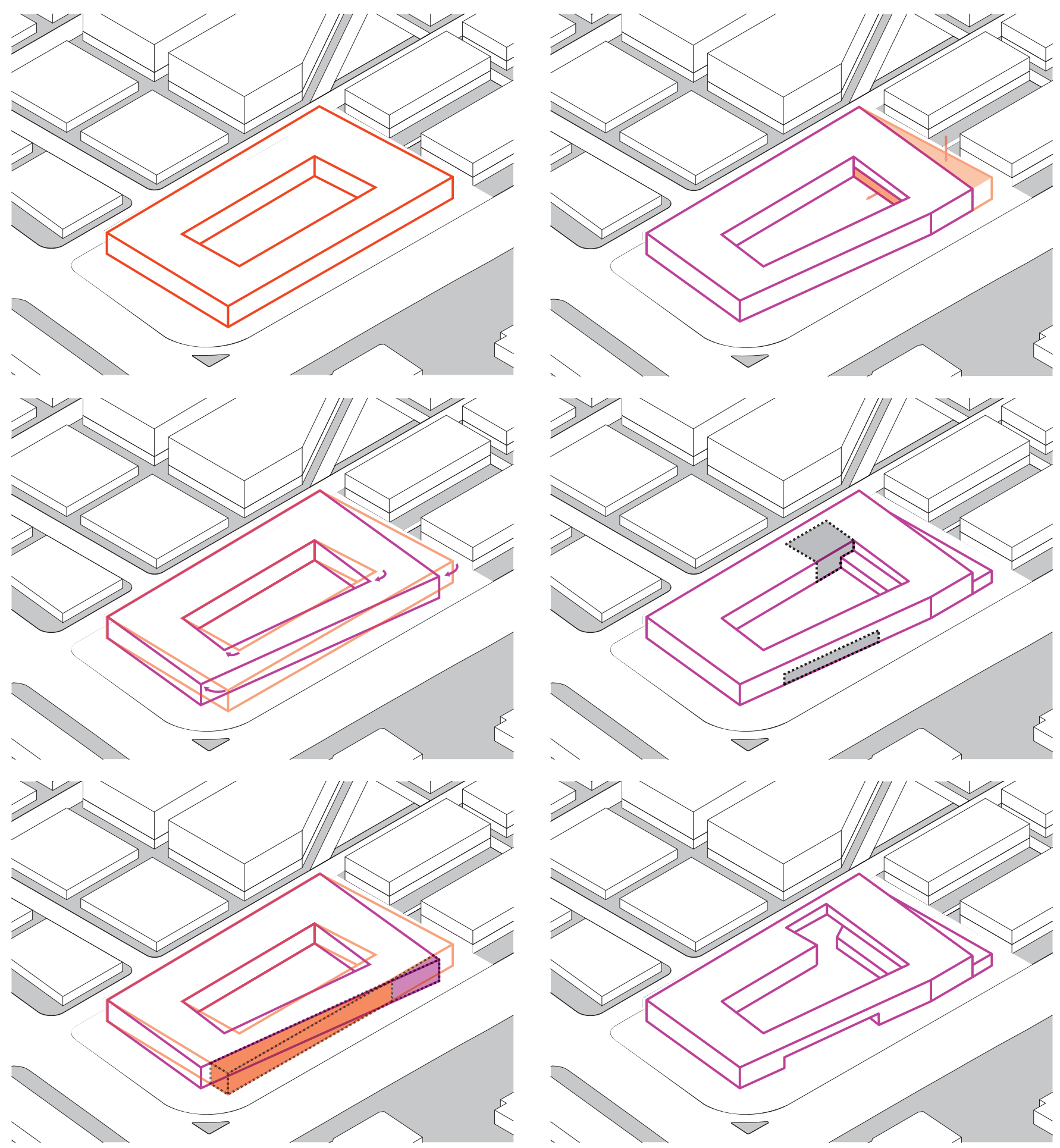

Fig.5.38 Massing Concept Diagram 


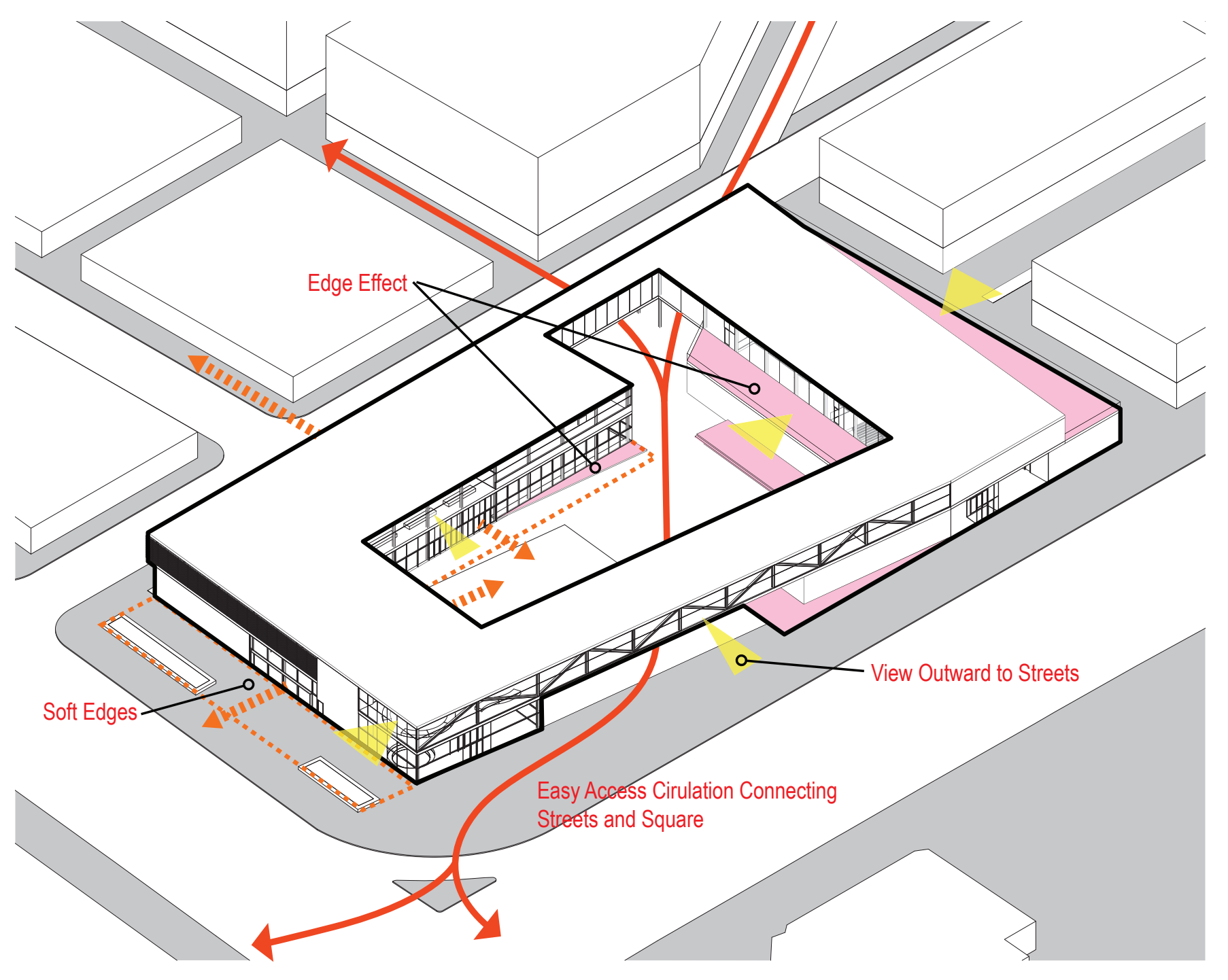

Fig.5.39 Concept Diagram 


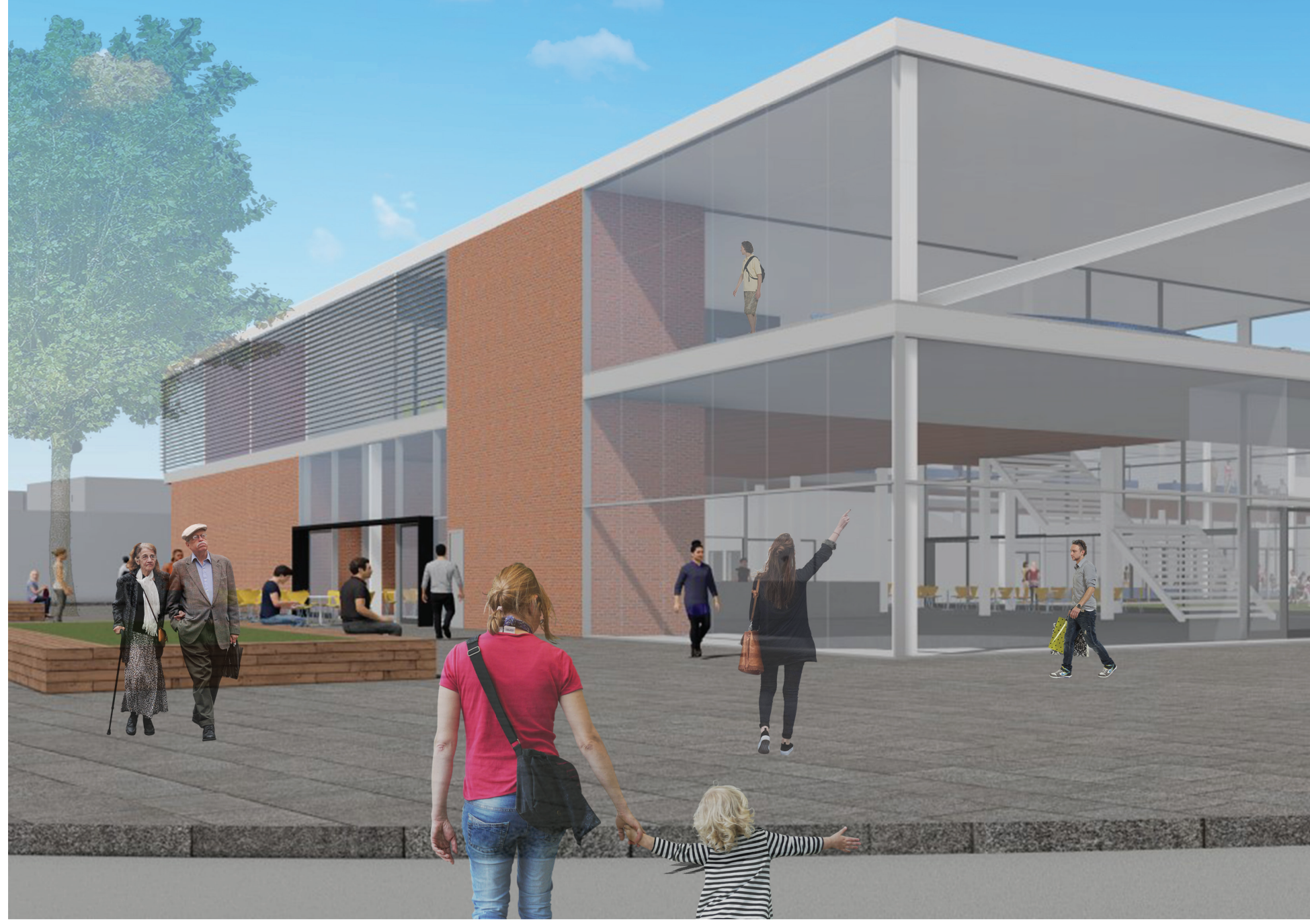




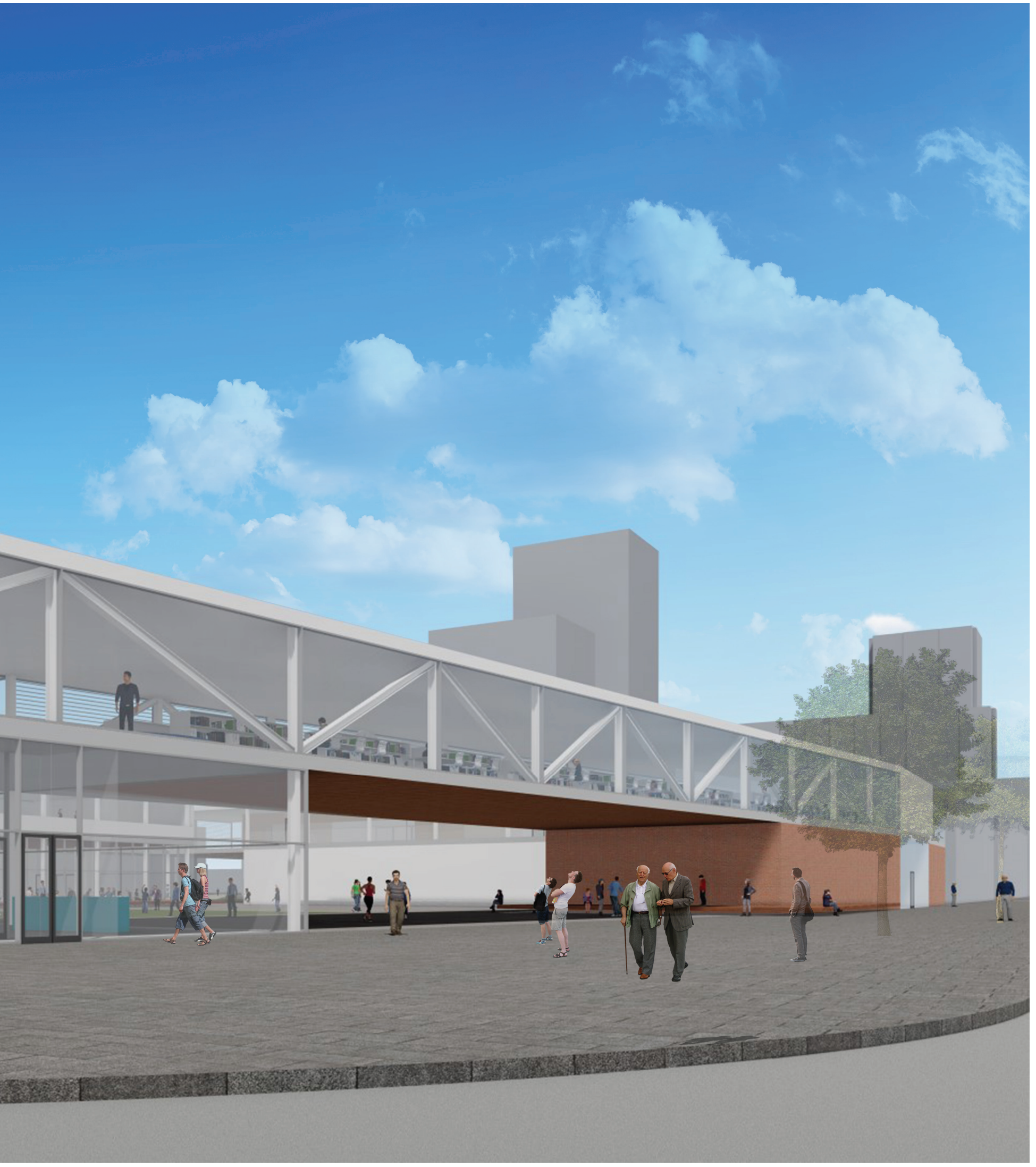




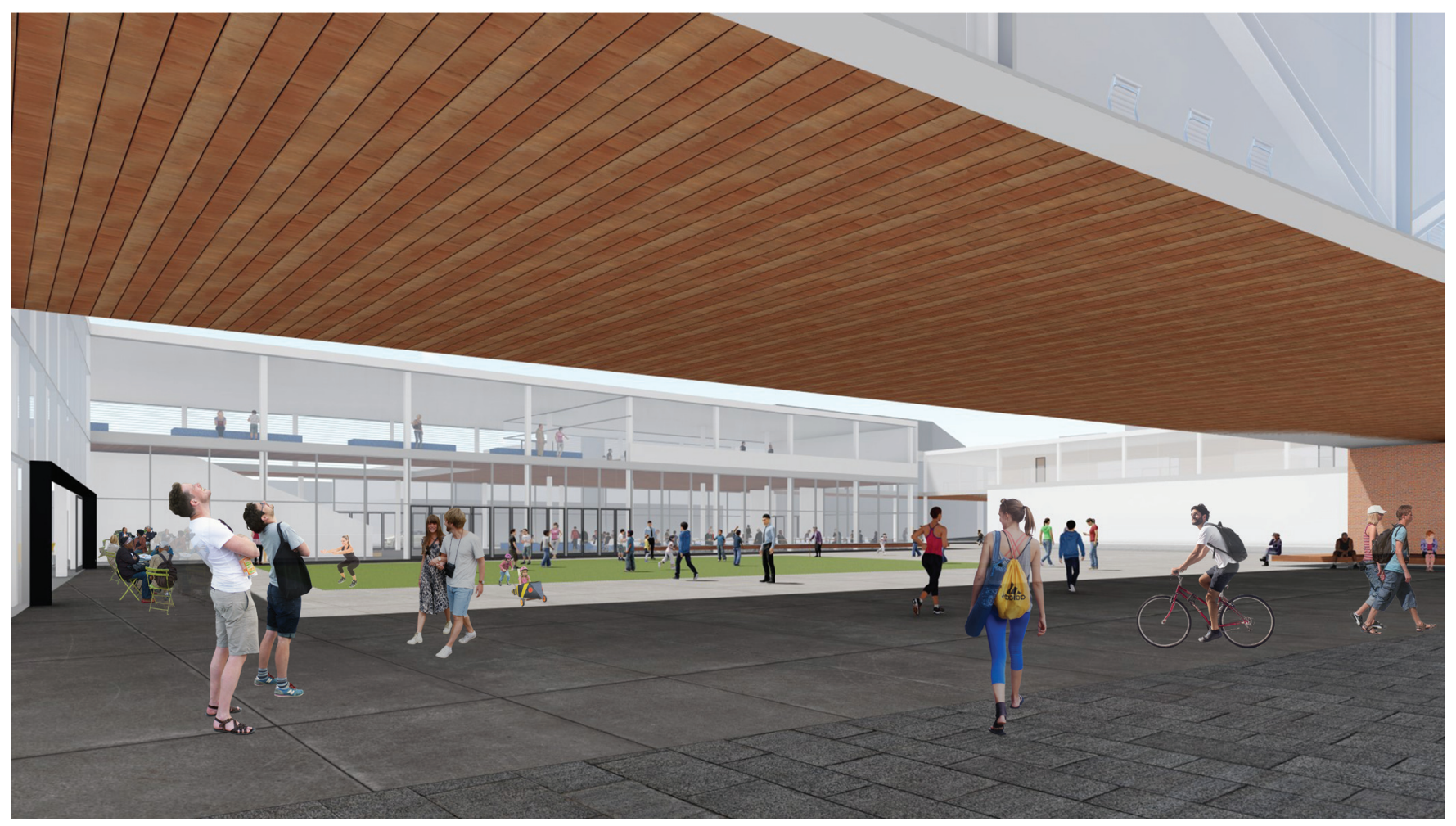

Fig.5.41 North Entry 


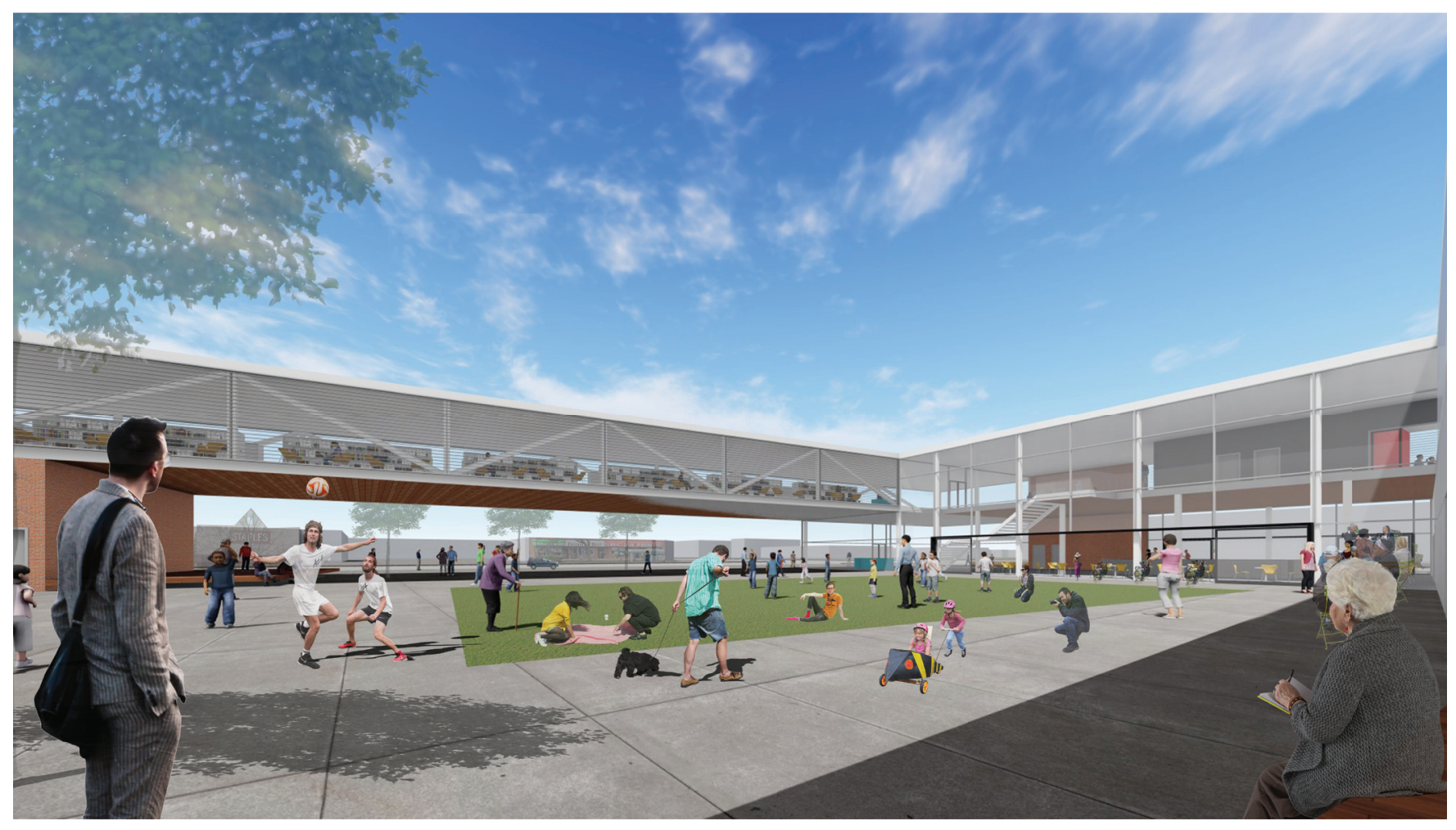




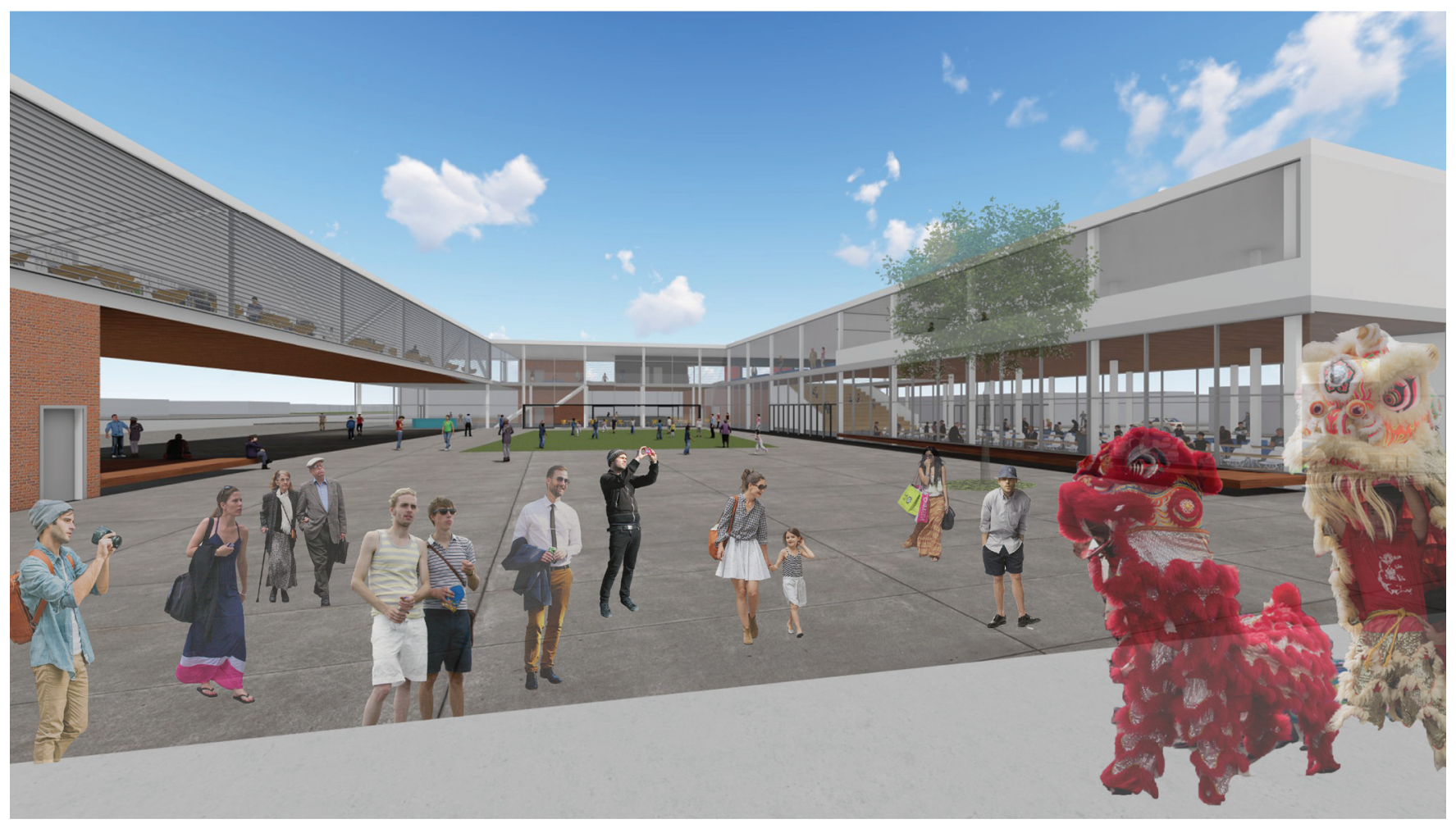




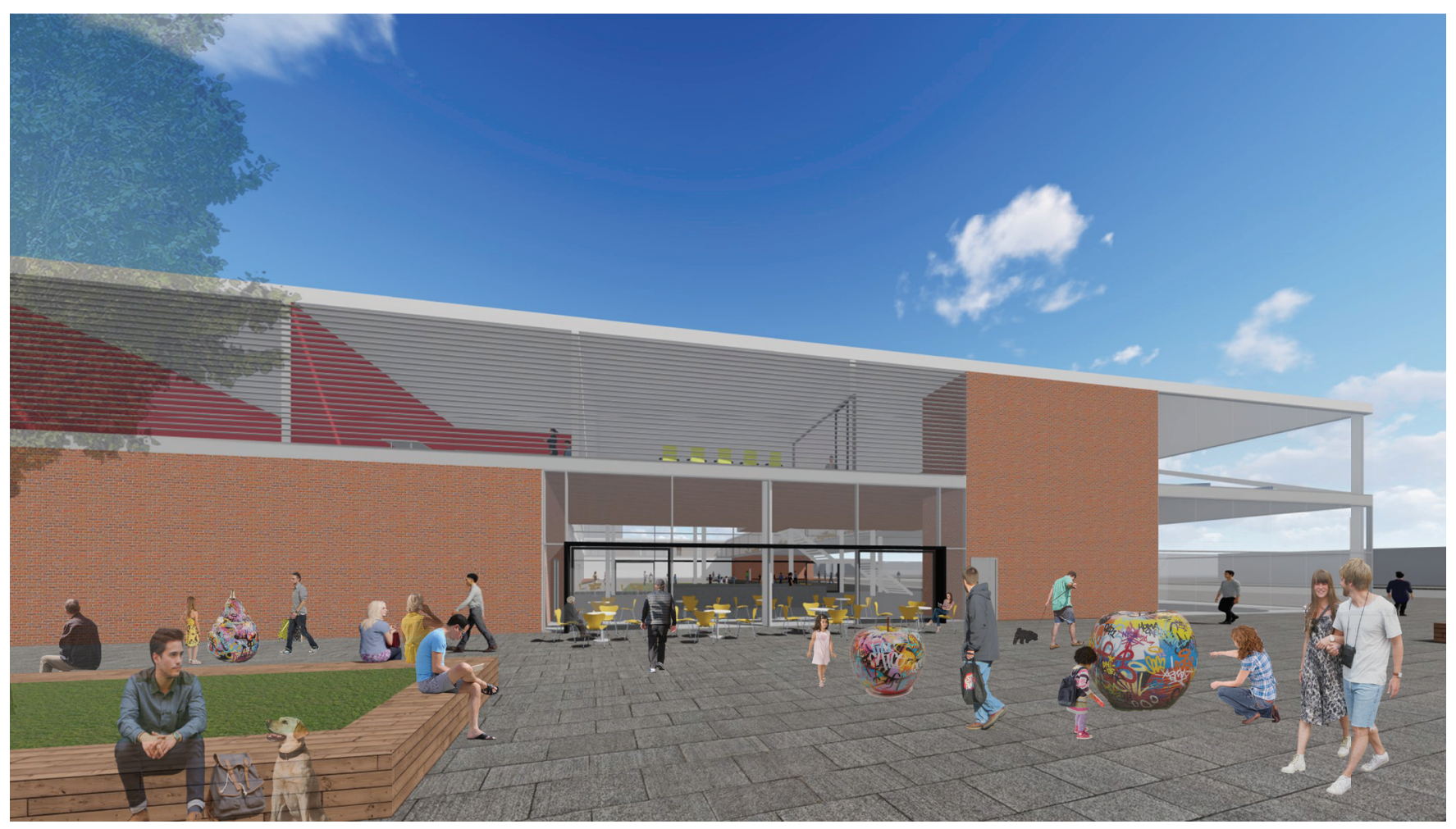

Fig.5.44 East Elevation 


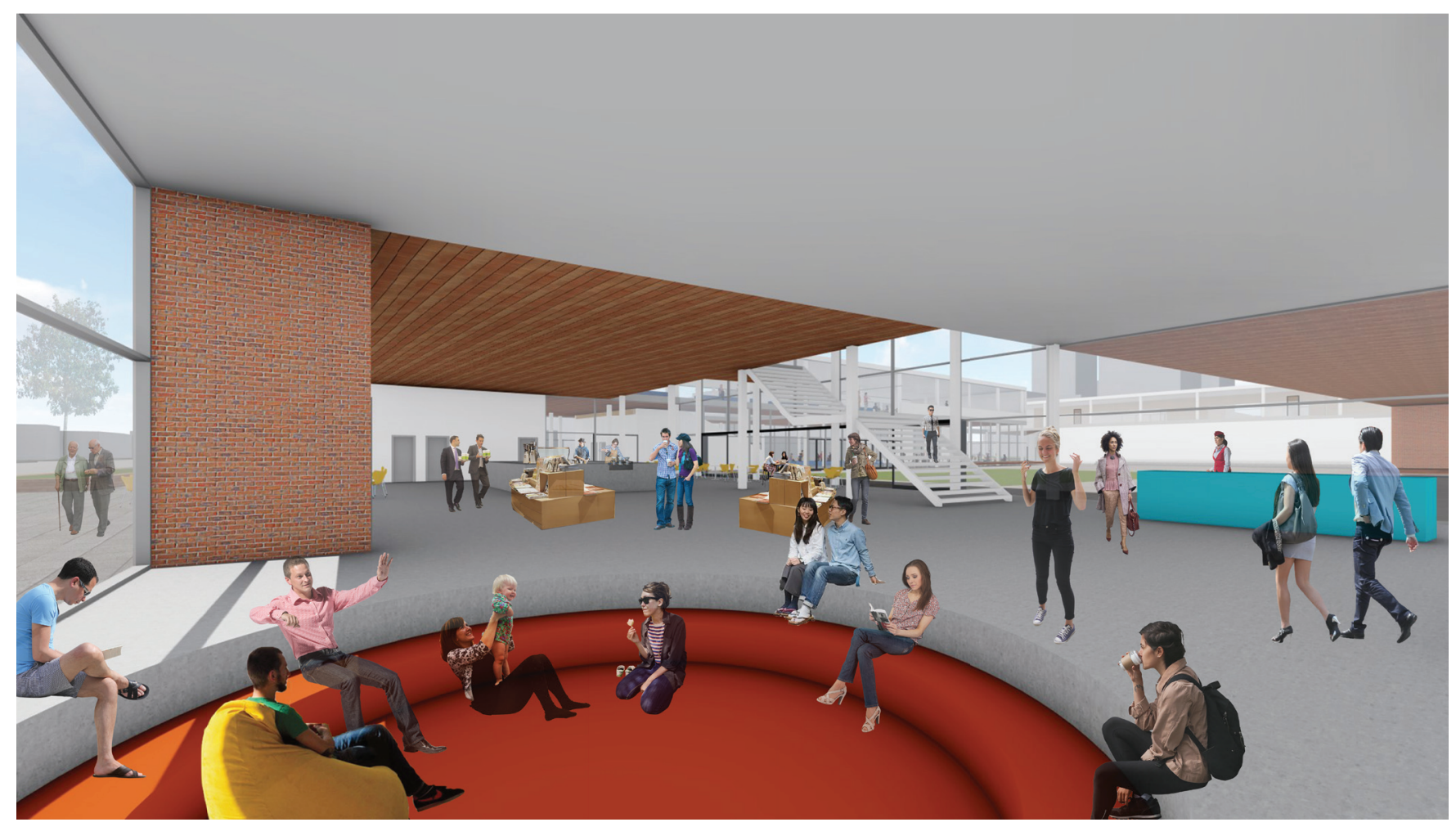




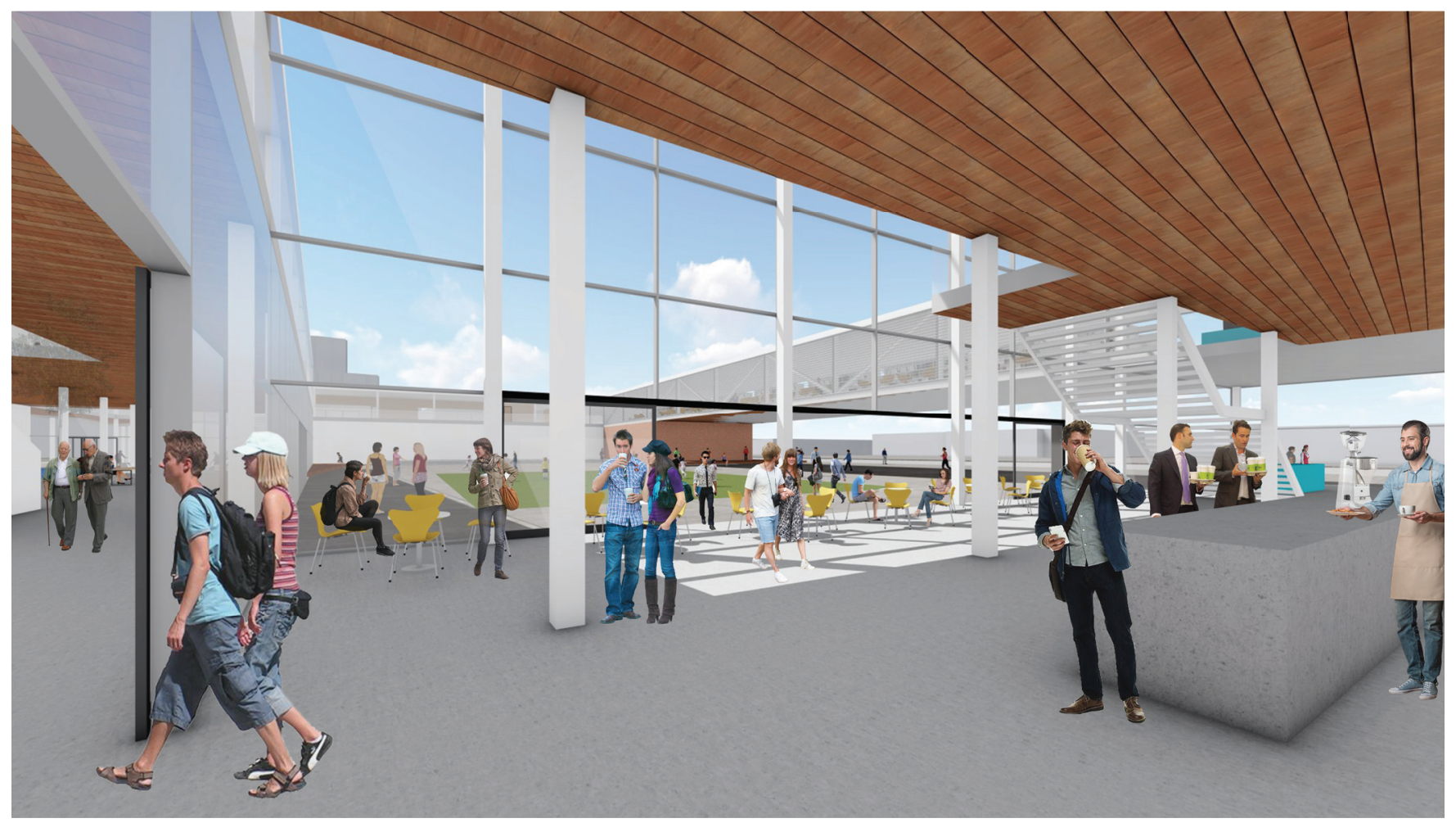

Fig.5.46 Cafe View Looking Towards Outdoor Square 


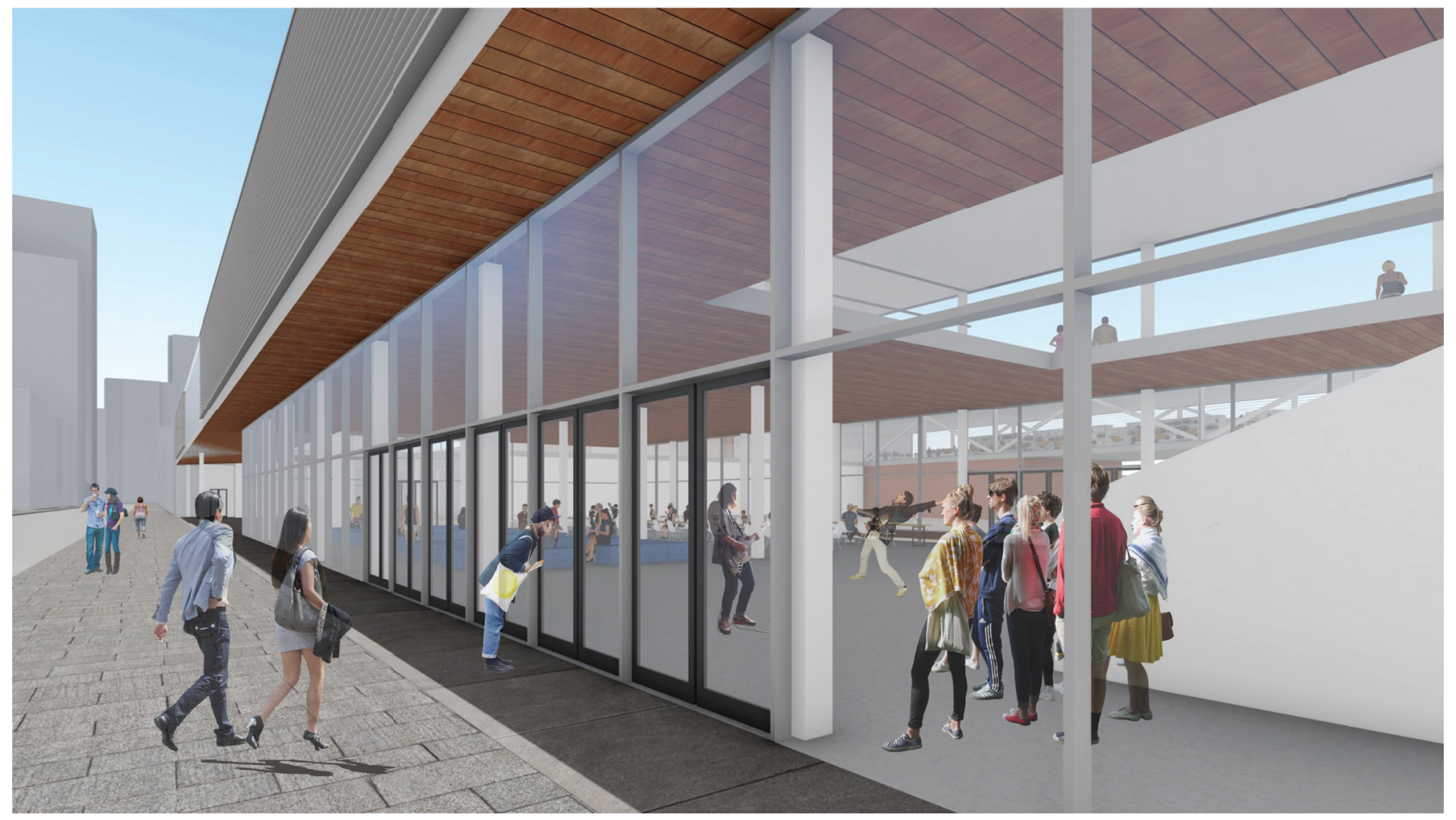




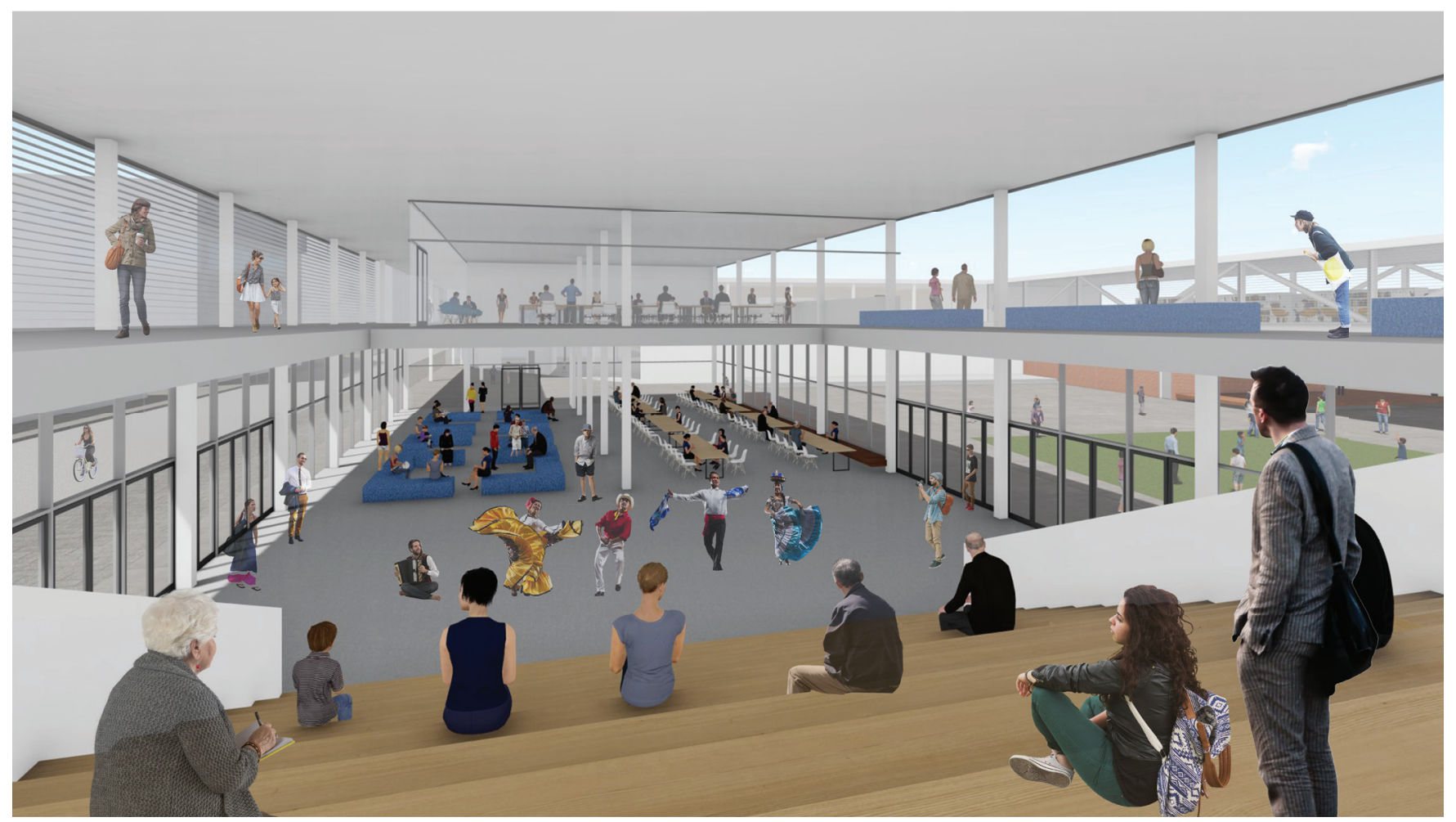




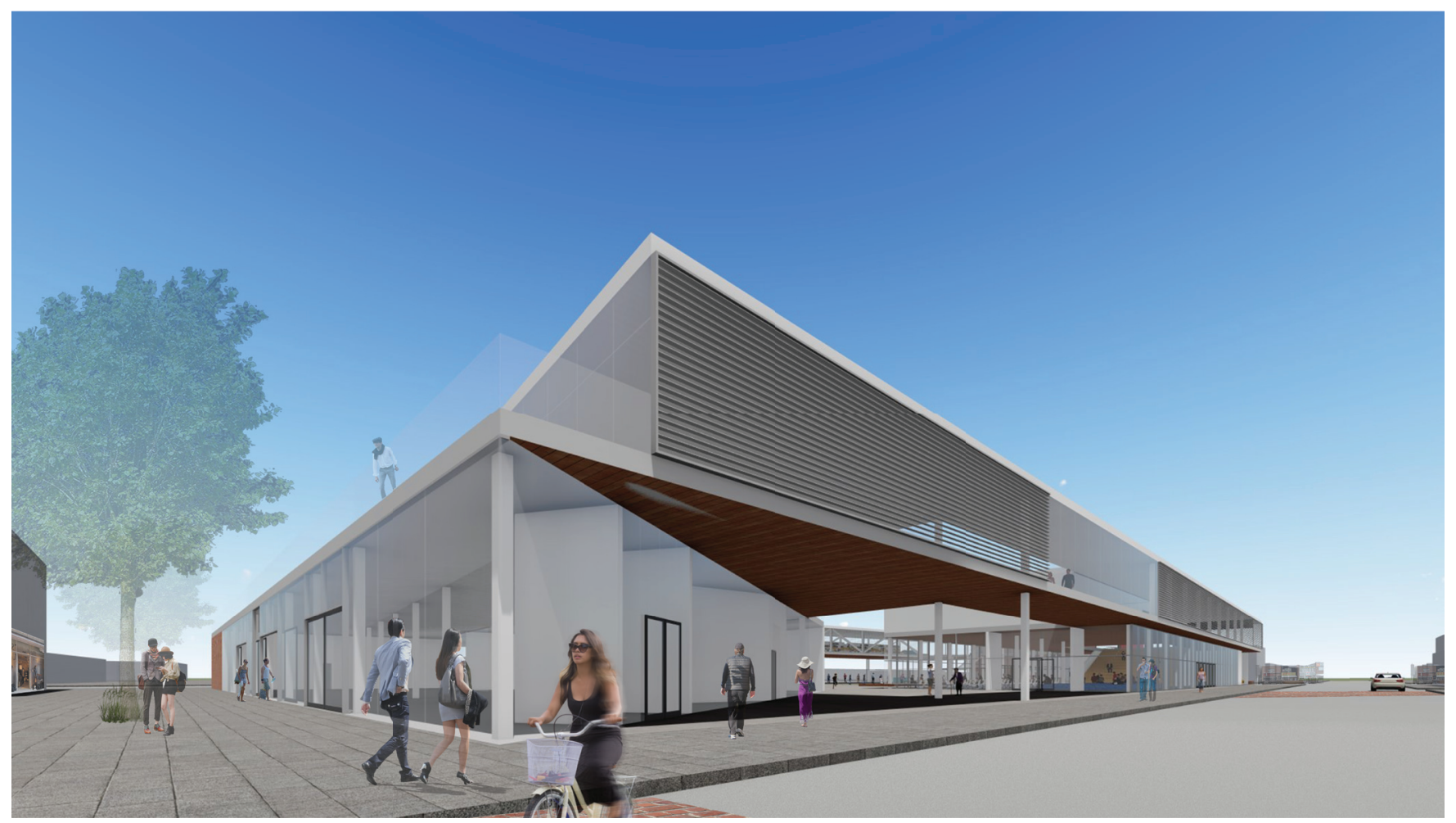




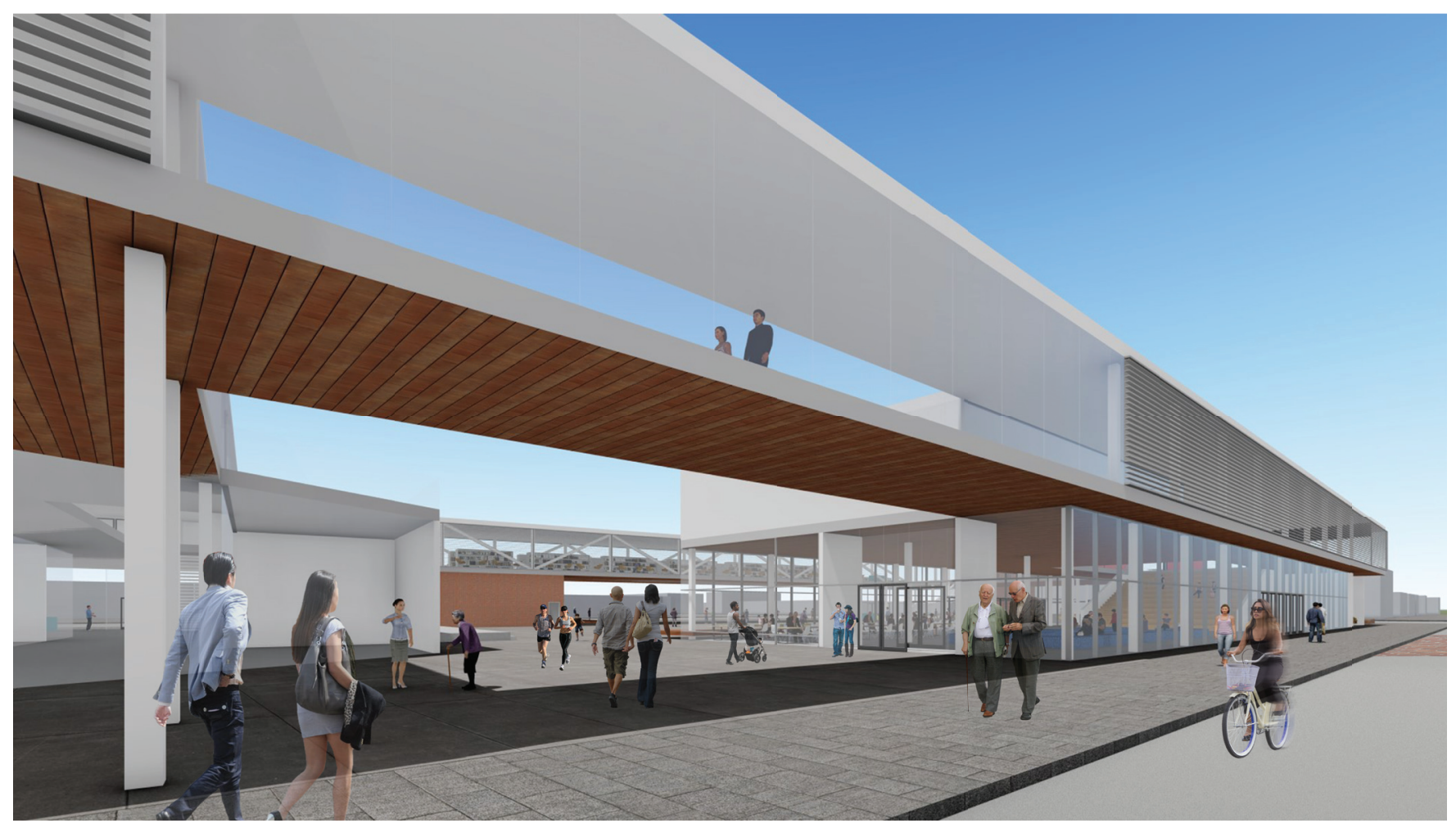




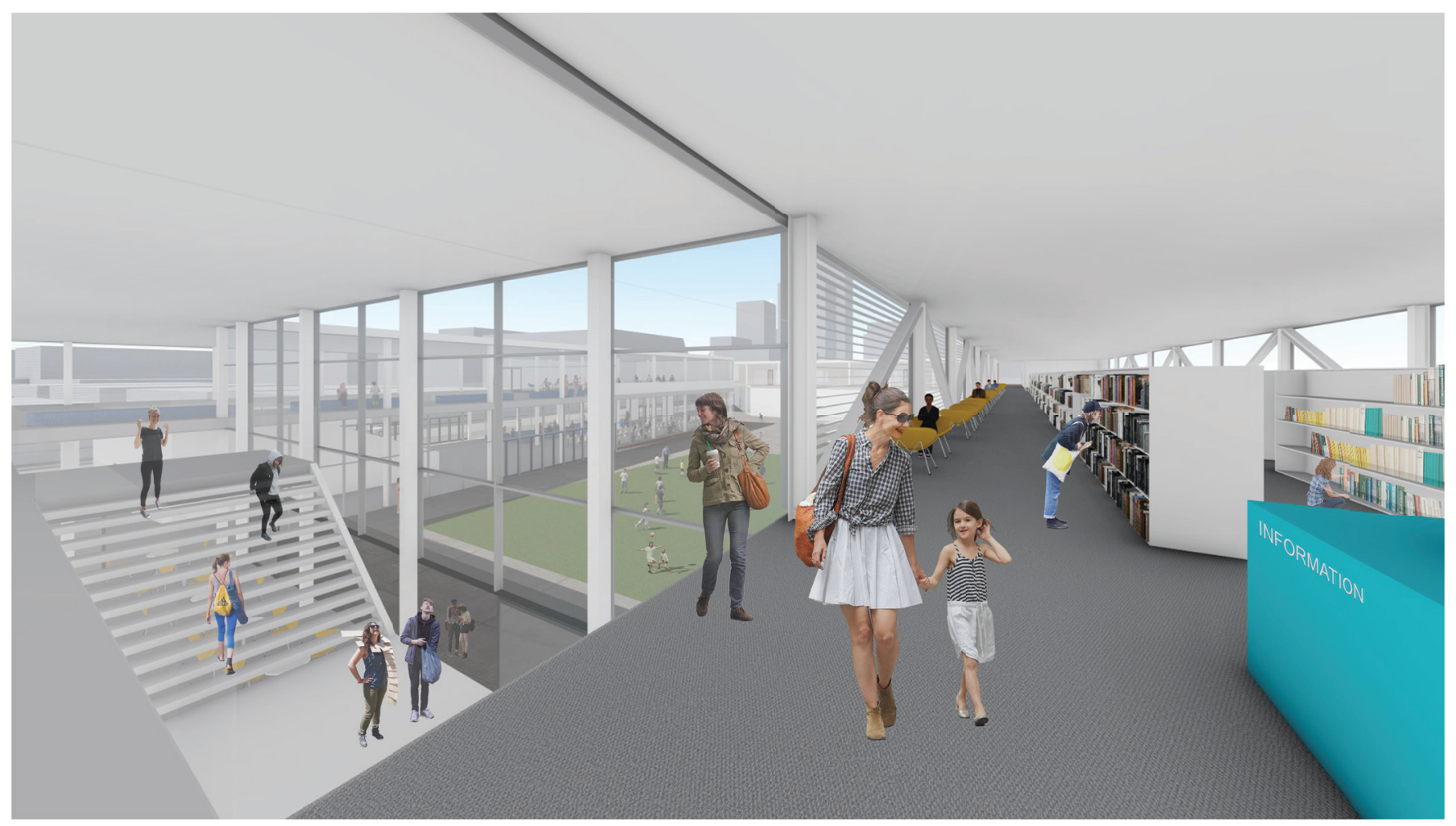

Fig.5.51 Library 


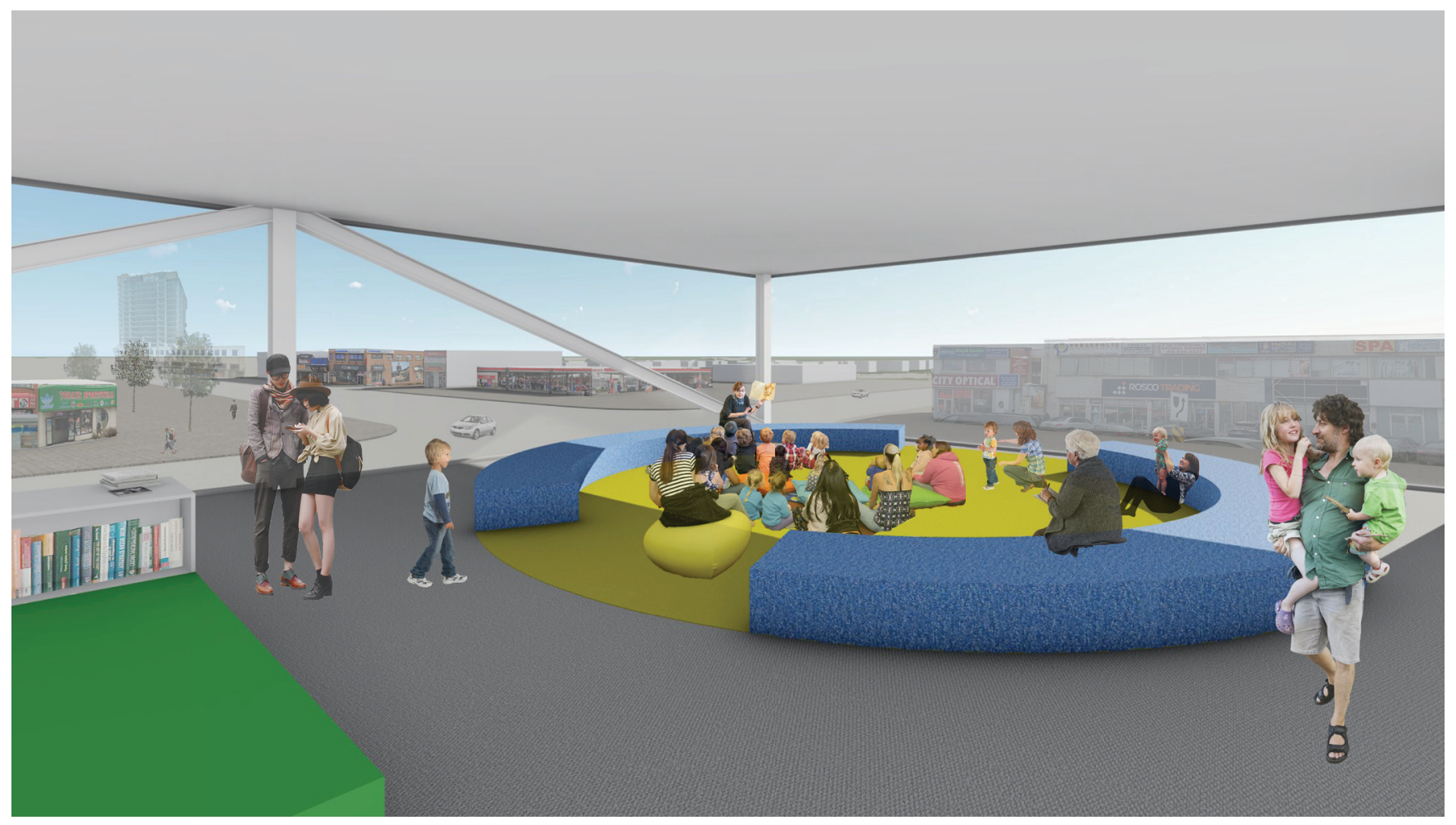

Fig.5.52 Library Seating Area 


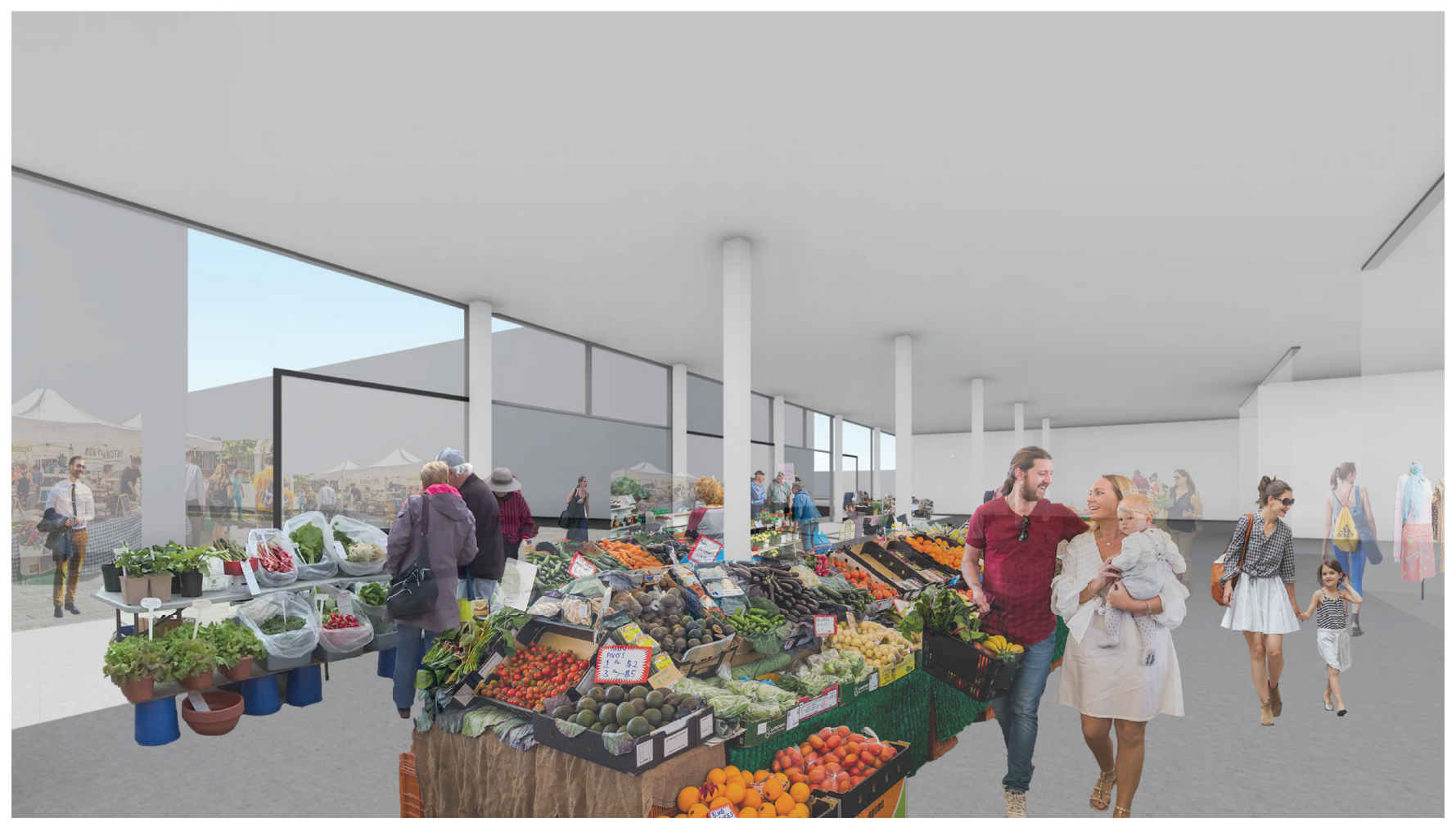




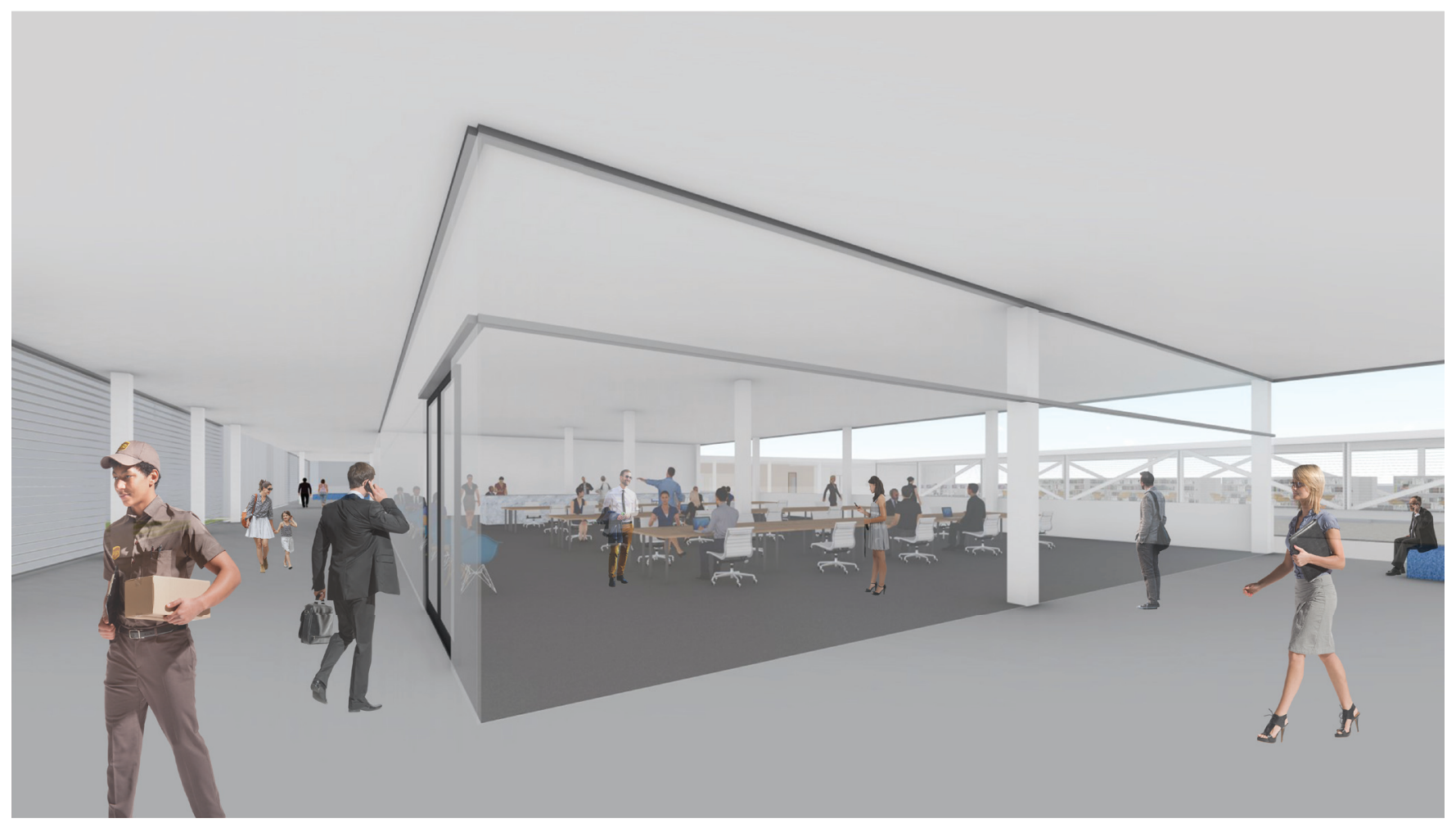




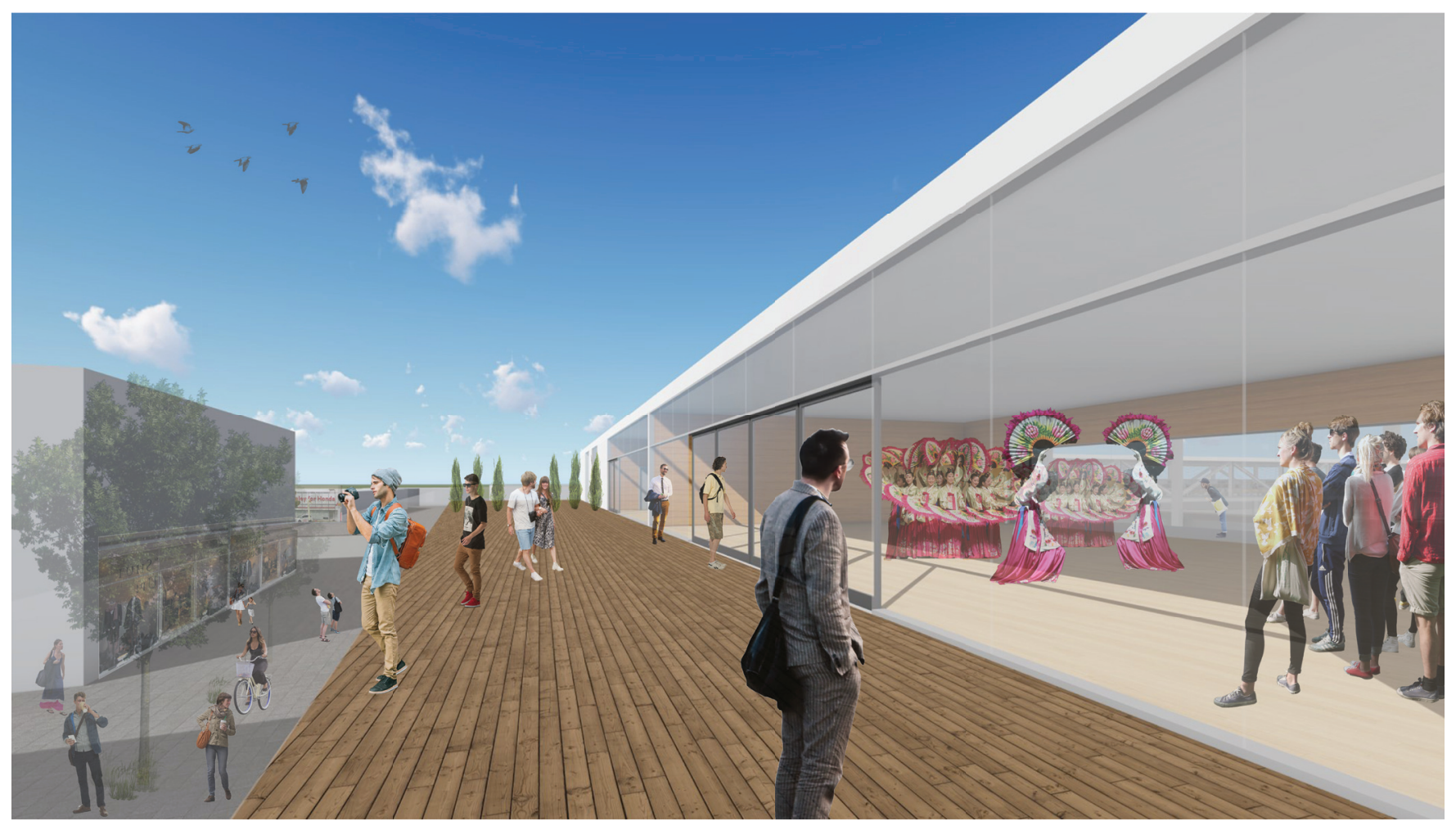

Fig.5.55 Event Hall and Rooftop Terrace 


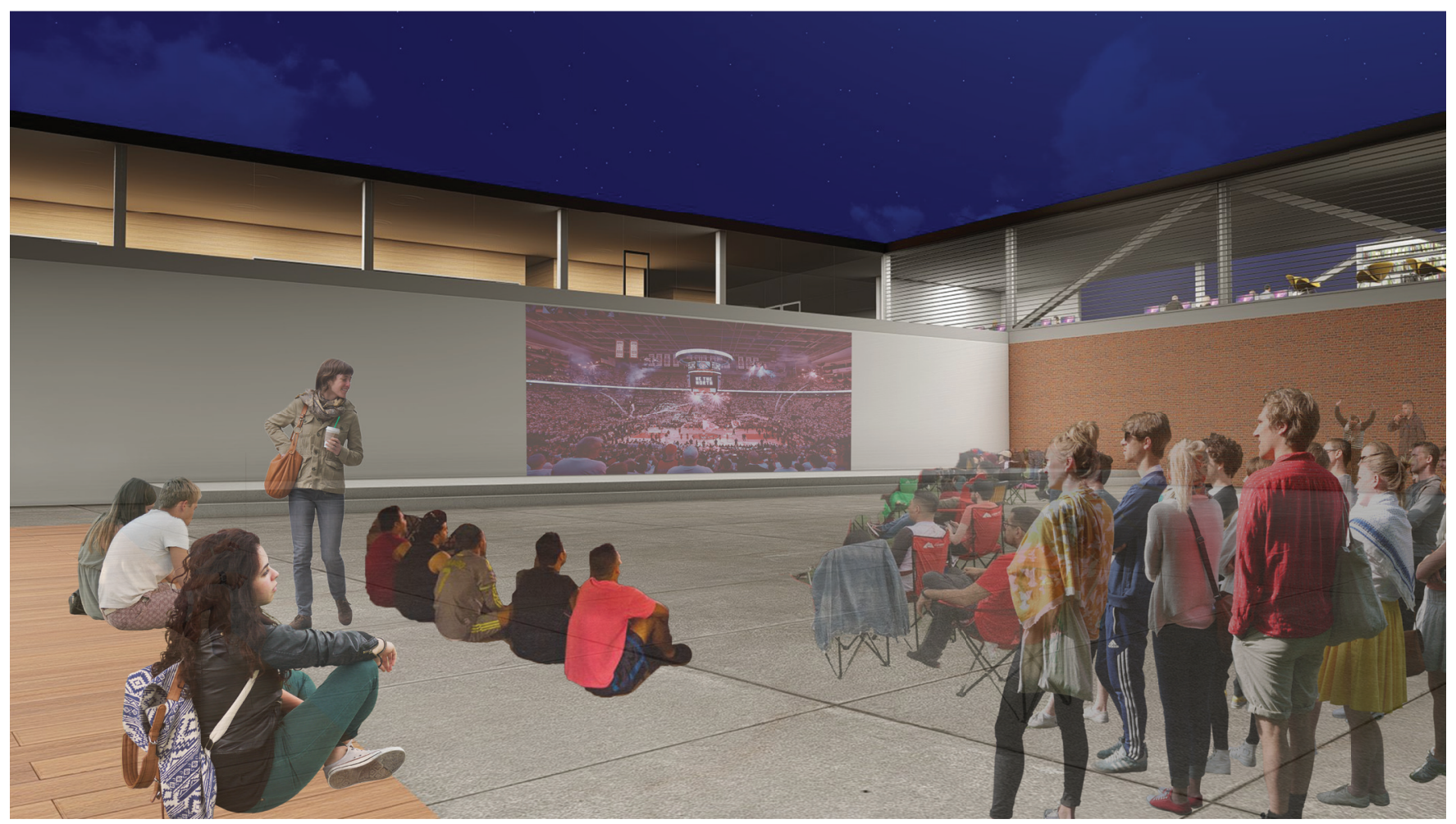

Fig.5.56 Night Gathering at Outdoor Stage 


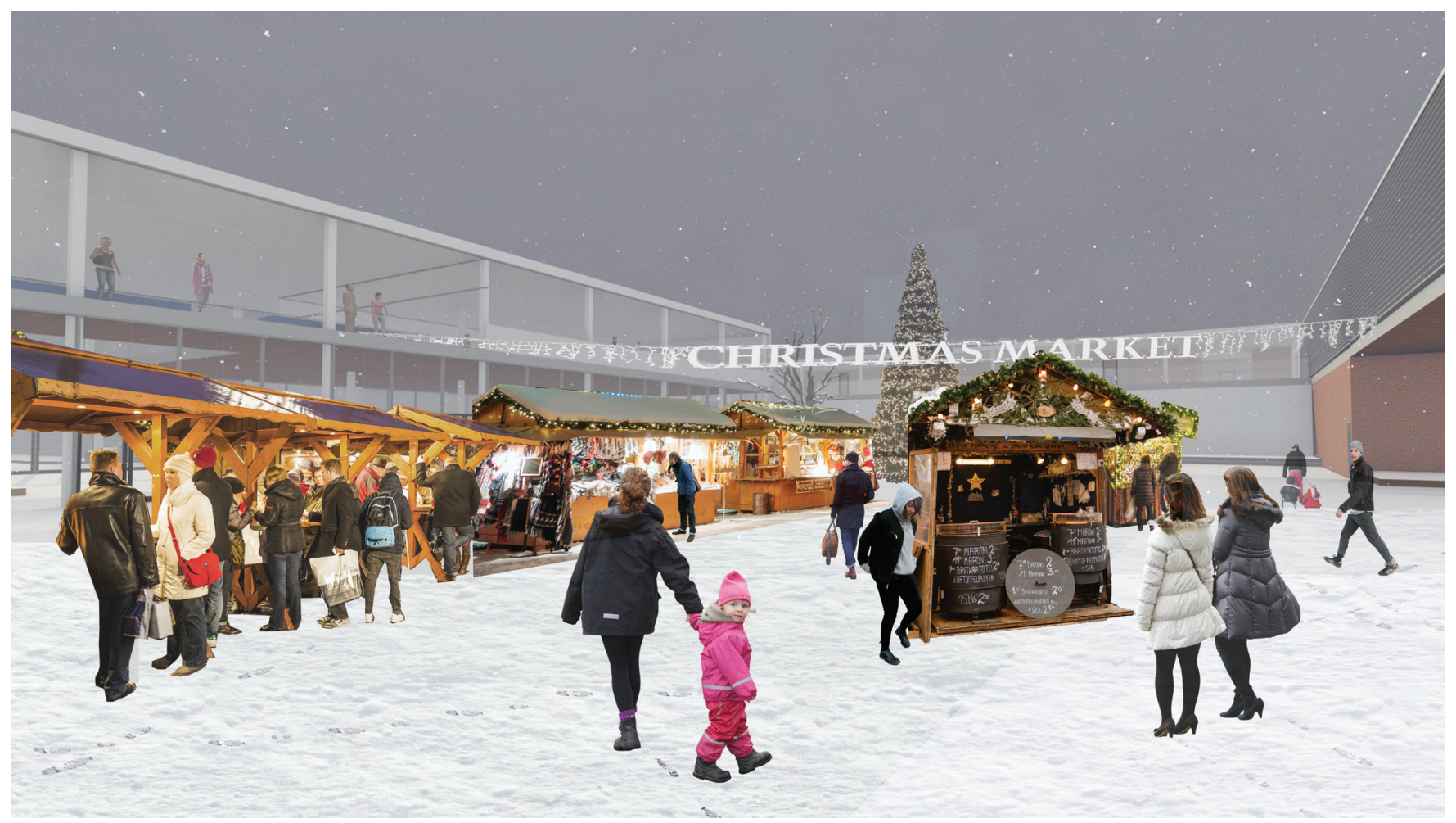

Fig.5.57 Christmas Market at Outdoor Square 


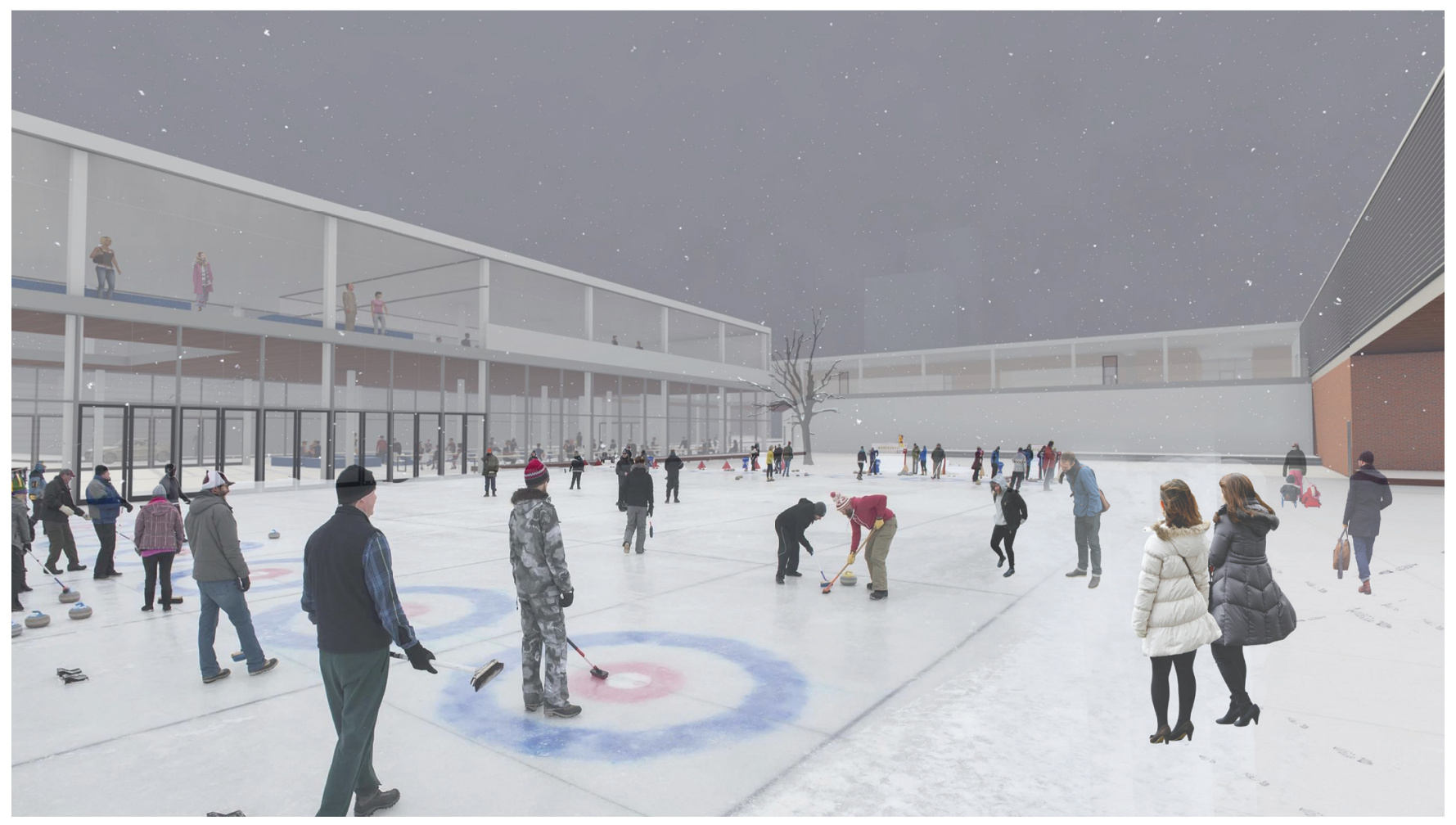

Fig.5.58 Winter Activity at Outdoor Square 

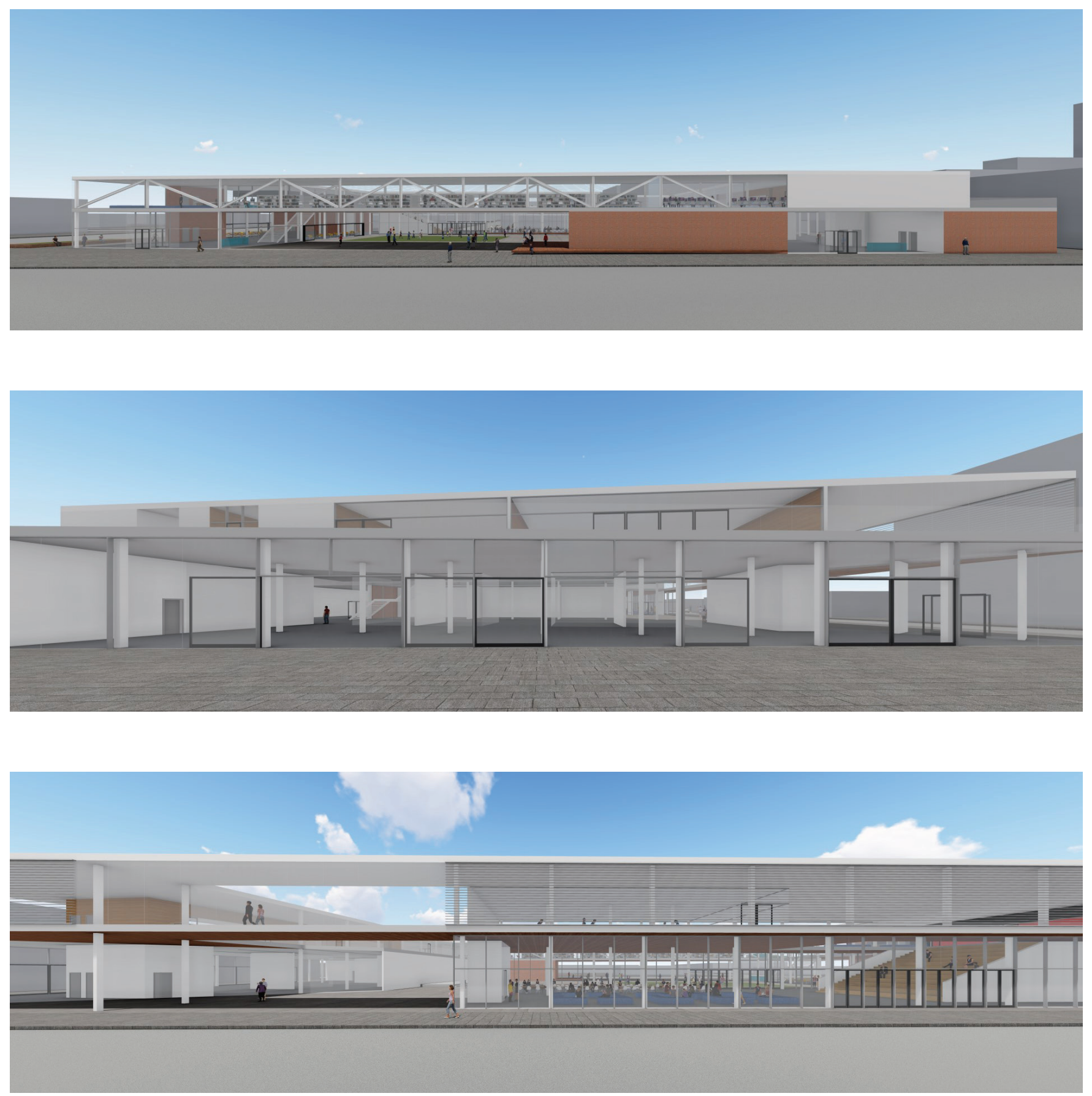


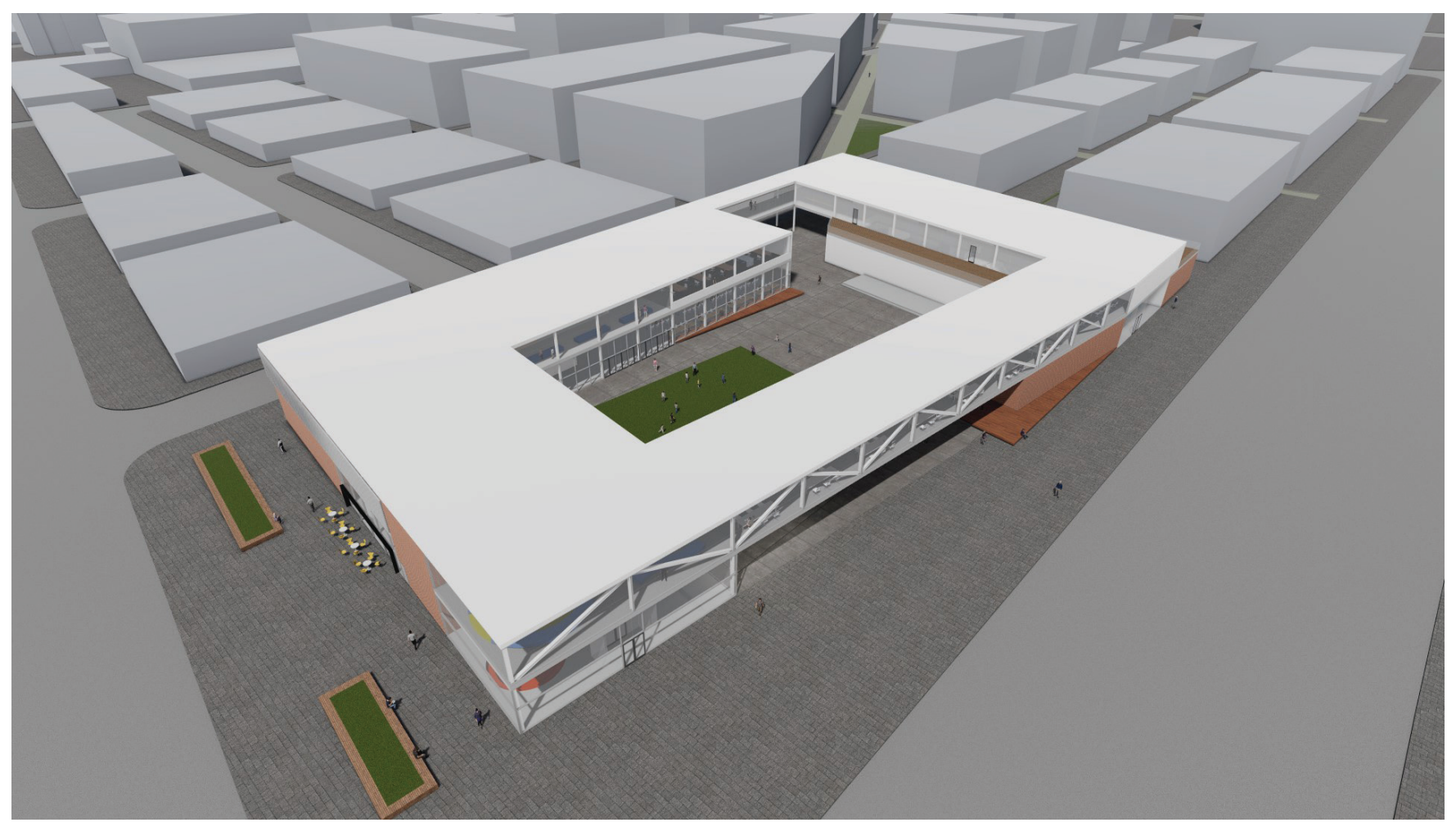

Fig.5.62 Aerial View 


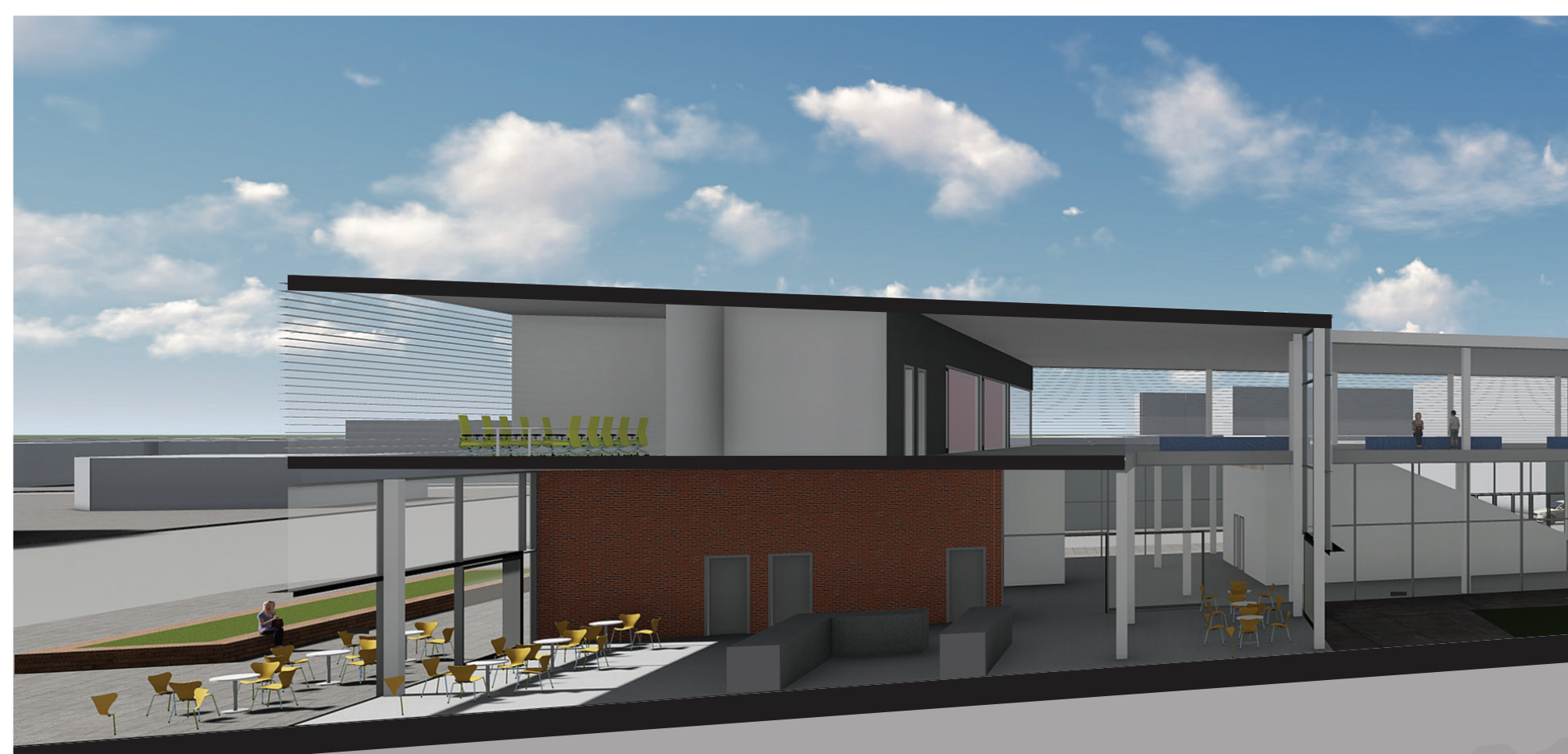




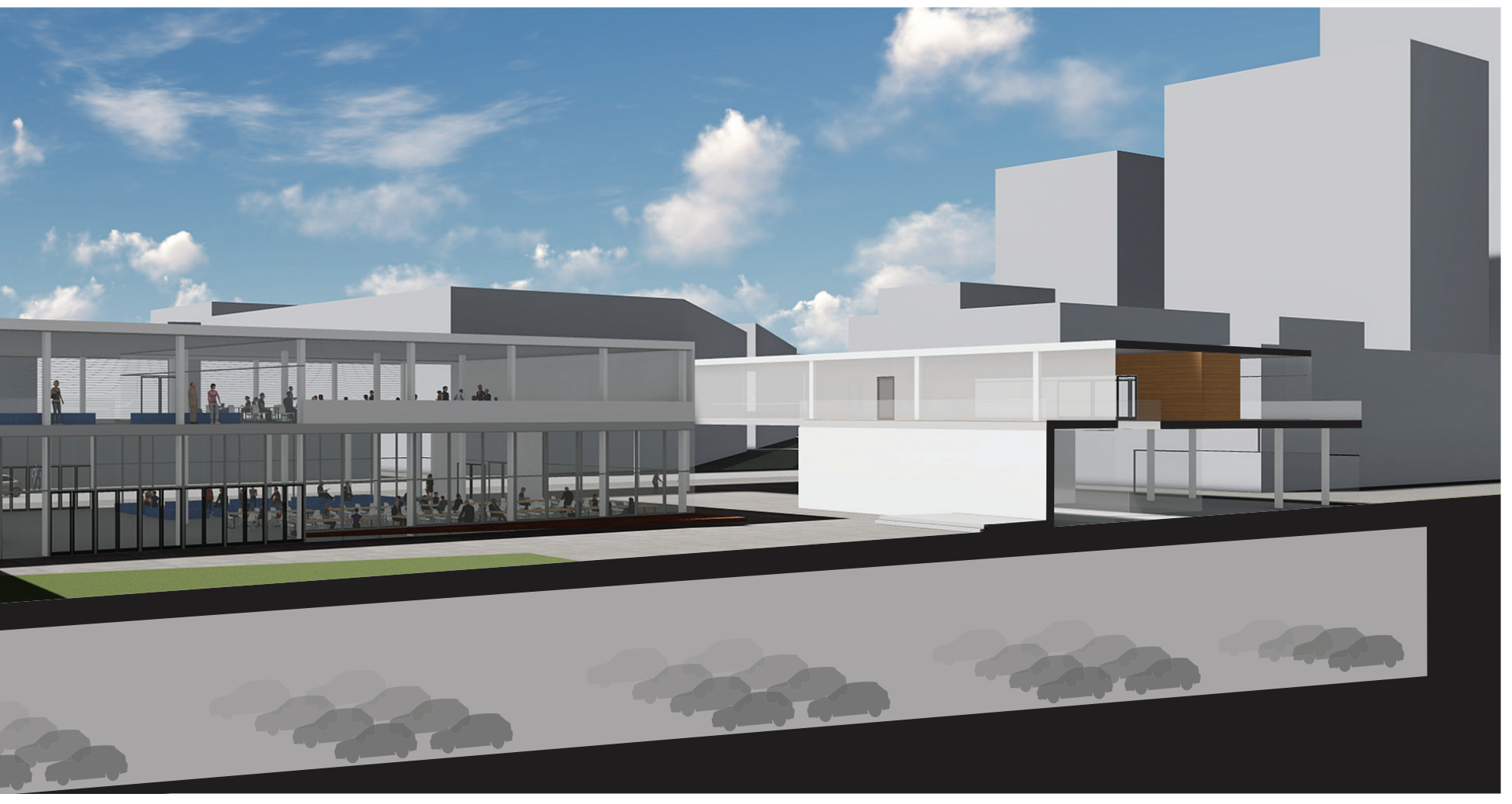




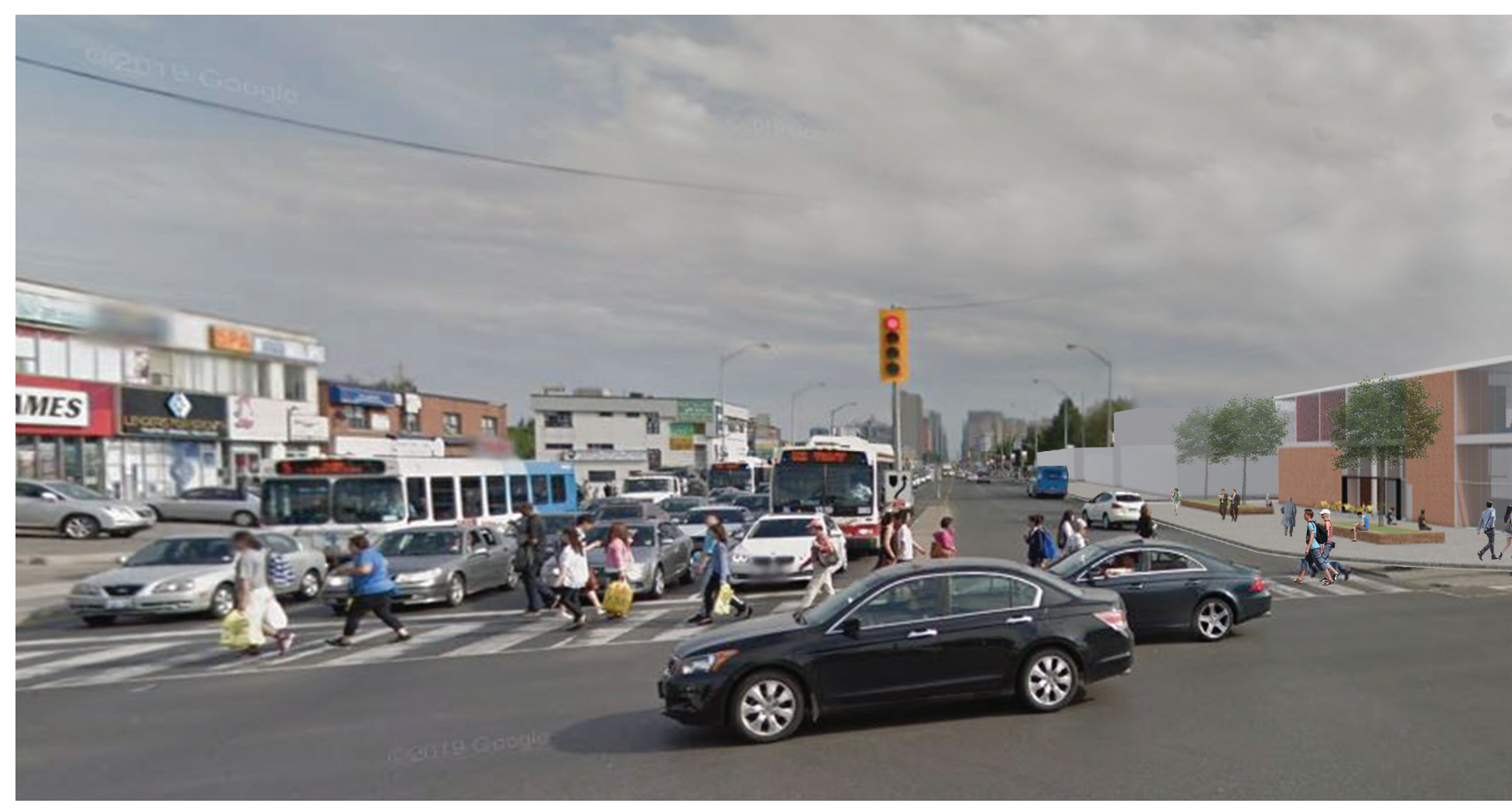




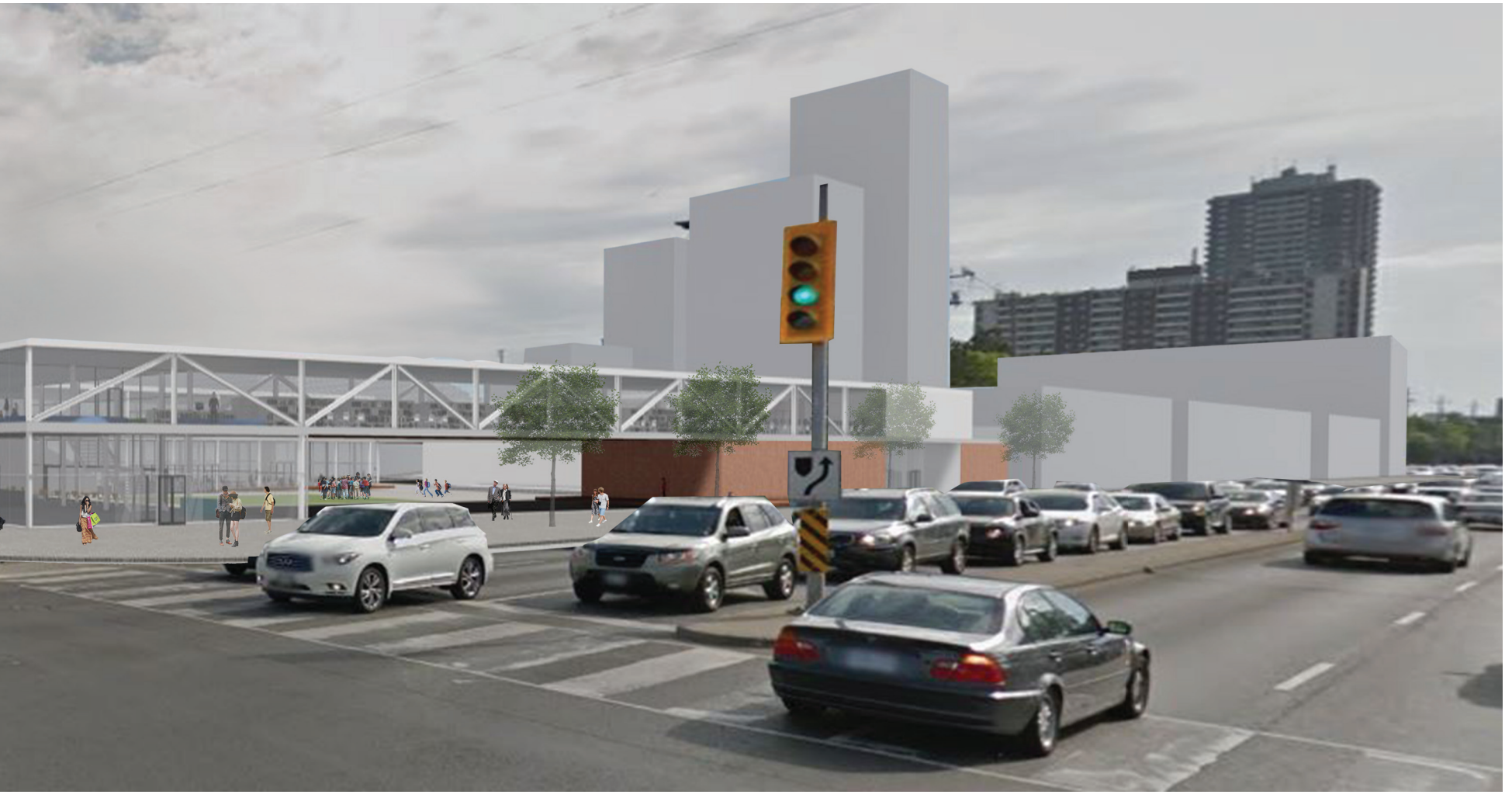




\section{SPECULATION}

As societal needs change, some buildings require re-examination as their functions may become irrelevant. There is evidence that shopping malls are slowly decaying and instead of adding new layers or renovating this typology, new public space can be generated by creating a new cultural hub that connects people in a neighbourhood and reintegrates it with the surrounding context. As this thesis examines, the suburbs lack a central meeting point that allows people within the neighbourhood to come together and connect, especially when the shopping malls which have been serving this function, are slowly in decay. When malls lose their function as a place to shop and socialize, the sites become lost spaces, which will disengage with the context and further segregate space within the suburbs. This thesis proposes an alternative that reintegrates these segregated sites into places that benefit the neighbourhood. People need this new meeting point for social interaction, and as the City of Toronto has pointed out, it is not always feasible to acquire land for public spaces. Privately owned spaces can contribute to encourage the healthy growth of the suburbs.

The typical large site of the mall becomes an ideal place for redevelopment into a denser community, with a mix of residential, commercial and public space with many internal pedestrian paths to ensure walkability. Learning from the success of malls and urban planning, it is important that new interventions at these sites incorporate a variety of aspects, such as the cultural, social and economic, since these are factors driving the operation of a neighbourhood 'downtown'. Within this new development, it is important to have a public gathering point, which this thesis proposes as a cultural hub that frames a public square, that would connect not just the new community within which it is situated, but acts as a bonding agent that connects to the surrounding neighbourhoods. Architecture not only helps to create these opportunities for social interaction within the building but also frames spaces that are essential for outdoor activities to take place, while implementing Gehl's idea of soft edges that invite people to move between indoors and outdoors or allow them to pause and observe their surroundings. This is to create opportunities for the optional and social activities to occur, which is what Gehl defined as factors that make public space work well. Without pauses in the pedestrian flow, it becomes difficult to congregate people at a place that make up the public life. Architecture containing these spaces with a mixture of primary functions increases the possibility to unite people, while the circulation, edges, corners, and designated areas are means to enhance 
sociability. These encounters are what make architecture interesting in the hope of creating a place for people to come in contact with others. It attempts to create moments that allow people to exchange ideas, to learn about other cultures and most importantly to feel a sense of belonging to a community through their engagement with various activities. This does not solve the problem of suburban sprawl, but responds to the need for centrality within the suburbs which the residents can identify as the nodes within their communities.

Architects can only envision the social activities happening at a neighbourhood meeting point. It is without doubt that public and private sectors can join in partnership in creating a better place for people to live, connect and interact. This thesis hopes to inspire a new approach to development not only through the profit-driven approach, but one that allows architecture to create suburban meeting points for people to gather and stimulate one another to create a vibrant and exuberant environment. 

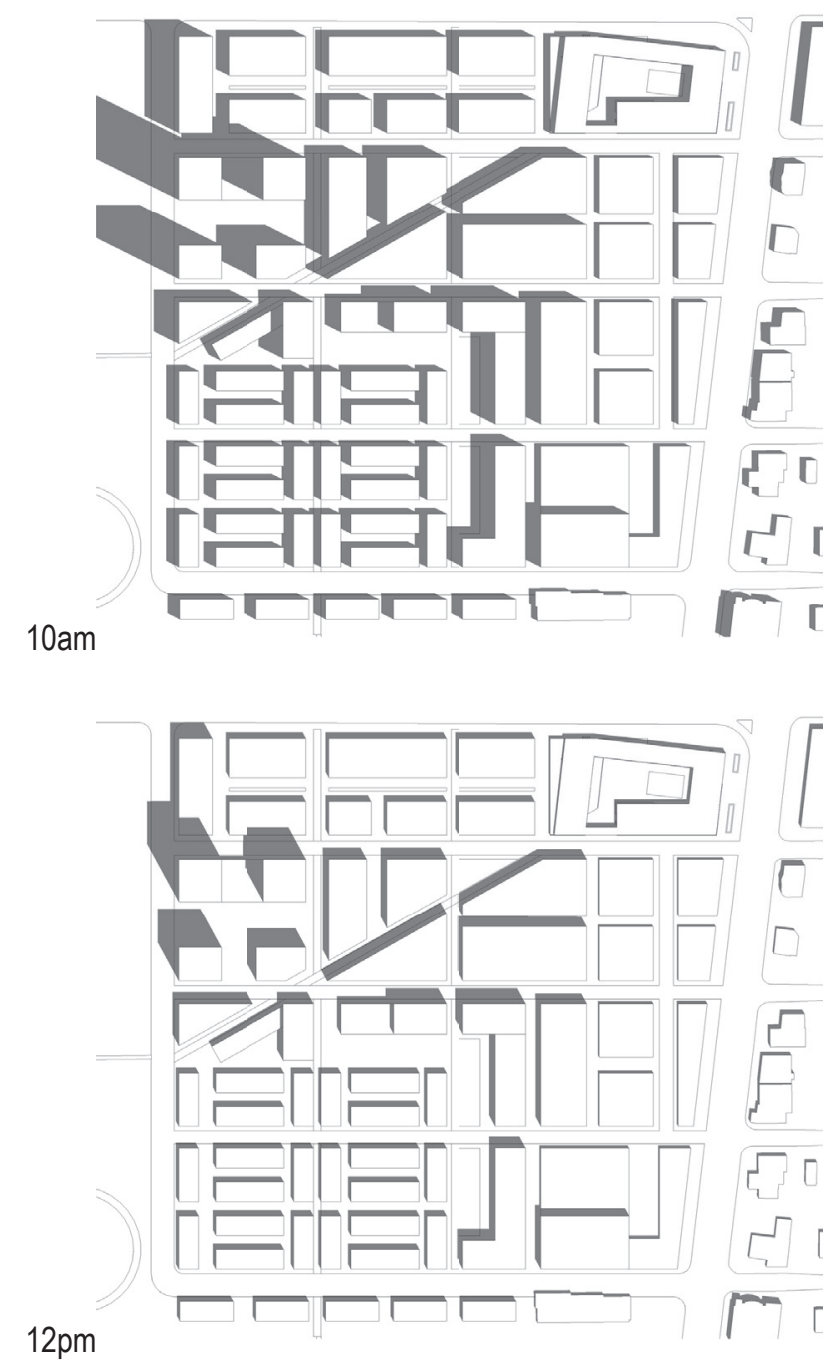

$12 \mathrm{pm}$

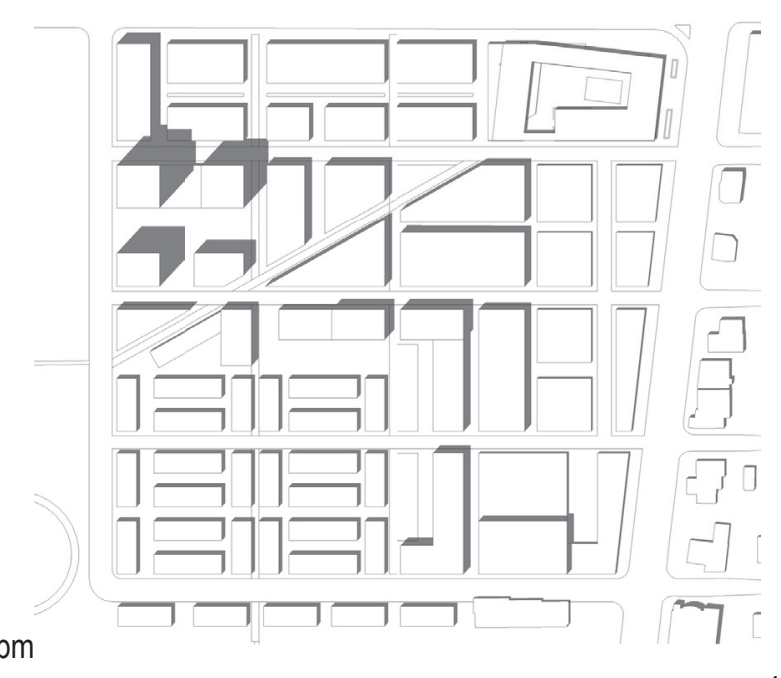

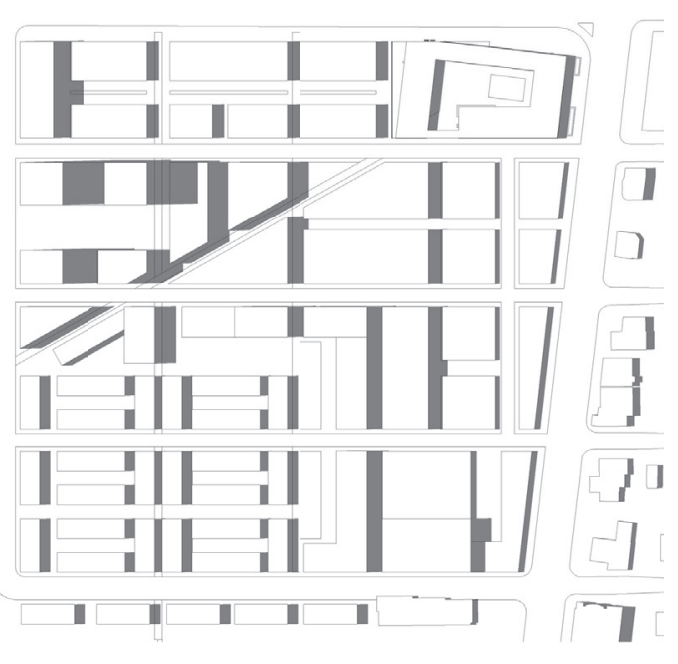

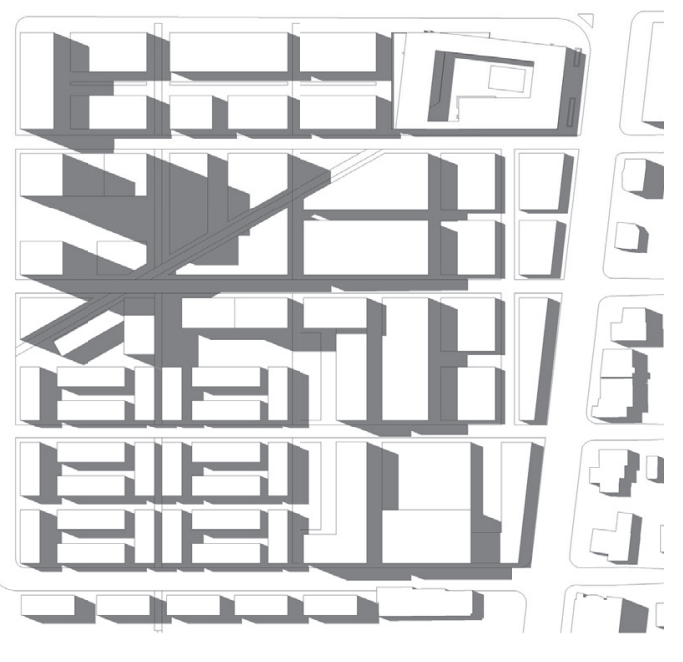

Fig.7.1 Sun Study - Summer Solstice 2019 


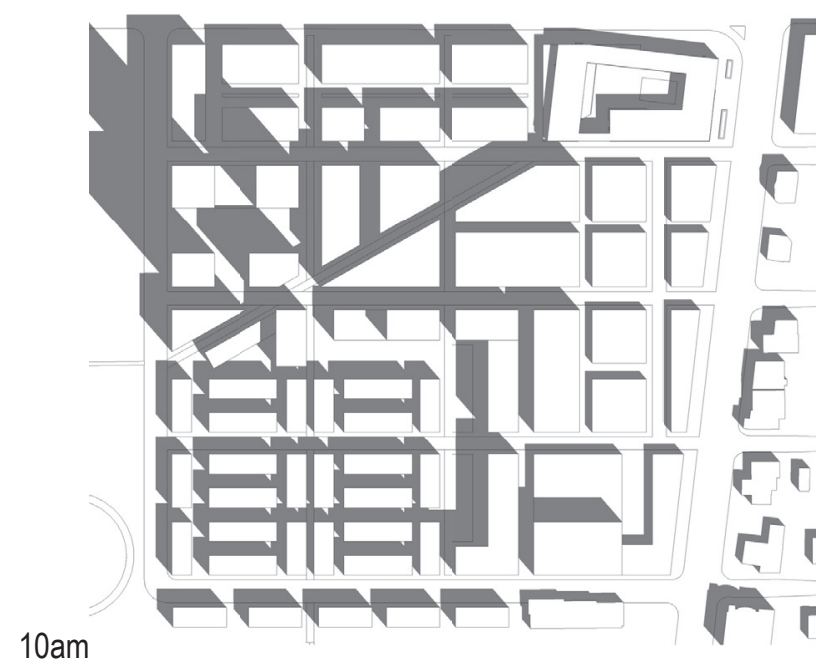

$12 \mathrm{pm}$
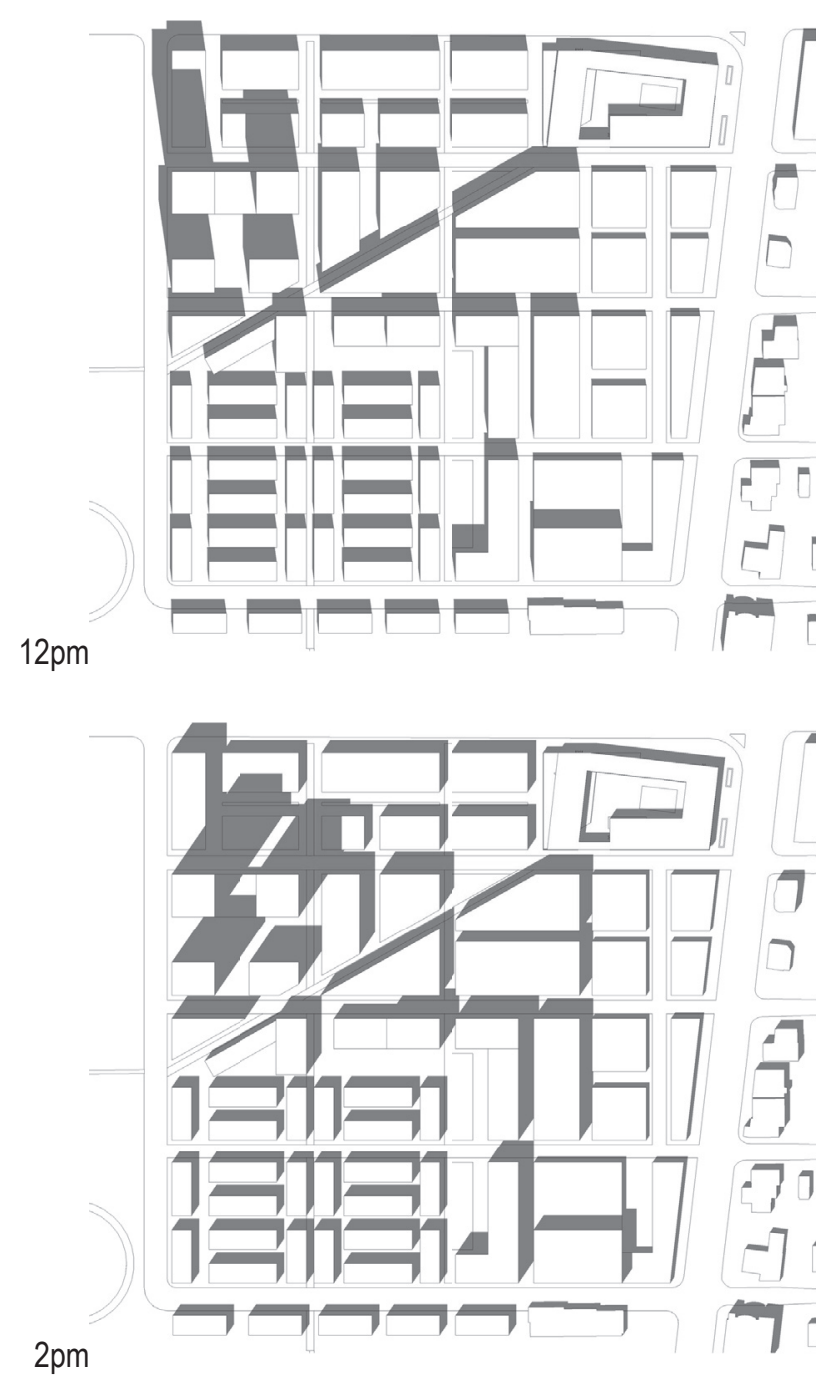
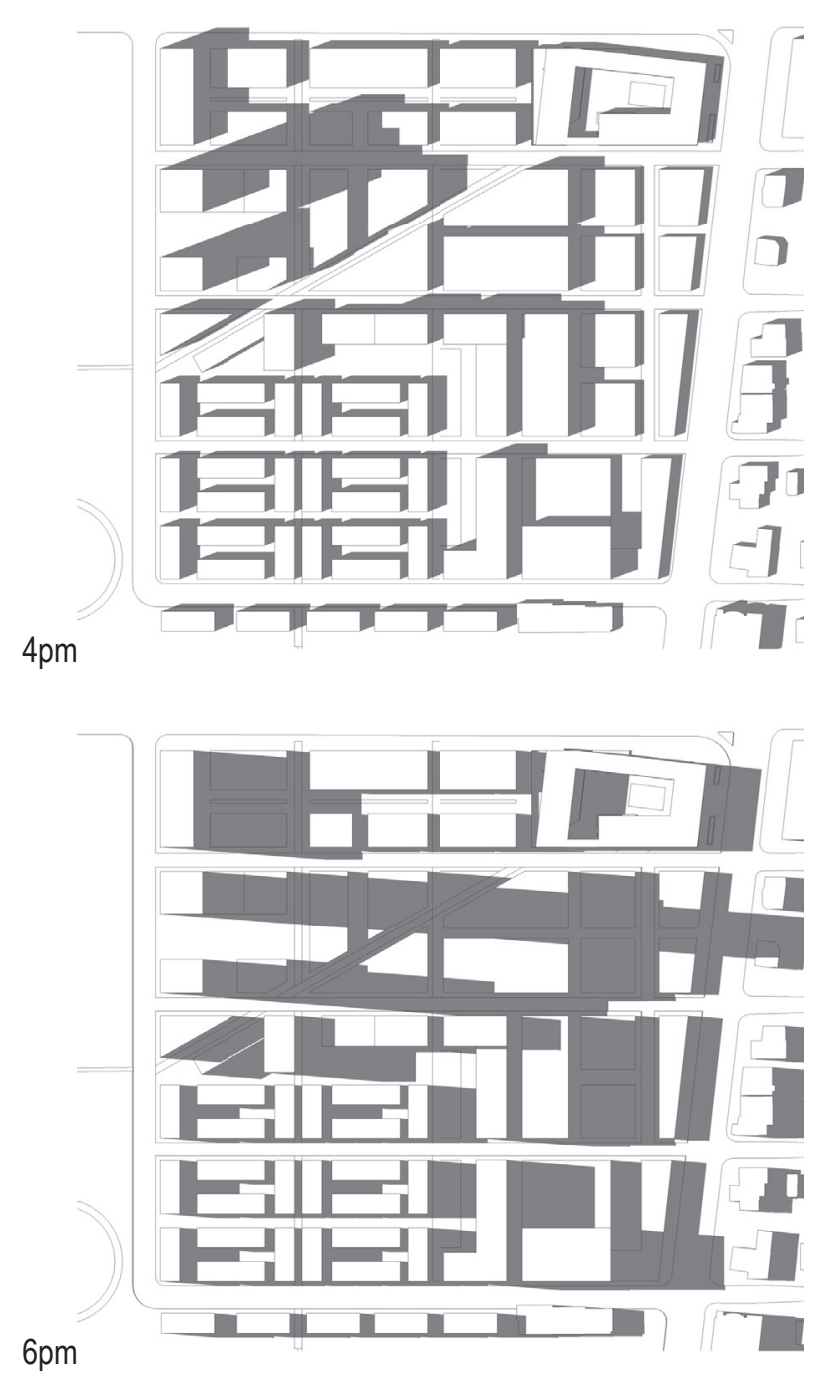

Fig.7.2 Sun Study - Fall Equinox 2019 


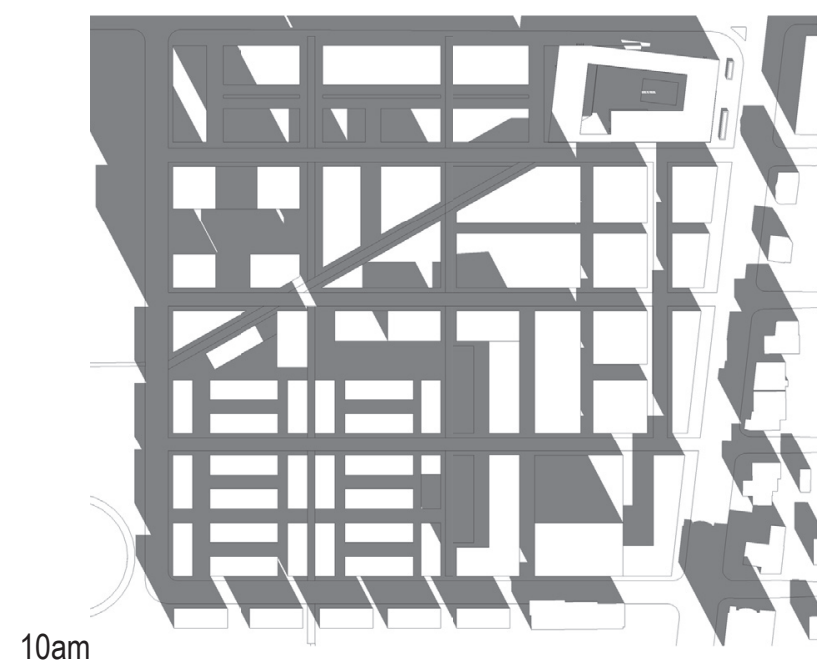

10am

12pm
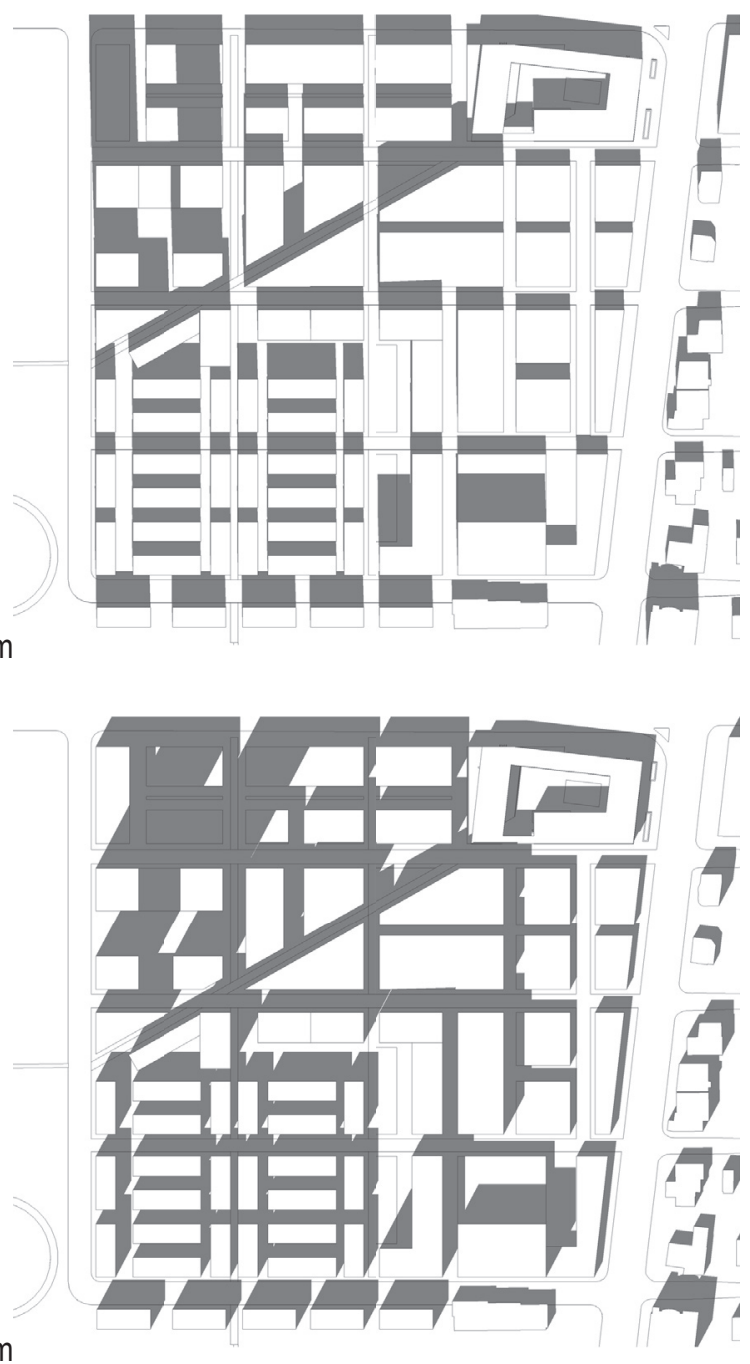
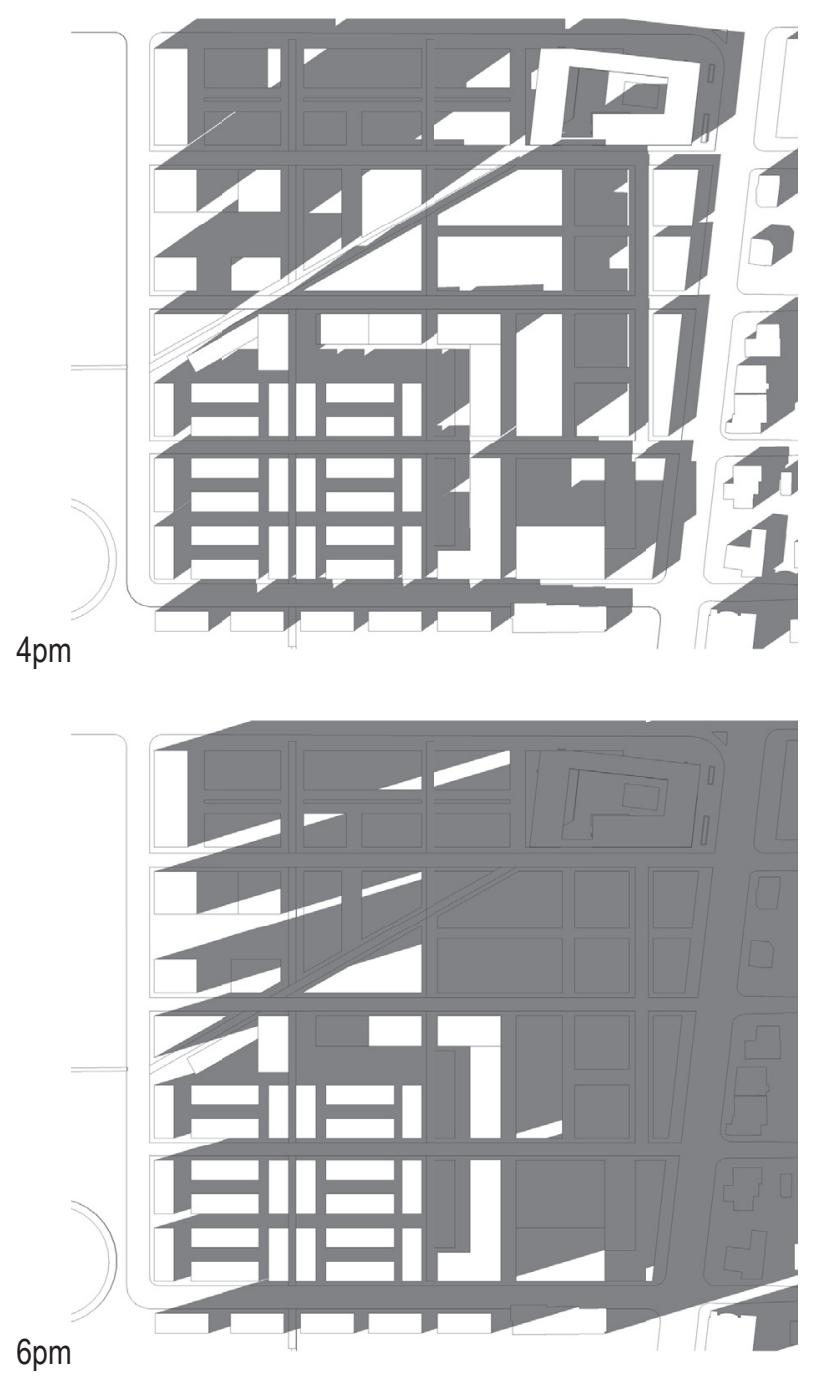

Fig.7.3 Sun Study - Winter Solstice 2019 

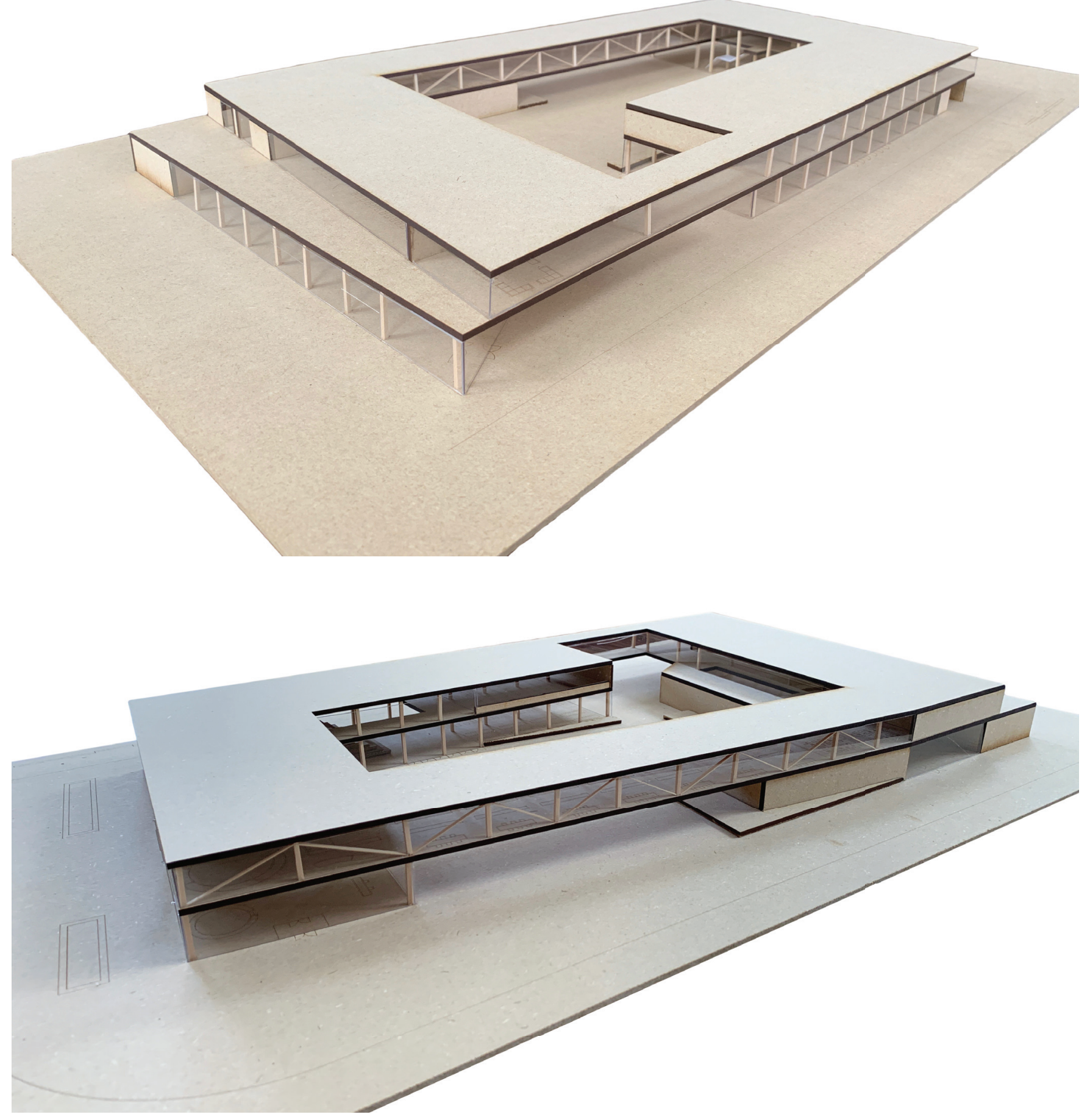

Fig.7.4 1:200 Model - South Perpsective

Fig.7.5 1:200 Model - North Perpsective 


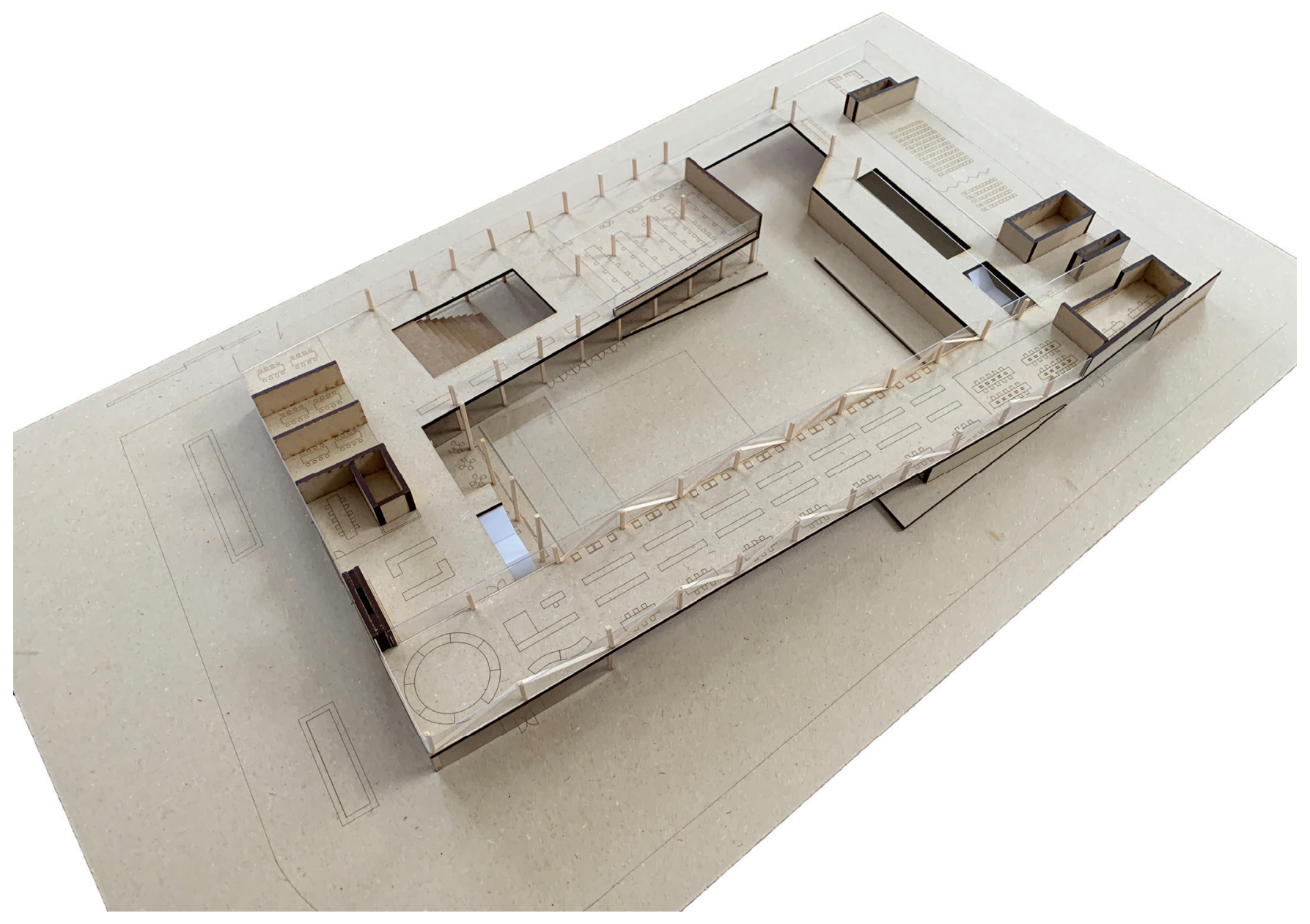

Fig.7.6 1:200 Model - Interior 

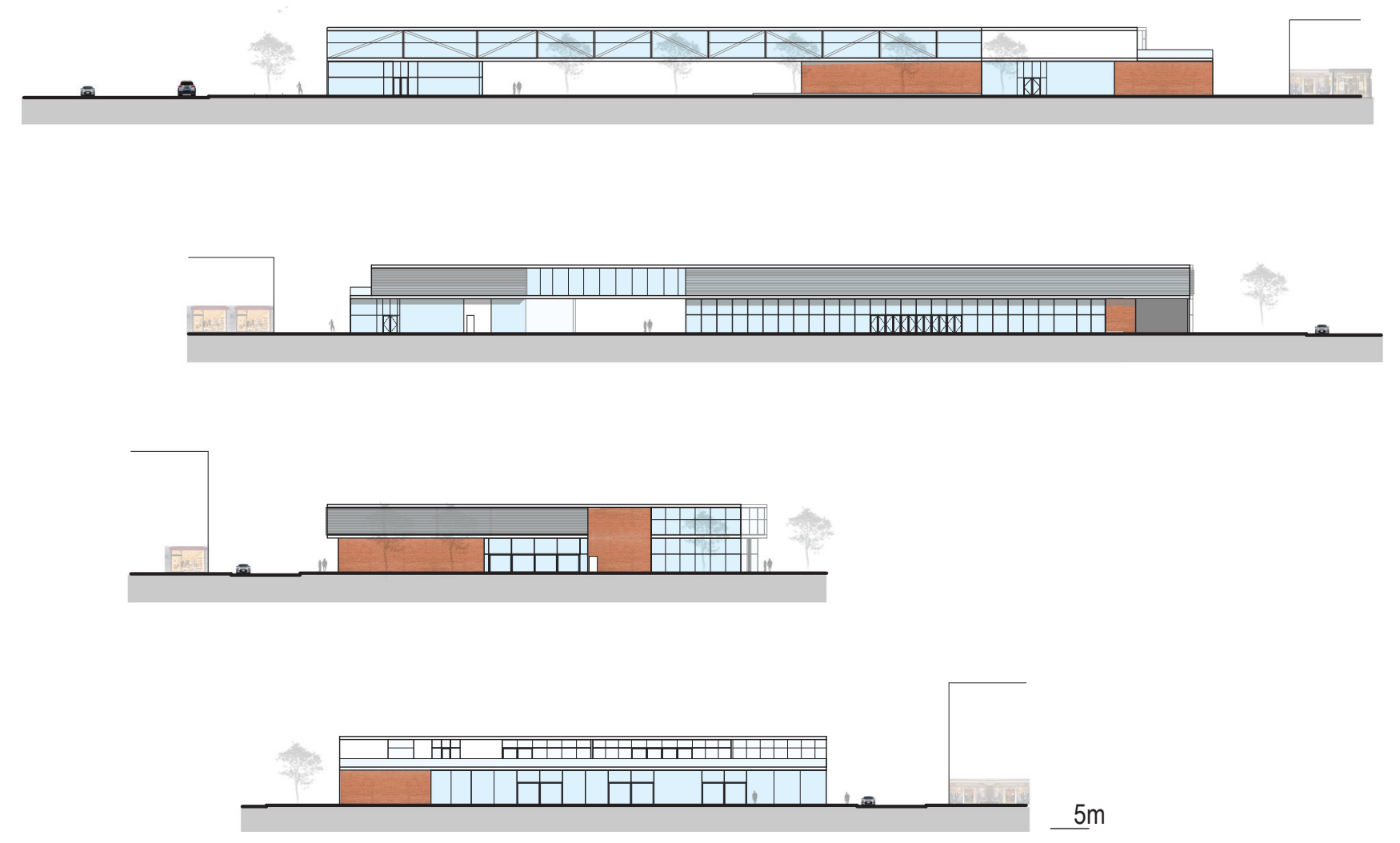

Fig.7.7 North Elevation

Fig.7.8 South Elevation

Fig.7.9 East Elevation

Fig.7.10 West Elevation 


\section{BIBLIOGRAPHY}

Bascaramurty, Dakshana. "The Rise and Fall of the Ethnic Mall." The Globe and Mail, 15 June 2012, www.theglobe andmail.com/news/toronto/the-rise-and-fall-of-the-ethnic-mall/article4277988/.

Carr, S., et al. "Needs in Public Space." Urban Design Reader, edited by Matthew Carmona and Steve Tiesdell, 1st ed., Architectural Press, 2007, pp. 230-240.

CBC News. "Live in Toronto and Want to Try Curling? Now Is Your Chance." CBC, 11 Jan. 2015, www.cbc.ca/news/ canada/toronto/live-in-toronto-and-want-to-try-curling-now-is-your-chance-1.2897129.

City of Toronto. City Planning Division. Protecting And Increasing Access To Privately Owned Publicly-Accessible Spaces (POPS). [Toronto]: City of Toronto, 2014. www.toronto.ca/legdocs $/ \mathrm{mmis} / 2014 / \mathrm{pg} / \mathrm{bgrd} /$ backgroundfile-70176.pdf.

City of Toronto. Newtonbrook East Neighbourhood Profile. [Toronto]: City of Toronto, 2018. www.toronto.ca/ext/sdfa/ Neighbourhood\%20Profiles/pdf/2016/pdf1/cpa50.pdf.

City of Toronto. Newtonbrook West Neighbourhood Profile. [Toronto]: City of Toronto, 2018. www.toronto.ca/ext/ sdfa/Neighbourhood\%20Profiles/pdf/2016/pdf1/cpa36.pdf.

City of Toronto. Public vs Private Property - Definition. 2018, www.toronto.ca/311/knowledgebase/kb/docs/ articles/311-toronto/information-and-business-development/public-vs-private-property-definition.html.

Crawford, Margaret. "Suburban Life and Public Space." Sprawl and Public Space: Redressing the Mall, edited by David J. Smiley, Princeton Architectural Press, 2002, pp. 21-30.

Curran, Raymond J. Architecture and the Urban Experience. Van Nostrand Reinhold Company Inc., 1983.

Delventhal, Shoshanna. "Who Killed Sears? 50 Years on the Road to Ruin." Investopedia, Investopedia, LLC, 15 Oct. 2018, www.investopedia.com/news/downfall-of-sears/.

Fishman, Robert. "Towards an Open-Minded Space." Sprawl and Public Space: Redressing the Mall, edited by David J. Smiley, Princeton Architectural Press, 2002, pp. 9-11.

Gehl, Jan. Cities For People. Island Press, 2010.

Gehl, Jan. Life Between Buildings: Using Public Space. Island Press, 2011.

Healing, Dan. "Calgary's Eerily Empty New Horizon Mall Postpones Grand Opening." Global News, 21 Sept. 2018, globalnews.ca/news/4473734/calgary-new-horizon-mall-empty/.

Jacobs, Jane. The Death and Life of Great American Cities. The Modern Library, 1961. 
Koolhaas, Rem. "Junkspace." October, vol. 100, Apr. 2002, pp. 175-190., doi:10.1162/016228702320218457.

Lang, Jon T., and Nancy Marshall. Urban Squares As Places, Links and Displays : Successes and Failures. Routledge, 2016. EBSCOhost, search.ebscohost.com/login.aspx?direct=true\&db=nlebk\&AN=1286833\&site =ehost-live.

Lorinc, John. "Home Sweet Mall." The Globe and Mail, 25 Jan. 2018, www.theglobeandmail.com/real-estate/ toronto/home-sweet-mall-a-new-kind-of-neighbourhood-building-intoronto/article37704089/.

Lynch, Kevin. The Image of the City. The M.I.T. Press, 1960.

Madanipour, Ali. Public and Private Spaces of the City. Routledge, 2003, ebookcentral-proquest-com.ezproxy.lib. ryerson.ca/lib/ryerson/detail.action?doclD=178858.

Montgomery, Charles. Happy City. Doubleday Canada, 2013.

Neal, Zachary P. "Locating Public Space." Common Ground?: Readings and Reflections on Public Space, edited by Anthony M. Orum and Zachary P. Neal, Routledge, 2010, pp. 1-10.

Peterson, Hayley. "A Giant Wave of Store Closures Is about to Hit the US." Business Insider, Insider Inc., 31 Dec. 2016, www.businessinsider.com/stores-closing-macys-kohls-walmart-sears-2016-12.

Project for Public Spaces. "The Re-Emergence of the Public Square." Project For Public Spaces, 30 Nov. 2010, www.pps.org/article/the-re-emergence-of-the-public-square.

Relph, Edward. Place and Placelessness. Pion Limited, 1976.

Scharoun, Lisa. America at the Mall: the Cultural Role of a Retail Utopia. McFarland \& Co., 2012.

Sewell, John. The Shape of the City: Toronto Struggles with Modern Planning. University of Toronto Press, 1993.

Smee, Michael. "Yorkdale's Massive Parking Lots to Be Transformed into New Neighbourhood." CBC, 14 Mar. 2019, www.cbc.ca/news/canada/toronto/yorkdale-parking-lot-new-neighbourhood-1.5055749.

Smiley, David. "Addressing Redress." Sprawl and Public Space: Redressing the Mall, edited by David J. Smiley, Princeton Architectural Press, 2002, pp. 13-18.

Toronto Public Library. "Toronto Public Library Strategic Plan 2016-2019." Strategic Plans, Annual Reports \& Statistics, www.torontopubliclibrary.ca/content/about-the-library/strategic-plan/pdfs/strat-plan-2016-2019. pdf. 
Trancik, Roger. "What Is Lost Space?" Urban Design Reader, edited by Matthew Carmona and Steve Tiesdell, 1st ed., Architectural Press, 2007, pp. 63-69.

Tuan, Yi-Fu. Space and Place: The Perspective of Experience. University of Minnesota Press, 1977.

Vuong, Oriena. "Mississauga, Brampton to Bring 'Jurassic Park' West Ahead of the NBA Finals." Global News, 28 May 2019, https://globalnews.ca/news/5327475/mississauga-brampton-raptors-jurassic-park-nba-finals/.

Whyte, William H. The Social Life of Small Urban Spaces. The Conservation Foundation, 1980.

Zevi, Bruno. Architecture As Space. Da Capo Press, 1993. 